\title{
Constructed Histories
}

Storytelling and the Practices of Architectural Conservation

\author{
Nathan Jensen
}

A thesis submitted to the Faculty of Graduate Studies and Research in partial fulfillment of the requirements for the degree of Master of Architecture

Carleton University, Ottawa, Canada

January, 2009

Nathan Jensen (C) 2009 


$\begin{array}{ll}\begin{array}{l}\text { Library and } \\ \text { Archives Canada }\end{array} & \begin{array}{l}\text { Bibliothèque et } \\ \text { Archives Canada }\end{array} \\ \begin{array}{l}\text { Published Heritage } \\ \text { Branch }\end{array} & \begin{array}{l}\text { Direction du } \\ \text { Patrimoine de l'édition }\end{array} \\ \begin{array}{l}\text { 395 Wellington Street } \\ \text { Ottawa ON K1A 0N4 } \\ \text { Canada }\end{array} & \begin{array}{l}\text { 395, rue Wellington } \\ \text { Ottawa ON K1A 0N4 } \\ \text { Canada }\end{array}\end{array}$

Your file Votre référence ISBN: 978-0-494-47525-6

Our file Notre référence

ISBN: 978-0-494-47525-6

NOTICE:

The author has granted a nonexclusive license allowing Library and Archives Canada to reproduce, publish, archive, preserve, conserve, communicate to the public by telecommunication or on the Internet, loan, distribute and sell theses worldwide, for commercial or noncommercial purposes, in microform, paper, electronic and/or any other formats.

The author retains copyright ownership and moral rights in this thesis. Neither the thesis nor substantial extracts from it may be printed or otherwise reproduced without the author's permission.
AVIS:

L'auteur a accordé une licence non exclusive permettant à la Bibliothèque et Archives Canada de reproduire, publier, archiver, sauvegarder, conserver, transmettre au public par télécommunication ou par l'Internet, prêter, distribuer et vendre des thèses partout dans le monde, à des fins commerciales ou autres, sur support microforme, papier, électronique et/ou autres formats.

L'auteur conserve la propriété du droit d'auteur et des droits moraux qui protège cette thèse. $\mathrm{Ni}$ la thèse ni des extraits substantiels de celle-ci ne doivent être imprimés ou autrement reproduits sans son autorisation.
In compliance with the Canadian Privacy Act some supporting forms may have been removed from this thesis.

While these forms may be included in the document page count, their removal does not represent any loss of content from the thesis.
Conformément à la loi canadienne sur la protection de la vie privée, quelques formulaires secondaires ont été enlevés de cette thèse.

Bien que ces formulaires aient inclus dans la pagination, il n'y aura aucun contenu manquant.

\section{Canada}




\begin{abstract}
A fundamental concern of the practices of architectural conservation is the protection of history, identity, and place, against a modernizing world that displaces and forgets. To achieve this, these practices have relied on recourse to the past, attaching themselves to the environment of old, as well as the atmosphere and social structures that characterized it. As a consequence, conservation has been guided by nationalist attitudes that seek to inscribe singular, dominant cultural codes onto the physical manifestation of history that is the built environment. Indeed, these practices, oriented through the antiquated lens of homogenizing nationalisms, attempt to transform the heterodoxies of the past into a new cultural orthodoxy.
\end{abstract}

This thesis proposes, however, that practices of conservation should include, at their core, the recognition of genuine epistemic and social difference. A building can be conserved only through the understanding and employment of its own heterogeneous story, one that endures in and through its plurality of meanings, and transcends any particular moment in its own accumulated history. For this reason, this thesis will explore the intersection of social theory and architecture as a means to reach a critical understanding of the motivations and ramifications of conservation practices. In doing so, it will not only criticize the nature of traditional architectural conservation, but will also propose a framework of storytelling as a potential alternative for future practices of conservation that would result in a more ethical and equally representative forum. 
To all those who have shared their stories, thank you. 


\section{Table of Contents}

List of Illustrations $\quad \mathrm{v}$

Preface vii

Introduction $\quad$ ix

Part One

1 The Construction of Meaning 1

2 The Place of Identity $\quad 7$

3 The Contemporaneity of History 13

Part Two

4 Theories in Practice 19

5 The Experience of Storytelling 22

6 The Bellinzona Story $\quad 27$

Part Three

7 A Proposal for the Future $\quad 37$

8 A Mythos in Practice 41

$\begin{array}{ll}\text { Conclusion } & 74\end{array}$ 


\section{List of Illustrations}

Fig. 1 The frontispiece of Vico's The New Science. Source: 4 http://www.odu.edu/-mcarhart/396/VicoFrontispiece.htm

Fig. 2 Global flight patterns. Source: http://www.lx97.com/maps/ 9

Fig. 3 The classical orders of architecture. Source: 14 http://en.wikipedia.org/wiki/Proportion_(architecture)

Fig. 4 Castelgrande, Bellinzona. Photograph by Patrik Loeff. Source: 28 http://www.flickr.com/photos/bupia/3137713863/

Fig. 5 Plans of Castelgrande entrance sequence. Source: Werner, Aurelio 31 Galfetti, 24.

Fig. 6 Section through Castelgrande entrance sequence. Source: Werner, Aurelio Galfetti, 22.

Fig. 7 The entrance to Castelgrande. Source: Werner, Aurelio Galfetti, 36,37 .

Fig. 8 The assent of Castelgrande. Source: Werner, Aurelio Galfetti, 38,43. 34

Fig. 9 The courtyard at Castelgrande. Source: Werner, Aurelio Galfetti, 30.

Fig. 10 The Carbide Mill. Photograph by Takashi Toyooka. Source: http://www.flickr.com/photos/takashi/6569538/

Fig. 11 The Chaudière Falls. Source: National Archives of Canada Collection.

Fig. 12 The first survey of Victoria Island, 1852. Source: City of Ottawa Archives Collection.

Fig. 13 The Carbide Mill, circa 1900. Source: NCC Library Collection.

Fig. 14 Ottawa Citizen article, February 5, 1975. Source: NCC Library Collection.

Fig. 15 Ottawa Citizen article, March 22, 1975. Source: NCC Library Collection. 
Fig. 16 Conceptual collage one. Image by author. 52

Fig. 17 Conceptual collage two. Image by author. 53

Fig. 18 Conceptual collage three. Image by author. 54

Fig. 19 Site investigation one. Image by author. 55

Fig. 20 Site investigation two. Image by author. 56

Fig. 21 Site investigation three. Image by author. 57

Fig. 22 Site investigation four. Image by author. 58

Fig. 23 Site investigation five. Image by author. 59

Fig. 24 Programmatic sketch. Image by author. 60

Fig. 25 Drawing one: preliminary plan and section. Image by author. 61

Fig. 26 Drawing two: preliminary sections and details. Image by author. 62

Fig. 27 Drawing three: detail of new roof. Image by author. 63

Fig. 28 Drawing four: detail of entry. Image by author. 64

Fig. 29 Drawing five: plans and section. Image by author. 65

Fig. 30 Drawing detail: plan and section of gallery entry ramp. Image by 66 author.

Fig. $31 \quad$ Drawing detail: new roof structure. Image by author. 67

Fig. 32 Drawing detail: east elevation. Image by author. 68

Fig. 33 Drawing detail: entry court threshold. Image by author. 69

Fig. 34 Drawing detail: section through new roof structure. Image by 70 author.

$\begin{array}{ll}\text { Fig. } 35 & \text { Sketch model. Photographs by author. }\end{array}$

Fig. $36 \quad$ Gallery and restaurant models. Photographs by author. 72 


\section{Preface}

"The storyteller is a man who has counsel for his readers."

$\sim$ Walter Benjamin ${ }^{1}$

In his essay The Storyteller: Reflections on the Works of Nikolai Leskov, Walter Benjamin speaks intelligibly of his deep regard for storytellers. He praises the storyteller's ability to express life, to encapsulate and impart his experience of the world. And through his ability to counsel, says Benjamin, the storyteller "joins the ranks of the teachers and sages."2 Nevertheless, Benjamin's argument - particularly his use of the term counsel raises a question regarding the nature of the relationship between the teller and his readers. Is this kinship one of power and dominance, or equality and fellowship?

An answer can be elucidated through Benjamin's own words. "A man listening to a story," he says, "is in the company of the storyteller." He shares a companionship with the storyteller - a connection that reflects the storyteller's roots in the people, and the interdependent relationship that is formed between the teller and his audience. As for the storyteller's counsel, Benjamin says it is never an authoritative answer, rather, it is a "proposal concerning the continuation of a story which is just unfolding." ${ }^{3}$ Indeed, the storyteller does not impose his beliefs on the reader, rather, the reader is allowed to formulate his or her own values and meanings. Under this light, storytelling becomes a vehicle of parity - one that promotes camaraderie and community, and fosters an attitude of custodianship. Benjamin illustrates this further by concluding, "The storyteller is the figure in which the righteous man encounters himself." 4

Working then from the perspective of scholars who have articulated the analogous relationship between storytelling and architecture ${ }^{5}$ (a relationship that can surely be 
extended to the conservation of architecture as well), I pose the following question: What is the relationship between conservation and its readers? Does the practice of conservation have counsel for its readers? Does it foster community custodianship and provide an openness of meaning, or is it utilized as a tool of cultural power that seeks to impose authoritarian interpretation?

The work to be presented here, therefore, will consider these questions just as it arises from them. Both in content and in structure, it will seek to utilize storytelling as a means to counsel rather than command, presenting its ideas in a manner reflective of storytelling itself.

\section{Notes}

1 Walter Benjamin, "The Storyteller: Reflections on the Works of Nikolai Leskov," in Illuminations, edited by Hannah Arendt, translated by Harry Zohn, (New York: Harcourt, Brace \& World, 1968).

2 Benjamin, "The Storyteller."

3 Benjamin, "The Storyteller."

4 Benjamin, "The Storyteller."

5 This arguement can be seen in the works of Marco Frascari, Vittorio Gregotti, and Alberto PerezGomez. Of noteworthy interest, Perez-Gomez argues that the idea of narrative in architecture tradition is reflected even in Vitruvius's Ten Books, where questions of decorum "depended on the capacity of the architect to understand the work at hand in relation to precedents articulated through their stories." See Alberto Perez-Gomez, "Hermeneutics as Discourse in Design," Design Issues 15, no. 2 (1999), 72. 


\section{Introduction}

"Unlike the compulsion to build, the impulse to preserve cannot be justified in terms of pure necessity. Yet its power lies precisely in its non-essential condition, in its creation of excess."

$\sim$ Jorge Otero-Pailos ${ }^{6}$

Architectural conservation, as one of the broadest and longest-lasting land-use movements in the Western states, bears significant authority in the social, economic, and political arenas of our society. ${ }^{7}$ The value of conservation, its ability to shape personal, social, and national identity, is paramount and recognized by both those actively involved in the practice, as well as the greater whole of society. ${ }^{8}$ Naturally, it is this involvement of all civic spheres that gives conservation its power as a social reform movement. ${ }^{9}$

Many who write within this discourse emphasize the search for the 'real' meanings of places $^{10}$, the unearthing of heritages unique to each place, the localized identities that provide a sense of rootedness and fixity of place. ${ }^{11}$ But how shall conservationists record the story of a building, a place? Potential answers to this question have been posed, with varying degrees of clarity, in the many charters, conventions, and declarations of the conservation movement. References to monuments "Imbued with messages from the past" (as in the Venice Charter) ${ }^{12}$, the search for the "authenticity" of place (as in the Nara Document) ${ }^{13}$, and the ability of heritage to solidify a "common history" and "common future" (as in the Declaration of Amsterdam) ${ }^{14}$ all stand as examples of this mode of thought.

Of course, all of these words (history, place, identity, etc) come trailing a multitude of connotations that should raise questions and criticisms about the nature of their usage in 
architectural conservation. Even the mere frequency of their use - in everything from scholarly discourses to mass media to pop culture - is suggestive of a shift from specified meanings (within an academic discourse) to something more akin to normalized buzzwords. As such, much of the writing on this subject is problematized by poor, if not incorrect, understandings of how concepts such as place, space, identity and history play their role in the construction of theories of architectural conservation.

What I'd like to suggest is that when we think about place as having one coherent character, or history as a thing that is bipartisan or 'common'15, we influence our purposes for conserving such a place. In this light conservation becomes a tool of social power; it structures the way we relate to social space, and affects who we recognize as citizens within it. But, while a great many theorists have recognized and discussed the role that architecture plays in the construction of subjectivity and national identity ${ }^{16}$, conservationists and theorists still tend to view the issue of intersubjectivity - the interpersonal relations constructed via the social structures and classes of society - quite uncritically. Considering it is at this locus that the world is being constructed in ways that adversely affect how we regard the public sphere, it is here that contemporary practices of conservation should orient their attention.

As architects, as conservationists, as social citizens we are charged with the responsibility to take these concerns into account if we are to ground a practice of conservation that recognizes the power of architecture to tell the stories of its citizens. It is in response to this challenge to conservation architects that I contextualize my research: the intersubjectivity of the shared built environment - its ability to affect the way we relate to those around $\mathrm{us}^{17}$ - envelopes the premise of this thesis investigation. 
The arguments to be presented in the coming chapters are organized into three parts.

Part One will set forth by contextualizing the practices of conservation within the realm of social discourse, and will seek to make clear both how and why the conservation field is used as a means of social construction. It will outline these practices through three propositions. First, to decipher the identity and meaning of buildings, we rely on codified systems of communication to assert value and signification through the act of interpretation. Unfortunately, like other forms of media, the communicative agency of conservation is often co-opted in a way that promotes partiality and partisanship through such acts. Second, that conservation relies on a notion of place and space that constructs singular notions of identity and necessitates the drawing of boundaries around such places. As a consequence, conservation becomes an agent of difference, and perpetuates a practice of hegemony and fear of 'the other' within the public sphere. And third, that the notion of history on which conservation depends is based on the modernist schema of a totalizing grand narrative, and as such, is easily exploited as a tool of social power to normalize the histories of alternate groups within the dominant socio-political order.

Proceeding from here, Part Two will set forth to establish an alternate approach to conservation, one that would include, at its core, the recognition of epistemic and social difference in both its theories and its practices. It will begin by arguing that a pragmatic approach is needed in the creation of theories of conservation, as a means to realign the insights of theory with the imperatives of practice. ${ }^{18}$ To do this, it will propose not a method, but a mythos of practice ${ }^{19}$, one that looks to the mechanisms and practices of the storytelling tradition to counteract the hegemonic practices of conservation, as outlined in Part One of this thesis. It will identify storytelling as a way to foster multiplicity, 
historical and cultural dialogue, and a more ethical practice of conservation through deployment of a plurality of social narratives. Lastly, this section will examine the work of Aurelio Galfetti, in particular his intervention at Castelgrande Bellinzona, Switzerland, as an example of architectural conservation that underscores the intentions of this thesis.

Finally, Part Three will document my proposal for the conservation of the Victoria Island Carbide Mill, located in Ottawa, Canada, according to the mythos outlined in this thesis.

\section{Notes}

6 Jorge Otero-Pailos, "The Contemporary Stamp Of Incompleteness," Future Anterior 1, no. 2 (2004), ii.

7 Max Page and Randall Mason, Giving Preservation a History: Histories of Historic Preservation in the United States, (New York; London: Routledge, 2004), 3.

8 Page, Giving Preservation a History, 9.

9 Page, Giving Preservation a History, 11.

10 The issue of 'real' meanings can be seen in the Nara Document on Authenticity and The Venice Charter, as well as writings as early as Ruskin and Viollet-le-Duc, and more recently, Herb Stovel.

11 Doreen B. Massey, Space, Place, and Gender, (Minneapolis: University of Minnesota Press, 1994), 151.

12 The Venice Charter: International Charter for the Conservation and Restoration of Monuments and Sites, Paris: International ICOMOS, 1964, http://www.icomos.org/venice_charter.html (accessed 25 October 2007).

13 Herb Stovel, "Appendix 1: Nara Document on Authenticiry" in Nara Conference on Authenticity, edited by Knut Einar Larsen, Japan: Agency for Cultural Affairs UNESCO World Heritage Centre, 1995.

14 The Declaration of Amsterdam, Amsterdam: Congress on the European Architectural Heritage, 1975, http://www.icomos.org/docs/amsterdam.html (accessed 25 October 2007).

15 Bickford outlines a critical understanding of 'common' as a normalizing term used to define group characteristics. She contends that conceptions of the common good are not neutral, rather, they favour the interests of those who control political, economic, and communicative resources. See Susan Bickford, "Reconfiguring Pluralism: Identity and Institutions in the Inegalitarian Polity," American Joumal of Political Science 43, no. 1 (1999), 89.

16 Susan Bickford, "Constructing Inequality: City Spaces and the Architecture of Citizenship," Political Theory 28, no. 3 (2000), 356.

17 For a discussion on the role of the built environment in the construction of the public sphere, see Bickford, "Constructing Inequality," 356.

18 Bickford, "Reconfiguring Pluralism," 87.

19 Perez-Gomez states, "the architect needs to have his or her own storia, the history-theory which is not a method but rather a new mythos..." See Alberto Perez-Gomez, "Architecture as Embodied Knowledge," Journal of Architectural Education 40, no. 2 (1987), 57. 
$|1|$

\section{The Construction of Meaning}

"Reality exists outside language, but it is constantly mediated by and through language: and what we can know and say has to be produced in and through discourse."

$\sim$ Stuart Hall ${ }^{20}$

The nature of architectural conservation - as a practice whose object of study includes both material and immaterial commodities - necessitates a twofold approach. In prerequisite it divides its interests between 'objectivity' and 'subjectivity'; between a model of scientific material-based procedures and a humanistic concern for questions of value and meaning. ${ }^{21}$ However, in recognizing this dichotomy, practitioners have attempted to close the gap by looking for one within the other - by looking for the meaning of a place within the physical manifestation of its built form. This, first and foremost, explains the tendency of practitioners to rely on styles, periods, and other aspects of the physical object to signify its meaning. But more importantly, as Jorge Otero-Pailos contends in his essay The Contemporary Stamp of Incompleteness, it suggests an origin of the professions long-standing proclivity to thinking that architectural conservation is an act of 'finding' and 'protecting' history that is imbedded in built fabric. This old notion - based on stable meanings fixed in material things - masked the practice of interpretation that is constitutive of conservation. ${ }^{22}$

Of course, there are reasons why conservation is practiced this way. Drawing much of its methodology from the modernist movement, the profession has relied heavily on Cartesian linear thinking - that is, ideas precede buildings and are inserted into them as meanings. ${ }^{23}$ This can be seen as both logical and practical - with architectural theory insisting on the autonomous nature of architecture ${ }^{24}$, it would make sense for 
conservationists to analyze it in this light. Furthermore, the physical reality of a building, a construction of bricks and mortar, suggests a fixity and solidity that serves only to emphasize this view of an invariable meaning in architecture. It is this practice - the search for stable, singular meanings permanently etched into the physical construct of architecture - that holds responsibility for the marginalization of interpretation in architectural conservation.

But meaning is not an innate, dormant feature of architecture that lies buried in wait, anticipating the next archeological dig. Nor can it be easily categorized via some common telos. ${ }^{25}$ Conceiving of it in this manner, says Alberto Perez-Gomez, "is as senseless as the notion that architecture can only provide material comfort or shelter." 26 Rather, the reality of architecture (and that of conservation as well) is infinitely more complex, shifting both with history and with culture. ${ }^{27}$ This is because we do not simply stumble upon value and meaning, rather, we produce it through an act of interpretation. ${ }^{28}$ Consequently, the significance of a building doesn't reside so much in the object itself, but in how we relate to it - in its ability to allow us to perceive ourselves as complete. ${ }^{29}$

For this reason, it's helpful to begin this investigation regarding architecture and conservation with a discussion about perception and interpretation - that is, how we perceive things within space and place, time and history - and how we then make meanings for (and from) these perceptions.

In his introduction to Umberto Eco's Interpretation and Overinterpretation, Stefen Collini states that the issue of interpretation, regardless of which ideological perspective 
one comes from, touches questions of 'human values' at every point. It provokes questions of 'moral issues' and 'ethics,' and queries our assumptions about knowledge and experience. ${ }^{30}$ As Eco himself states, "The fact that our knowledge is relational and that we cannot separate facts from the language by means of which we express (and construct) them, encourages interpretation." ${ }^{31}$ In this light, interpretation can be seen as a foundation of cultural life - it permeates our every action and provides for the embodiment of meaning in society. ${ }^{32}$ As Perez-Gomez notes,

"The observer always sees in terms of the experience and beliefs which constitute the very fabric of his or her own existence. We are, therefore, condemned to 'interpret.' We make the world in every instant as we polarize it through the motility of our body... In architecture a realization of this personal dimension of knowledge is paramount, founded on an authentic, passionate historical grounding, on an understanding of what we (as humanity) have made." ${ }^{33}$

This is, as Perez-Gomez notes himself, a reference to the work of Giambattista Vico. In The New Science, Vico argues that the nature of culture - its true origins - lies in mythic thought, a form of metaphorical thinking that locates the imaginative capacity for human thought to make meanings for the things that we perceive. He holds that while modern thought is dependent on 'intelligible universals' - concepts or abstractions which move from particulars to universals - mythic thought employs 'imaginative universals' a form of meditation where the meaning of the whole work comes independently to the reader, as he 'narrates it to himself.'34

Consequently, no longer is the reader assigned the role of 'observer of content', nor is the work a simple 'repository of content'. Instead, by re-enacting the author's role as maker through the process of interpretation - the reader and the work become co-authors in the 'divining' of cultural meanings. ${ }^{35}$ Perez-Gomez reiterates this point: "Our personal storia 
becomes the normative intellectual framework for 'making.' The 'tool' is our human disposition, our personal fascination and wonder." ${ }^{36}$

Of course, this raises some serious questions about both subjectivity and objectivity in the practice of architectural conservation. The argument is clear: that true objectivity can ever be had in practices of history and architecture is a fallacy - and Vico's elucidation of knowledge and culture tells us so. But while some would claim that this line of arguing leads directly to subjectivity - an attitude of 'anything goes' - this is certainly not the case. Rather, it brings to light that all meanings are

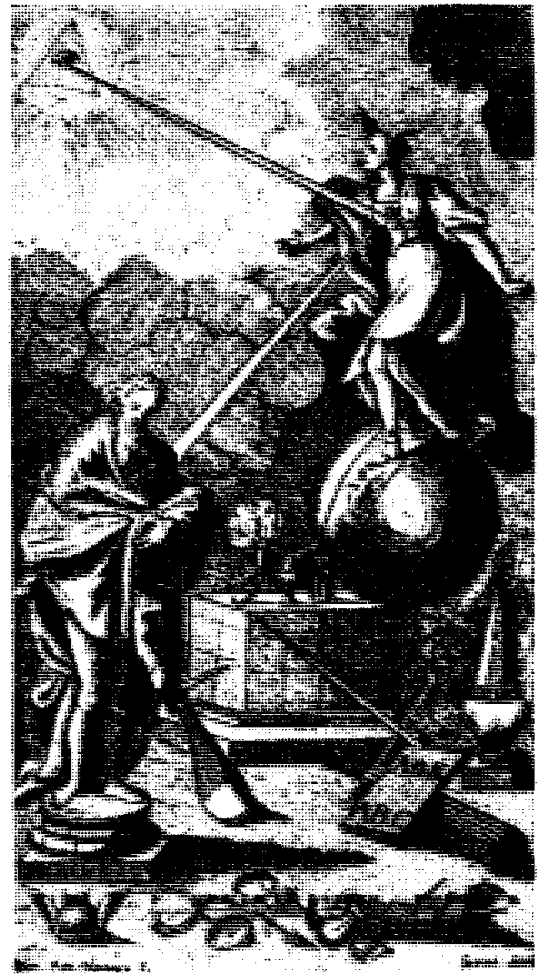

Fig. 1 The frontispiece of Vico's The New Science.

culturally bound - that our interpretations are inescapably tied to the internalization of cultural values and knowledge that is an intrinsic dimension of modernity. ${ }^{37}$ Conservation, therefore, must be seen as both productive of, and dependent upon, the social constructions and relations that exist in our society. While meanings are produced at an individual level, they are dependent upon the values instilled in the intersubjective realm. This is iterated by Umberto Eco, when commenting on textual interpretation that,

"When a text is produced not for a single addressee but for a community of readers - the author knows that he or she will be interpreted not according to his or her intentions but according to a complex strategy of interactions which also involves the readers, along with their competence in language as a social treasury. I mean by social treasury not only a given language as a set of grammatical rules, but also the whole encyclopedia that the performances of that language have 
implemented, namely, the cultural conventions that the language has produced..." 38

The danger in this culturally bound 'making' though is that meanings can become interwoven with an ideological value, and thus can be used to impose dominant cultural orders. ${ }^{39}$ They become subject to the whole range of deep codes of culture, where, as Stuart Hall states, "the sign becomes open to new accentuations and [...] enters fully into the struggle over meanings - the class struggle in language." ${ }^{\prime 4}$ This is because 'meaning' (in this relativistic context) is no longer a fixed entity, rather, it is open to articulation within wider ideological discourses, allowing it to be exploited and transformed for social purposes. ${ }^{41}$ It is in this way that language and conservation merge as powers to control the multiplicity of meaning. As Barthes has remarked, it is the new accentuations that have "a close communication with culture, knowledge, history, and it is through them, so to speak, that the environmental world invades the linguistic and semantic world. They are, if you like, the fragments of ideology." 22 Thus, to establish any meaning (whether in conservation or not), we must refer through these codes - the codes of social order and political power ${ }^{43}$ - an act that is highly asymmetrical, nonequivalent, and hegemonic.

The problem then, for conservation, is that it is embedded in these practices; it relies on language, culture, and one's personal storia to form the basis of its purpose in practice to locate value and meaning in the built environment. As a result, it is opened up to both a multiplicity of readings, but also the potential to be used as a tool of social power - to impose a singular authoritarian interpretation instead of allowing for an openness of meaning. It becomes, using the words of Stuart Hall, an 'ideological apparatus ${ }^{344}$ - one that stifles the pluralistic nature of our society and limits the stories that it is capable of 
telling. It is this limitation on stories, and their variegated meanings, which founds a major problem for conservation practices.

\section{Notes}

20 Stuart Hall, "Encoding/Decoding," in Media Studies: A Reader, edited by Paul Morris and Sue Thornton, (Edinburgh: Edinburgh University Press, 1996), 169.

21 Kunze elucidates this idea in reference to disciplines such as geography that have a natural association with the physical sciences and tend to be rooted more in practice than in theory. Considering the context in which it is stated (a discussion on Vico's philosophy of culture and its application to the study of place) its use is being extended to cover conservation as well. See Donald Kunze, "Giambattista Vico as a Philosopher of Place: Comments on the Recent Article By Mills," Transactions of the Institute of British Geographers New Series 8, no. 2 (1983), 237.

22 Jorge Otero-Pailos, "The Contemporary Stamp Of Incompleteness," Future Anterior 1, no. 2 (2004), ii.

23 Otero-Pailos, "The Contemporary Stamp Of Incompleteness," iii.

24 Perez-Gomez is highly critical of contemporary architectural theory, claiming they are purposefully devoid of philosophy and cosmology, and function within a practice that is reduced to an autonomous system of rational prescriptive rules. Refer to the Introduction of Alberto Perez-Gomez, Architecture and the Crisis of Modern Science, (Cambridge, Mass.: MIT Press, 1983).

Otero-Pailos, "The Contemporary Stamp of Incompleteness," iv.

Alberto Perez-Gomez, "Hermeneutics as Discourse in Design," Design Issues 15, no. 2 (1999), 71.

Perez-Gomez, "Hermeneutics as Discourse in Design," 71.

28 This argument regarding the 'finding' and 'protecting' of history, as well as the masking of interpretation in the practice of conservation, is from Jorge Otero-Pailos, "The Contemporary Stamp Of Incompleteness," Future Anterior 1, no. 2 (2004), iii.

29 Perez-Gomez, "Hermeneutics as Discourse in Design," 71.

30 Umberto Eco, and Stefan Collini, Interpretation and Overinterpretation, (Cambridge; New York: Cambridge University Press, 1992), 21.

31 Eco, and Stefan Collini, Interpretation and Overinterpretation, 143.

32 For a more detailed discussion on the embodiment of knowledge, see Alberto Perez-Gomez, "Architecture as Embodied Knowledge," Journal of Architectural Education 40, no. 2 (1987).

33 Perez-Gomez, "Architecture as Embodied Knowledge," 58.

34 Donald Kunze, Thought and Place: The Architecture of Eternal Place in the Philosophy of Giambattista Vico, (New York: P. Lang, 1987), 239.

35 Kunze, Thought and Place, 137.

36 Perez-Gomez, "Architecture as Embodied Knowledge," 58.

37 This paragraph based on arguments in Perez-Gomez, "Architecture as Embodied Knowledge," 58.

38 Eco, and Stefan Collini, Interpretation and Overinterpretation, 67-68.

39 For a detailed discussion on dominant cultural orders, see Hall, "Encoding/Decoding," 172.

40 Hall, "Encoding/Decoding," 171.

41 Hall, "Encoding/Decoding," 171.

42 Barthes quoted in Hall, "Encoding/Decoding," 172.

43 Hall, "Encoding/Decoding," 172.

44 Hall refers to the institutional position of broadcasting itself as an 'ideological apparatus'. I apply this institutional position to conservation as well. See Hall, "Encoding/Decoding," 174. 
$|2|$

\section{The Place of Identity}

"Society recreates its space on the basis of concrete space, always already provided, established in the past."

$\sim$ Alain Lipietz ${ }^{45}$

The relationship between language, culture, and the practice of architectural conservation, as laid out in the previous chapter, leads to another point of investigation one that revolves around our conceptions of 'place'.

The practice of architectural conservation is inextricably bound to, and dependant upon, the notion of 'place'. As Jorge Otero-Pailos points out, conservation "is a process of interpreting objects in such a way as to create history of a very special kind: one dependent on places, a site-specific history." ${ }^{46}$ This draws several connections between conservation, language, and the dependency the practice has on the manner in which we conceive and construct our ideas about places.

Consider, for a moment, our cities and communities. They are places in the sense that they identify commonalities that exist between citizens: they represent shared desires, values, and goals. But this overlapping of interests must be articulated through what David Black refers to as a 'grammar of geography' - a shared vocabulary that identifies the value of a place. Without such a grammar, space would remain indeterminate terrain - as devoid of particular character as any point of desert or sea. ${ }^{47}$ Black states,

"Maps continue to identify certain national boundaries in deserts or wastelands by the scandalous designation of 'undetermined,' very much as earlier mapmakers used to speak about terra icognita. The problem here is not so much that the places were all along out there and that the mapmakers simply did not know what to write or draw. Rather, there simply are no places at all until they can 
become incorporated into a vocabulary of interests - hence the discoverer's penchant for naming rivers, mountains, islands, inlets." ${ }^{48}$

On this account places are very much determined through the 'maps of meaning' ${ }^{49}$ of a culture and its language - they emerge from the acts of assertion and reading (encoding and decoding), which allow for the creation of meaning of places. Thinking of places in this way implies that they are not so much geographic locales, but a product of the social relations that exist at such a locale. They are, as Doreen Massey points out, "constructed out of a particular constellation of social relations, meeting and weaving together at a particular locus... articulated moments in networks of social relations." ${ }^{\circ 0}$ But to say this is to recognize the authority these relations have over the shape and form of the places we inhabit.

It is helpful to reflect on this in relation to the public sphere. Contemporary theorists of the public sphere have stressed its role as a central space of opinion formation. ${ }^{5}$ Some argue that the institutional criterion of the public sphere fosters an attitude of inclusivity and a disregard of status (such as Habermas) ${ }^{52}$, while others counter that it is a bourgeois conception that contributes only to hegemony, exclusion, and the bracketing of inequalities (such as Fraser) ${ }^{53}$. In either case, if we expand our definition of the public sphere to include the built environment - a material dimension that certainly participates in the shaping of that sphere - then we can begin to understand the potency of the built environment (the object of conservation) as 'a space of attention orientation' ${ }^{54}$ It aligns our relation to social space, affects who we recognize as citizens within it, and constructs particular forms of intersubjectivity reflective of these practices. The question then, is what kind of 'place' does conservation rely on, and what sort of relations do these places produce? 


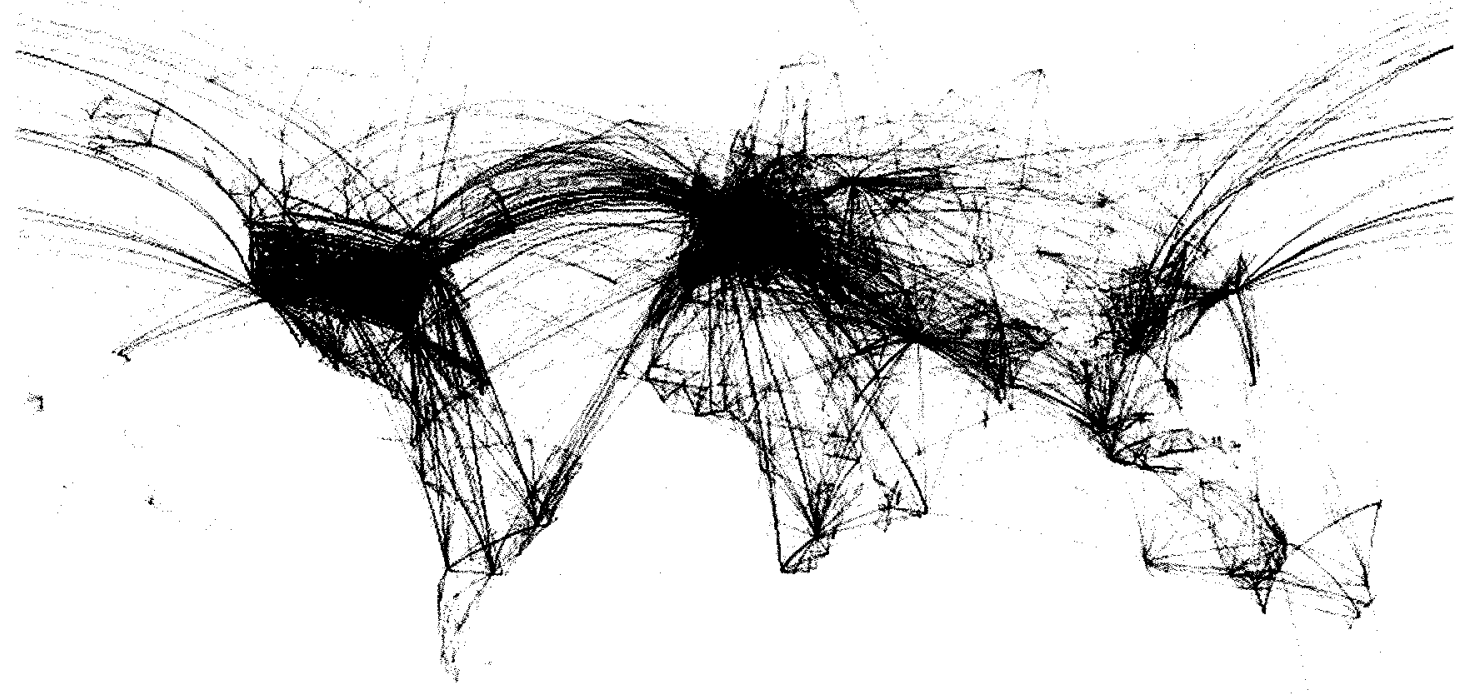

Fig. 2 Global flight patterns.

In order to carry out its work, conservation depends on a formulation of place that is founded on localized cultures, customs, and traditions. Its aim: to search out the 'real' meanings of places, the unearthing of heritages, and the locating of long, internalized histories. $^{55}$ However, this conception of place lies in tension with the era of globalization, instantaneous communication, and immense spatial upheaval in which we live. We inhabit a world of transnational corporations, worldwide production markets, and global migration patterns, all of which vastly alter our behaviour towards those we interact with (both locally and globally). Because of this, Massey argues that as the world economy has shifted, the frameworks that constitute 'locality' and 'place' have progressively disappeared. ${ }^{56}$ The once clear divisions between city and country (and even country and world) have disintegrated, transforming the world into what Marshall McLuhan dubs "a single global village". ${ }^{57}$ In reaction we yearn for 'a place to call home', because as Robins elucidates, in times of great change "the driving imperative is to salvage centred, bounded and coherent identities - placed identities for placeless times." $\$ 8$ 
Setting aside any debate of what may actually constitute these things (and whether its even possible to pinpoint such things), the mere association of conservation with these foundations renders it an essentialist practice - one that holds within it the temptation of relapsing into past traditions, of sinking back into the ideals of former times. ${ }^{59}$ Place becomes a source of stasis and refuge, safety and security. ${ }^{60}$

Bickford believes that this can be seen no more clearly than in our idea of the home - the 'place to call home' of which conservation yearns. She states that the home is idealized as a place of nurturance and safety, of comfort and shared interests, but most importantly, a retreat from the world of danger and instability. ${ }^{61}$ Quoting Honig's insightful analysis of the 'dream of home', she makes clear the dangerous effects that this notion provokes. "The phantasmatic imaginary of home (as safe haven in a heartless world) leaks into the politics of its bearers, animating a longing for a more homelike, (would-be) womblike universe, unriven by difference, conflicts, or dilemmas, a well-ordered and welcoming place." ${ }^{.2}$ Of course, any attempt to satisfy these desires for security and stability through a conception of place necessitates the recognition of difference and boundaries - between safe and unsafe, private and public, inside and outside, and 'us' and 'them'. Thus, attempts to fix the meanings of places through the practice of conservation - to enclose and defend them by constructing singular, fixed and static identities - must be seen as a counterpositioning against the Other. ${ }^{63}$

A particularly useful lens through which to understand these practices then, is Richard Sennett's conception of 'the inside' and 'the outside'. He argues that both are fundamental dimensions of human life - the former evoking a sense of privacy and intimacy, the latter a sense of risk and exposure. However, Sennett maintains that the 
'inside' (as an origin of the 'self' and its identity) has become the predominant focus of modern societal life. As such, the public - the space in which conservation operates becomes a realm of risk, uncertainty, and fear of exposure. It is this fear of exposure, as Bickford elucidates - both of strangers themselves, as well as their perceptions of the world from a different social location - that are manifested in the material presence of the environment. ${ }^{64}$

Clearly, these practices are inegalitarian - they are the fabrication of a dominant cultural order that seeks the illusion of safety and security at the actual expense of others; they are, as Bickford writes, undemocratic because of this inequality, but also because they attempt to substitute one perspective for many $y^{65}$ - they fail to recognize a multiplicity of stories. In this way, places - and the practice of conservation that depends upon such places - become material constructions that are intended to obscure and conceal the differences and plurality that exists within culture, by way of a tamed and prettified version of public space. ${ }^{66}$ We resort to such tactics, McLuhan argues, because when faced with a destabilizing and traumatizing shift in the social, political, or economic environments, we tend to make the old environment as visible as possible. ${ }^{67}$

There is then, at the very heart of the practice of conservation, a dependence on both the physical structure, as well as social structure, of the environment it seeks to protect. It utilizes place as a means to access the past, and in doing so, it perpetuates in some form the social space of the past as well. This is, as Bickford says, a purging technique that operates to screen some citizens from others - and what we stand to lose in building up the worldly artifice in this way is the possibility of a ethical public realm, one that depends on the presence of a multiplicity of stories of perceiving and perceived others. ${ }^{68}$ 
Thus, it is only through an understanding of place as a social construction that conservation practices may be able to recognize the variegated meanings of a site. Meanings that are construed and mediated through storytelling.

\section{Notes}

45 Alain Lipietz, "The Spaciality of Social Life: Towards a Transformative Retheorization," in Social Relations and Spacial Structures, edited by Derek Gregory and John Urry, (Basingstroke, Hampshire: Macmillan Education, 1985), 98.

46 Jorge Otero-Pailos, "The Contemporary Stamp Of Incompleteness," Future Anterior 1, no. 2 (2004), ii.

47 This paragraph is based on arguments in J. Pickles, David W. Black, and Donald Kunze, Commonplaces: Essays on the Nature of Place, (Lanham: University Press of America, 1989), 17-18.

48 Pickles, Commonplaces: Essays on the Nature of Place, 18.

49 Hall articulates the idea of 'maps of meaning' as structures of social reality that include a whole range of social meanings, practices, and usages written into them. See Stuart Hall, "Encoding/Decoding," in Media Studies: A Reader, edited by Paul Morris and Sue Thornton, (Edinburgh: Edinburgh University Press, 1996), 172.

50 Doreen B. Massey, Space, Place, and Gender, (Minneapolis: University of Minnesota Press, 1994), 154.

51 Susan Bickford, "Constructing Inequality: City Spaces and the Architecture of Citizenship." Political Theory 28, no. 3 (2000), 356.

52 For more detail regarding this, see Jurgen Habermas, The Structural Transformation of the Public Sphere: An Inquiry into a Category of Bourgeois Society, (Cambridge, Mass.: The MIT Press, 1989).

53 For more detail regarding Fraser's theory, see Nancy Fraser, "Rethinking the Public Sphere: A Contribution to the Critique of Actually Existing Democracy," Social Text 25, no. 26 (1990).

54 Bickford, "Constructing Inequality," 356.

55 Massey's ideas regarding the reason we search for a particular type of 'place' reflect nicely the 'grammer of geography' outlined by Black. Massey, Space, Place, and Gender, 151.

56 Massey, Space, Place, and Gender, 162.

57 McLuhan claims that the electronic media constitute a 'retribilizing process' that is responsible for a decentralizing of the state that is highly traumatic in literate, institutionalized countries. See Marshall McLuhan, "Playboy Interview: Marshall McLuhan," Playboy, March 1969.

58 Robins quoted in Massey, Space, Place, and Gender, 162.

59 Massey states that under this reading 'place' becomes essentialized, carrying with it a specific set of characteristics based on an ideal image of the past. See Massey, Space, Place, and Gender, 119.

60 Massey, Space, Place, and Gender, 151.

61 Bickford, "Constructing Inequality," 364.

62 Honig quoted in Bickford, "Constructing Inequality," 364.

63 Massey, Space, Place, and Gender, 168.

64 This paragraph is based on Bickford's elucidation of 'the outside', in which Sennett's argument is utilized. See Bickford, "Constructing Inequality," 357.

65 Bickford, "Constructing Inequality," 358.

66 Bickford, "Constructing Inequality," 362.

67 Marhall McLuhan, "Playboy Interview."

68 Bickford, "Constructing Inequality," 363. 
$|3|$

\section{The Contemporaneity of History}

"History as human-generated change is not 'natural,' it is part of the modern Western consciousness."

$\sim$ Alberto Perez-Gomez ${ }^{69}$

Through the discussion of the significance of language and place as formative devices in the practice of conservation, I have alluded to a third, admittedly self-evident foundation of architectural conservation - history.

It is difficult to imagine any theory of architectural conservation that does not depend heavily on a reductive, methodological notion of history to construct the value of a work. One needs to consider little more than the established practice of historiography in conservation - the cataloging of buildings into preconceived 'historical' categories ${ }^{70}-$ to satisfy a need for evidence. Like the utilization of classical categorization in the sciences, placing discrete entities into categories establishes the conditions necessary to interrogate meanings via a static, defined, enclosed set of properties that are common to their members. The convenience of this method is obvious; once labeled a member of a particular categorical cluster, the application of historical value is effortless under the guise of a common telos. ${ }^{71}$

But imagining history in this manner - as a succession of disparate, all-encompassing 'spirit of the times' phases - is problematic. It requires a conception of history that is both static and objectified (an assumption that accommodates the conservation of architecture well, considering the materiality of architecture and its implied fixity). Perez-Gomez reflects on this subject, stating that a great deal of recent writing, ranging 
from scientific and methodological approaches to the continuation of the project of critical rationality from the Enlightenment, often reiterates this view of history as "an accumulation of uninteresting shells, quite dead and unyielding." He continues, “This sense of history is easily embraced because it coincides with popular assumptions about linear temporality and technological progress, viewing the past as an alien and closed book." ${ }^{2}$

This rationalization - originating in the

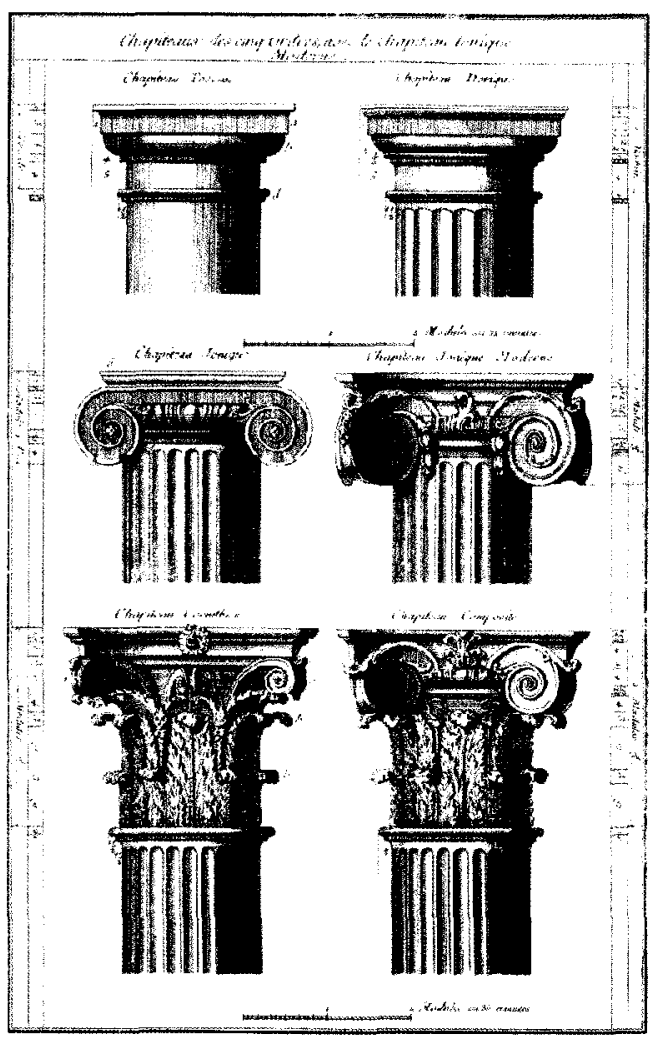

Fig. 3 The classical orders of architecture. scientific method that finds satisfaction only in determinacy ${ }^{73}$ - suggests that the stories of time themselves are artifacts, and carry the same definable characteristics, such as size and shape, that can be mapped to any other physical entity. In this light, we begin to see the differences between distinct historical periods: gothic, baroque, victorian, modern all with their own specific traits and durations. This practice, argues Perez-Gomez, shows a general disregard for the history of architecture as a complex, multifaceted cultural order, one with significant epistemological connections that are embodied in a diversity of artifacts. $^{74}$ Yet, despite many critiques of exactly this practice ${ }^{75}$, we still attempt to reduce history (and the history of conservation and architecture) to a typology, or to a single, progressive and continuous line of dialectical moments. ${ }^{76}$ The 
consequences of this, on both the practice of conservation and the structures of intersubjectivity that the practice fosters, are many.

Doreen Massey argues that a beneficial way to analyze these perspectives on history is through our approach to space. Similar to our notion of place, we are accustomed to thinking of space as a singular consistent reality; a reality that can be drawn on paper in the form of a map, giving space static, definable, and clear characteristics. On this reading, space becomes a thing that we travel across from 'here' to 'there', always understood via our own singular experience. But conceiving of space in this manner causes it to differentiate, holding other places, peoples, and cultures at a distance. This, Massey says, is not an innocent maneuver, for by this means others are deprived of their own histories. The spatial politics of this act are no more apparent than in Western history's account of the voyages of discovery, for it is only after the 'discovery' of the new world and its people, that it becomes recognized as a valid part within history. Prior to this it is held static, an immobilized space without its own concurrent history, just awaiting our arrival. ${ }^{77}$

Of course, conceiving of space and history in this manner should be seen as a derivative of Western modernity. It's indicative of what Massey calls the cosmology of 'only one narrative', in that it obliterates the multiplicity and heterogeneity of space, and proposes that societies exist within an historical queue. ${ }^{78}$ Indeed, the frameworks of Progress, of Development, and of Modernization, and the succession of modes of production elaborated within Marxism (despite Marx's recognition of divergent cultural structures $^{79}$, all propose scenarios in which the direction of human history is foreseen and defined. ${ }^{80}$ But, as has been thoroughly exposed by postmodern thinkers, the West 
(in these stories) was the principal agent of history - relegating non-Western societies to a marginal position in the past. The arrogance of these Western grand narratives led the modernists to project their own culture's unique development onto the globe - even claiming that modernization contained universally valid forms of life (e.g., science, bureaucracy, socialism, secularism). ${ }^{81}$ However, as Seidman points out, "Not much effort is required to see that behind the aggrandizing intellectualism of the modernists were the expansionist politics of the age of colonialism." 82

In this way, the grand narratives of industrialization, modernization, and democratization all presumed to uncover not just universal forms of life, but a universal, uniform social process that could be applied to any society. In consequence, they repressed important differences between societies by perpetuating Western hegemonic aspirations - they are "little more than myths that aim to authorize certain social patterns." 83

Yet, while theory suggests that we've moved past these naïve, all-encompassing ideas of modernization, their attitudes seem to be reflected in the project of globalization. Like the modernist narrative before it, contends Massey, the tale of globalization is one of inevitability. Whether seen through the lens of technological advancement, market expansion, or assimilating economies, globalization comes to have almost the ineluctability of modernity's story of progress. While third world countries may not be at the same stage of development as other, more 'advanced' nations, it is presumed they will follow along this same path of development. This, then, is a tale of a single directed trajectory. ${ }^{84}$ On this, Massey states, 
"This convening of contemporaneous geographical differences into temporal sequence, this turning it into a story of 'catching up', occludes present-day relations and practices and their relentless production, with current rounds of capitalist globalization, of increasing inequality. It occludes the powergeometries within the contemporaniety of today's form of globalization." 85

Furthering the hegemony of this act, is the assertion that this particular configuration of globalization can be the only possible form - its inevitability obscuring the possibility of seeing any alternatives. In this way, the term 'Globalization', just like that of "Capitalism', comes to be a normalizing euphemism that fails to recognize the contemporaneous multiplicity of history. ${ }^{86}$

It is, as Massey so eloquently states, all appallingly apparent. The power of maps to hide the heterogeneity of space; the real problems of thinking about and appreciating place; the failed recognition of a plurality of different stories; even this version of globalization which dismissively places others to the past. These practices all promote the conception of our world as both singular and closed - an always-already completed holism. ${ }^{87}$ What this all adds up to then, is a portrayal of the present-day context as still dependent upon the same colonial practices that dominated the modernist intellectualism that came before it. Our conception of history, and also that of space, still lacks a recognition of other realities, other trajectories, other stories. The repercussions of this on our practices of conservation are apparent. When we perpetuate imperial attitudes, regardless of whether we project them onto people far or near, we fail to address the plurality of stories that are happening across space and across time, even in our own localities. In this way, despite the decentralizing reformation of society argued by Marshall McLuhan (or, rather, as a reaction to it, as pointed out in the previous chapter), we persist to practice conservation through the historic lens of centralizing nationalisms - ones that forge mass 
states, homogenized ethnic groups, and a national identity, all the whilst denying the multiplicity of values across cultures and their stories. ${ }^{88}$

\section{Notes}

69 Alberto Perez-Gomez, "Hermeneutics as Discourse in Design," Design Issues 15, no. 2 (1999), 76.

70 Jorge Otero-Pailos, "The Contemporary Stamp Of Incompleteness," Future Anterior 1, no. 2 (2004), iv.

71 Otero-Pailos, "The Contemporary Stamp Of Incompleteness," iv.

72 Perez-Gomez, "Hermeneutics as Discourse in Design," 75-76.

73 Perez-Gomez discusses extensively the tendency of scientific progress to reduce theory to pure instrumentality. See Perez-Gomez, Architecture and the Crisis of Modern Science, "Architecture as Embodied Knowledge," "Hermeneutics as Discourse in Design."

74 Perez-Gomez, "Hermeneutics as Discourse in Design," 75.

75 Postmodern theorists are responsible for such thinking. See J.F. Lyotard, The Postmodern Condition; Doreen B. Massey, "Space-Time," For Space; Steven Seidman, "The End of Sociological Theory".

76 Perez-Gomez, "Hermeneutics as Discourse in Design," 75.

77 This paragraph is based on arguments in Doreen B. Massey, For Space, (London; Thousand Oaks, Calif:: SAGE, 2005), 4.

78 Massey proposes that globalization constructs a notion of history as a queue in which third world countries are just 'behind' in history. See Massey, For Space, esp. Chapter 6.

79 Steven Seidman, "The End of Sociological Theory: The Postmodern Hope," Sociological Theory 9, no. 2 (1991), 138.

80 Massey, For Space, 11.

81 This paragraph is based on arguments in Seidman, "The End of Sociological Theory," 139.

82 Seidman, "The End of Sociological Theory," 139.

83 Seidman, "The End of Sociological Theory," 139.

84 For a more detailed discussion on the patterns of globalization, see Massey, For Space, esp. Chapter 6.

85 Massey, For Space, 82.

86 Massey, For Space, 83.

87 Massey, For Space, 14.

88 Marshall McLuhan, "Playboy Interview: Marshall McLuhan," Playboy, March 1969. 


\section{Theories in Practice}

"All this points to the nature of every real story. It contains, openly or covertly, something useful" $\sim$ Walter Benjamin ${ }^{89}$

Through the previous three chapters, this thesis has shown that the practices of conservation are intricately tied to, and reflective of, the social structures of society. Our constructions of language, place, space, and history all play a significant role in the way that we carry out the work of architectural conservation. The arguments presented have also suggested that because of these ties, conservation has become, for all intents and purposes, an institutionalizing practice - one that regulates, legitimizes, and perpetuates the unequal social structures and power relations that exist within our society.

There is, of course, already a great deal of theory that criticizes such practices. Postmodernist thinkers, both in architectural conservation and social theory discourses, have presented critiques of these aggrandizing practices $^{90}$ (as I've pointed out in my previous discussions). But few present a means to address these issues practically. Bickford suggests, in the context of social theory, that this can be ascribed to a division between the study of 'words' and of 'things' (drawing on the terms outlined by Barrett). She notes that many contemporary theorists focus on language and the production of meaning, analyzing processes of symbolization and signification. But she states that, "these concerns are often absent from social scientific thinking about worldly 'things' like social structures and political institutions." ${ }^{p 1}$

We should think about this division, then, in terms of representation, because it is a lack of representation (of the study of 'words' in the study of 'things' and vice versa) that leads 
to this dichotomy. As Pitkin points out in The Concept of Representation, "representation, taken generally, means the making present in some sense of something which is nevertheless not present literally or in fact." What is absent, then, in the practice of architectural conservation, is the representation of its theories regarding humanistic concerns in its procedures and methods in the material world. But how is it that these theories can be made to be present? Seidman suggests a pragmatic approach one that constructs theories based on their practical implications. He states,

"When one appeals solely to the truth of a discourse to authorize it intellectually and socially, one represses reflection on its practical-moral meaning and its social consequences. A discourse that justifies itself solely by epistemic appeals will not be compelled to defend its conceptual decisions based on moral and political grounds. The practical or moral significance of the discourse will go unattended or else will be considered only in the most cursory way." ${ }^{93}$

A pragmatic turn, he argues, would counteract such a practice, by endorsing a socially informed moral analysis in which a practitioner would be compelled to defend a particular theory by analyzing its benefit in accordance with its social consequences. ${ }^{94}$ In this way the practice would be more ethical, because it would necessarily take into account the social relations that it creates within the realm of the wider public sphere. ${ }^{95}$

If we further this idea then, in terms of conservation, what this newfound pragmatism in theory must represent, is a practice based on an expanded and variegated sense of citizenship. ${ }^{96}$ It should recognize that places do not have singular identities, that history cannot outline any universal story, and that language can never produce only one single meaning. Bickford elucidates by stating, 
"We need institutional spaces that allow groups to present themselves to one another in a plurality of ways: as located in particular social structures, as capable of questioning seriality, and as capable of forming active judgments on serialized and nonserialized existence. The multiplicity of 'presentations' keeps visible the paradoxical and partial quality of citizen presence. This account suggests, then, that a central set of questions to be directed toward attempts at institutional reform is whether they can foster this plurality." ${ }^{\prime 9}$

Thus, what should be materialized through this reformation of practice, is a certain kind of relations between citizens in society - relations that are productive of heterogeneous public identity and have the potential to exceed the context of politics. ${ }^{98}$ The next chapter will suggest that a way of approaching this task is through the framework of storytelling.

\section{Notes}

89 Walter Benjamin, "The Storyteller: Reflections on the Works of Nikolai Leskov," in Illuminations, edited by Hannah Arendt, translated by Harry Zohn, (New York: Harcourt, Brace \& World, 1968).

90 See Bickford, "Reconfiguring Pluralism", "Constructing Inequality"; Massey, Space, Place, and Gender, "Space-Time", For Space; Otero-Pailos, "The Contemporary Stamp of Incompleteness"; Seidman, "The End of Sociological Theory", "The Political Unconscious of the Human Sciences".

91 For a detailed discussion on Bickford's ideas regarding the division between practice and theory, as well as 'words' and 'things', refer to Susan Bickford, "Reconfiguring Pluralism: Identity and Institutions in the Inegalitarian Polity." American Journal of Political Science 43, no. 1 (1999), 88.

92 Pitkin's The Concept of Representation quoted in Bickford, "Reconfiguring Pluralism," 96. The quote continues, "Now to say something is simultaneously both present and not present is to utter a paradox."

93 Steven Seidman, "The End of Sociological Theory: The Postmodern Hope." Sociological Theory 9, no. 2 (1991): 135.

94 Seidman states, "The social critic has a responsibility, it seems to me, not only to say what is wrong with current realities in some broad, abstract way but also to make his or her critique as specific as possible so as to make it socially relevant. Similar, the critic should be compelled at least to outline in some detail the social changes desired and the consequences that would follow for the individual and society." See Seidman, "The end of Sociological Theory," 142.

95 Seidman argues that a pragmatic turn in theory would allow it to be judged by a wider audience on its moral implications. This, he says, implies a more democratic public realm. See Seidman, "The end of Sociological Theory," 136.

96 Bickford, "Reconfiguring Pluralism," 91.

97 Bickford, "Reconfiguring Pluralism," 100.

98 Bickford, "Reconfiguring Pluralism," 100. 
$|5|$

\section{The Experience of Storytelling}

"Storytelling reveals meaning without committing the error of defining it."

$\sim$ Hannah Arendt ${ }^{99}$

It can be said that stories, like the music and dance that in many societies accompanies the telling of stories, are a kind of theatre where we collaborate in reinventing ourselves and authorizing notions, both individual and collective, of who we are. They are a means to reconcile our identities, a way to re-place our 'being-in-the-world' within the context of the continual flux of interaction with others. ${ }^{100}$ Under this reading, stories are situated - their form, meaning, and functions - in culturally defined events ${ }^{101}$. They are segments of the flow of experience that are "authored and authorized dialogically and collaboratively in the course of sharing one's recollections with others." 102 For this reason, stories can never exist as purely personal constructions, instead, they reference the worldly perceptions of all who have come in contact with them. Benjamin reflects this thinking, stating, "The storyteller takes what he tells from experience - his own or that reported by others. And he in turn makes it the experience of those who are listening to his tale." 103 Storytelling, then, is the process by which this theatre of shared experience is materialized, and as such, is the mediator between the individual and the collective realms - the site where personal experiences and shared views are contested and recombined.

Hannah Arendt has written extensively on this topic. She states that storytelling is never simply a matter of creating either personal or social meanings, but an aspect of "the subjective in-between" in which a multiplicity of private and public interests always 
coincide. ${ }^{104}$ This revelation places storytelling firmly in the realm of intersubjectivity - as an oscillation between the individual act of meaning-making within one's own perception of the world, and the culturally-defined rules and structures that are continually exerted onto these perceptions. Thus, while every story discloses an agent who experienced the events recounted, this particular subject never remains the sole author of his or her own story, for the story comes into being through its relationship to an "already existing web of human relationships." ${ }^{105}$ In this light, storytelling may be seen as a process that strikes a balance between these realms - between the actor and the acted upon (in that it reworks and remodels subject-object relationships). ${ }^{106}$ This is a relationship that is typical of all narrative events. ${ }^{107}$

The importance of this balance lies in its ability to provide an opportunity for these antithetical, yet mutually dependant realms to affect transformation upon the other. That is to say that storytelling, through its event, translates the locus of action and meaning from "one context of relationship to another," ${ }^{\prime 108}$ and in doing so, alters the experience that both the actor, as well as the acted upon, has of the world. They are, to use an analogy that I will return to later, 'joints' - constructed via the dialogue that weaves these experiences together. The outcome of this is twofold. First, storytelling becomes a tool for a subject to mitigate the patterns of dominant cultural codes and meanings in society, by providing a means for a subject to assert his or her own perceptions back onto the world. Indeed, in constructing and construing stories we reflect our desire to restore viability with others, while simultaneously reconciling our autonomy and affirming our collective ideals in the face of disparate experiences. ${ }^{109}$ But the second outcome is that, in traversing the border between these two spheres, a boundary that would normally demarcate different social domains, we see that 
storytelling becomes an agent that is capable of blurring, transgressing, and even abolishing these boundaries. ${ }^{110}$ This is why, in both Arendt's view as well as LeviStrauss', stories are always 'in-between' - they create “indeterminate and ambiguous situations that involve contending parties, contrasted locations, opposing categories of thought, and antithetical domains of experience." 111

To recognize this - that storytelling is a means to abolish the boundaries that demarcate singular conceptions of the world - is also to recognize that the foundation of storytelling rests on its ability to change our experience of the way things are. As Jackson notes, storytelling is a "strategy that involves making words stand for the world, and then, by manipulating them, changing one's experience of the world." 112 This is because once we move past fixed identities, locations, and categories, and embrace a variegated dialogue, we are able to open up to new horizons; new potentialities that project from the historically constructed notion of who or what we are (based on our experiences of the past), to who or what we may become. By no means, though, does this suggest an abandonment of these experiences; rather, in a Janus-like fashion ${ }^{113}$, this in-between position places us in the 'here and now', looking in two directions at once.

It is at this junction between being and becoming, individual and collective, and past and future (brought on by storytelling's innate ability to traverse boundaries), that a pragmatic and ethical theory of architectural conservation can be found. If conservation were to approach the historicity of a building through this lens, it would recognize - as supported by the arguments in this thesis - the intricate connection that exists between the intersubjective realm (the place of identity construction), the built environment (the artifacts that manufacture and reflect these identities), and the language through which 
we articulate and construe them. After all, buildings are the "joints of the construction of human culture... compelling demonstrations of how we inhabit the world," 114 and as such, demand attention in both a material and immaterial way. Perez-Gomez expresses this necessity in reflecting upon the architect's social responsibility. "By understanding these forms of specific embodiment and articulating their lessons in view of our own tasks, we will have a greater chance to construe an appropriate architecture, an intersubjective reality that might fulfill its social and political task as an affirmation of culture,"115 one being 'made' (in the Viconion sense) through the interweaving of our stories and experiences. He continues, stating that the issue for architecture, and by extension conservation, is a disclosure of the political order "from the chaosmos of experience, starting from the perceptions of meaning that our culture has shared and embodied in historical traces, while projecting imaginative alternatives going beyond stifling and repressive inherited institutions." ${ }^{116}$

Thus, by naming its intentions in deference to a "space of experience" (the narratives of the past) and with respect to a "horizon of expectations" (the narratives of the future), storytelling provides conservation with an opportunity to reconcile a historicity that lacks an understanding of plurality, with an ambiguous, undetermined, and potential-filled future. In this way, the words of Umberto Eco provide the only suitable culmination of this story,

"When I write a novel, [...] I realize that I am not trying to impose a conclusion: I stage a play of contradictions. It is not that I do not impose a conclusion because there is no conclusion; on the contrary, there are many possible conclusions (frequently each of them being impersonated by one or more different characters). I refrain from imposing a choice between them not because I do not want to choose but because the task of a creative text is to display the 
contradictory plurality of its conclusions, setting the readers free to choose - or even to decide that there is no possible choice."117

It is through this contradictory plurality of conclusions - that is, conclusions that are not

imposed by the author, but are 'made' through the act of construing by the reader - that storytelling becomes the appropriate mythos for conservation.

\section{Notes}

99 The original source of this quote is from Bartlett's Book of Quotations, 1907.

100 Michael Jackson, The Politics of Storytelling: Violence, Transgression, and Intersubjectivity, (Copenhagen: Museum Tusculanum Press, 2002), 16.

101 Richard Bauman, Story, Performance, and Event: Contextual Studies of Oral Narrative, (Cambridge; New York: Cambridge University Press, 1986), 2-3.

102 Jackson, The Politics of Storytelling, 22.

103 Walter Benjamin, "The Storyteller: Reflections on the Works of Nikolai Leskov," in Illuminations, edited by Hannah Arendt, translated by Harry Zohn, (New York: Harcourt, Brace \& World, 1968), ?.

104 Hannah Arendt, The Human Condition, (Chicago: University of Chicago Press, 1958), 182-184.

105 Hannah Arendt, The Human Condition, 184.

106 Jackson, The Politics of Storytelling, 16.

107 Bauman, Story, Performance, and Event, 4.

108 Jackson, The Politics of Storytelling, 18.

109 Jackson, The Politics of Storytelling, 18.

110 Jackson, The Politics of Storytelling, 25.

111 Jackson, The Politics of Storytelling, 25.

112 Jackson, The Politics of Storytelling, 18.

113 According to Roman mythology, Janus was the god of gates, doors, doorways, beginnings and endings. He was gifted with two heads, so as to look to the past and the future, simultaneously.

114 Frascari, Marco, Monsters of Architecture: Anthropomorphism in Architectural Theory, (Maryland: Rowman and Littlefield, 1991), 22.

115 Alberto Perez-Gomez, "Hermeneutics as Discourse in Design," Design Issues 15, no. 2 (1999), 78.

116 Perez-Gomez, "Hermeneutics as Discourse in Design," 78.

117 Eco, Umberto, and Stefan Collini, Interpretation and Overinterpretation, (Cambridge; New York: Cambridge University Press, 1992), 140. 
$|6|$

\section{The Bellinzona Story}

"Restoration is never, in the often used and attractive phrase, renewal of former glory."

$\sim$ Aurelio Galfetti ${ }^{118}$

An appropriate example of the mythos this thesis proposes can be seen in the work of the Swiss architect Aurelio Galfetti, in particular his conservation project at Castelgrande Bellinzona, located in the canton of Ticino, Switzerland.

The potential conservation of Castelgrande - the oldest and largest of three castles in the area dating back to at least $590 \mathrm{AD}$ - first came to public attention following the end of the Second War World. As the sole castle existing within an urban centre, both local authorities and private investors cast an eye on Castelgrande in hopes of finding a suitable use for it. While the castle was deemed of little architectural value (as it was never a seat of nobility, rather, a humble military facility), its urban site suggested a unique opportunity. Accordingly, many proposals were put forth. However, the project inevitably came up against an impenetrable fog of quarrels, in no small part because of its civic location ${ }^{119}$ - a fact that inscribed an array of stories into the memories of the local citizens, and thus demanded that any project meet general approval. ${ }^{120}$

To add further complications, politicians seemed possessed by a fascination with ruins and populist ideas of monuments - both of which rung the bells of high money-making potential and labeled any alternative approaches as threatening to this aim. ${ }^{121}$ Galfetti, however, was not to be swayed by all of this disagreement; he desired to see the 'transformation' of Castelgrande by opening it to new dialogue, new interpretations. 


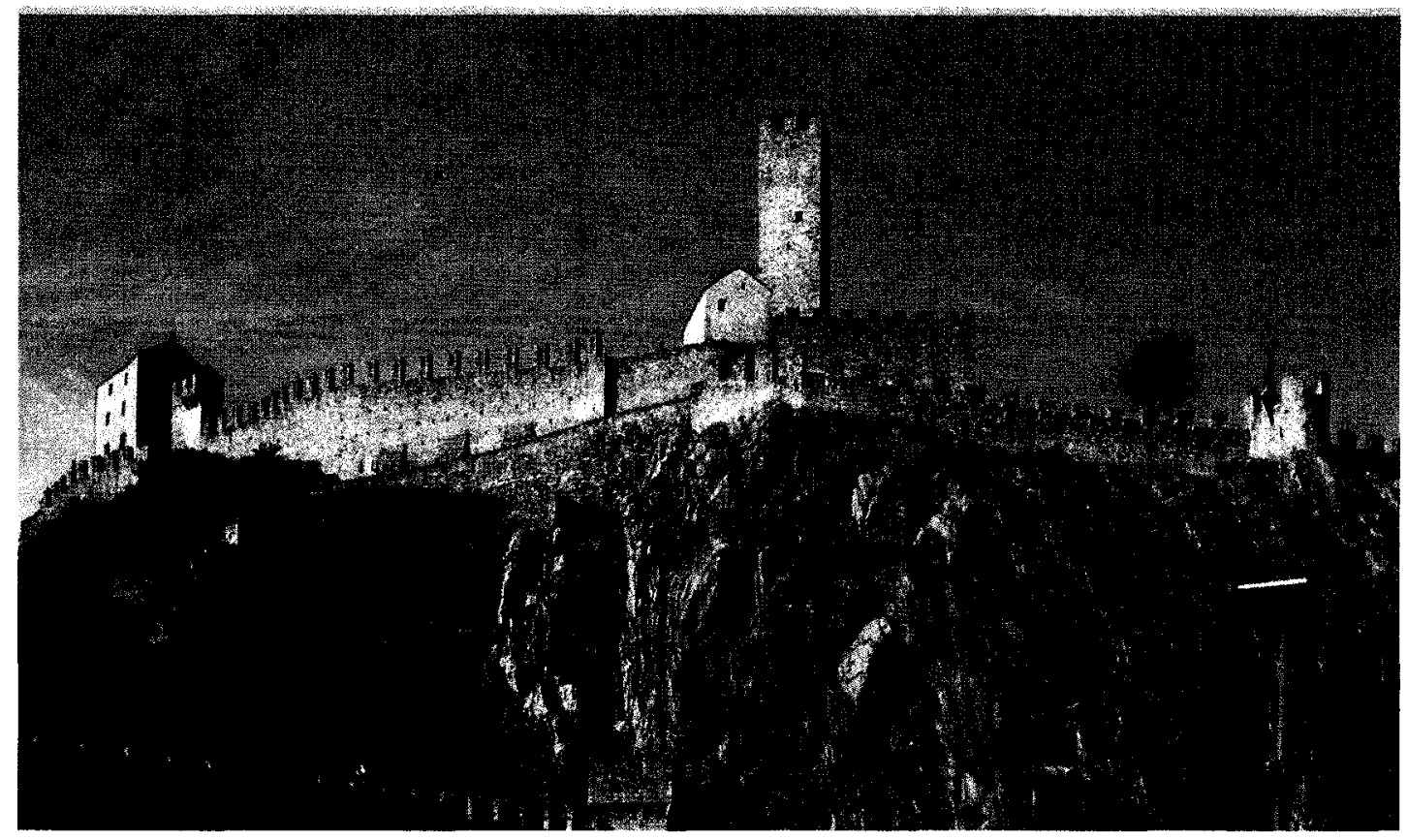

Fig. 4 Castelgrande, Bellinzona.

Galfetti's vision for the project was based not on the employment of typological rigour (as would normally be employed in such a case) but on 'didactic seriousness and dialectical ingenuity'. ${ }^{122}$ He sought to understand the particular historical experiences, events, and stories of the place, and then through transformation (a process analogous to storytelling), tell a new story for a new context (that of the late $20^{\text {th }}$ Century), which would simultaneously present novel perspectives as well as historical ones. In this way, he was engaging in a negotiation between the "space of experience" and the "horizon of expectation", the terms defined by Ricoeur and utilized by Perez-Gomez to outline a theory of hermeneutics in architecture. ${ }^{123}$ Galfetti himself has suggested this much:

"I should like to make clear that restoration is not reconstruction of the past, but topicalization of the past; restoration is never, in the often used and attractive phrase, renewal of former glory. In the field of architecture restoration is always transformation, because although it is important that we restore in order to conserve, we also restore in order to provide an appropriate response to new 
requirements, new 'content'... the only possible conservationist restoration available is that which allows a building to die in peace. Even mere cleaning, plain painting is transformation... For me restoration means conservation by topicalization. By topicalization I understand that one first of all discovers and emphasizes the particularly expressive factors of an existing building and then from the point of view of the new purpose and in a different light that makes them more clearly readable and moves them closer to the spirit of our times one lets them come into being again." 124

Thus, under this light, the dialogue at which Galfetti aimed was much more than a simple juxtaposition between the old and the new ${ }^{125}$ - and this is apparent in the work. At times he emphasizes one story, while later calling that same story into question. Galfetti's entrance sequence speaks clearly of this tact. Despite an existing historic path that romantically meandered up to the castle (which was to be kept regardless), Galfetti decided to relocate his entrance to an inconspicuous corner wedged between the rock face and the old town wall. Here, after getting permission to cut a gateway in the towns sacrosanct fortifications, he created a new entrance passage - a completely artificial crack carved into the gneiss rock and lined with concrete, an entrance into "an ancient tomb"126 (Fig. 7). This tomb would then permit visitors to ascend the rock (Fig. 8), emerging to its surface to face little more than the shadows of the castle's towers and some minor ruins (Fig. 9) - a rather underwhelming conclusion to a such a grand and imposing entrance. ${ }^{127}$ This was, of course, Galfetti's intention - he employs the ambiguous and inconclusive nature of storytelling to emphasize the importance of Castelgrande's history - by introducing such a grand statement, by calling attention to the rock itself, even by relocating the entrance to be level with the city - while simultaneously calling such history into question and proposing alternate narratives - by undermining the fortifications, changing one's relationship to the rock, and emphasizing the vacuous space (and history) of the castle's ruins itself. In this way, Galfetti used the 
'joints' between stories, as well as the joints between architectural spaces, to create dialogue within the project and call attention to the multiplicity of interpretations that can - and do - exist at the site. The result of this is an indeterminate and ambiguous space, constructed of contrasting and antithetical domains of experience - a multiplicity of stories that are posed beside, even against, one another, positing a variety of readings depending on one's contextual interpretation. Seen in this way, Frank Werner points out, Galfetti's approach is a manner of treating the monument not as an objectifiable fact, but as a working hypothesis that is always in the making. ${ }^{128}$

It is through these articulations then, that Galfetti's theory of practice - "transformation not restoration"129 - becomes evident. But, more importantly, it is through a process of storytelling that Galfetti is able to achieve such transformation. Indeed, it is the relationship between stories - the 'in between' state of which Arrendt and Levi-Strauss spoke - that provides Castelgrande with its richness, complexity, and openness to dialogue. An openness to dialogue that allows a plurality of meanings, construed through a plurality of cultures, resulting in an ethical and equally representative forum. 

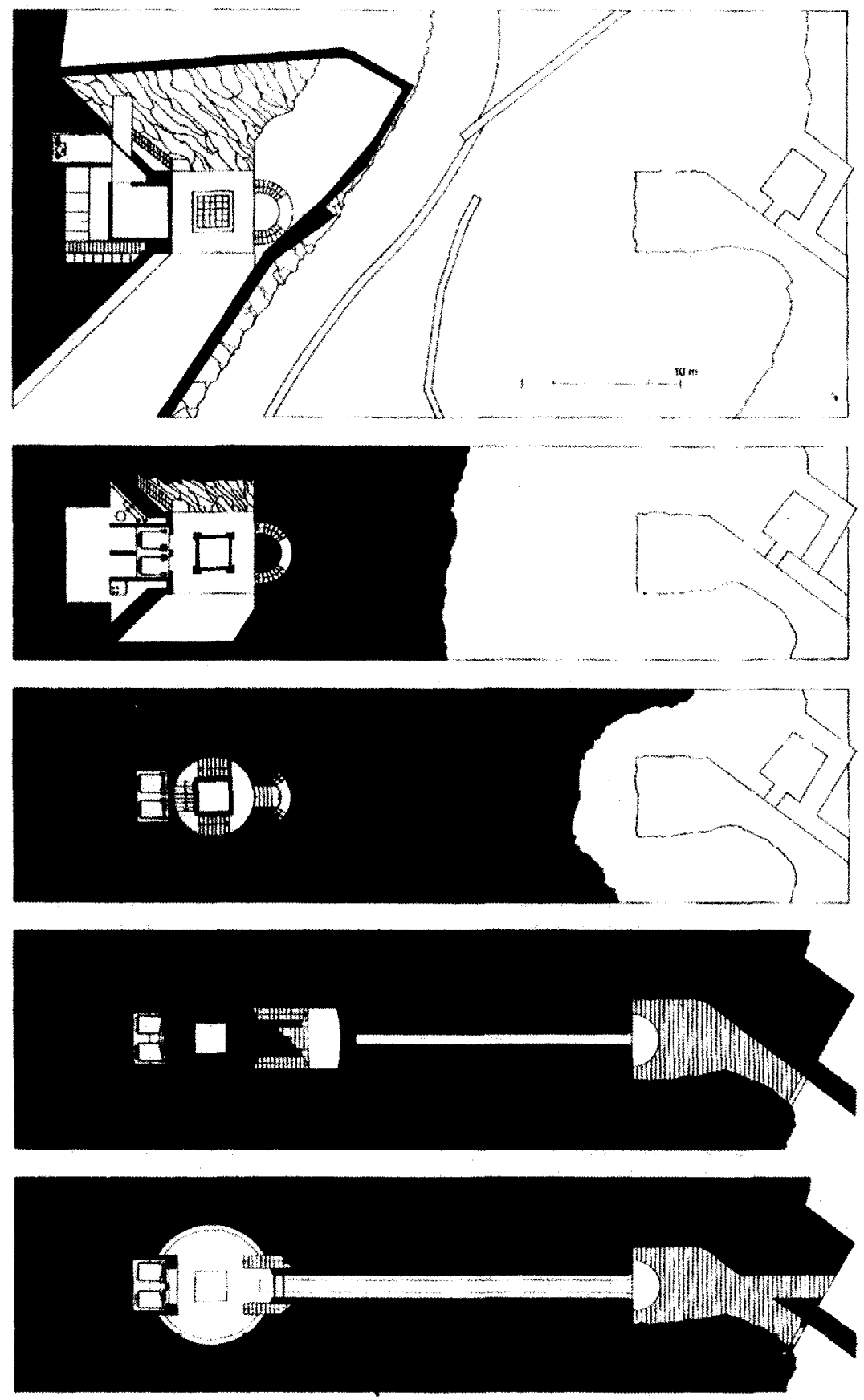

Fig. 5 Plans of Castelgrande entrance sequence. 


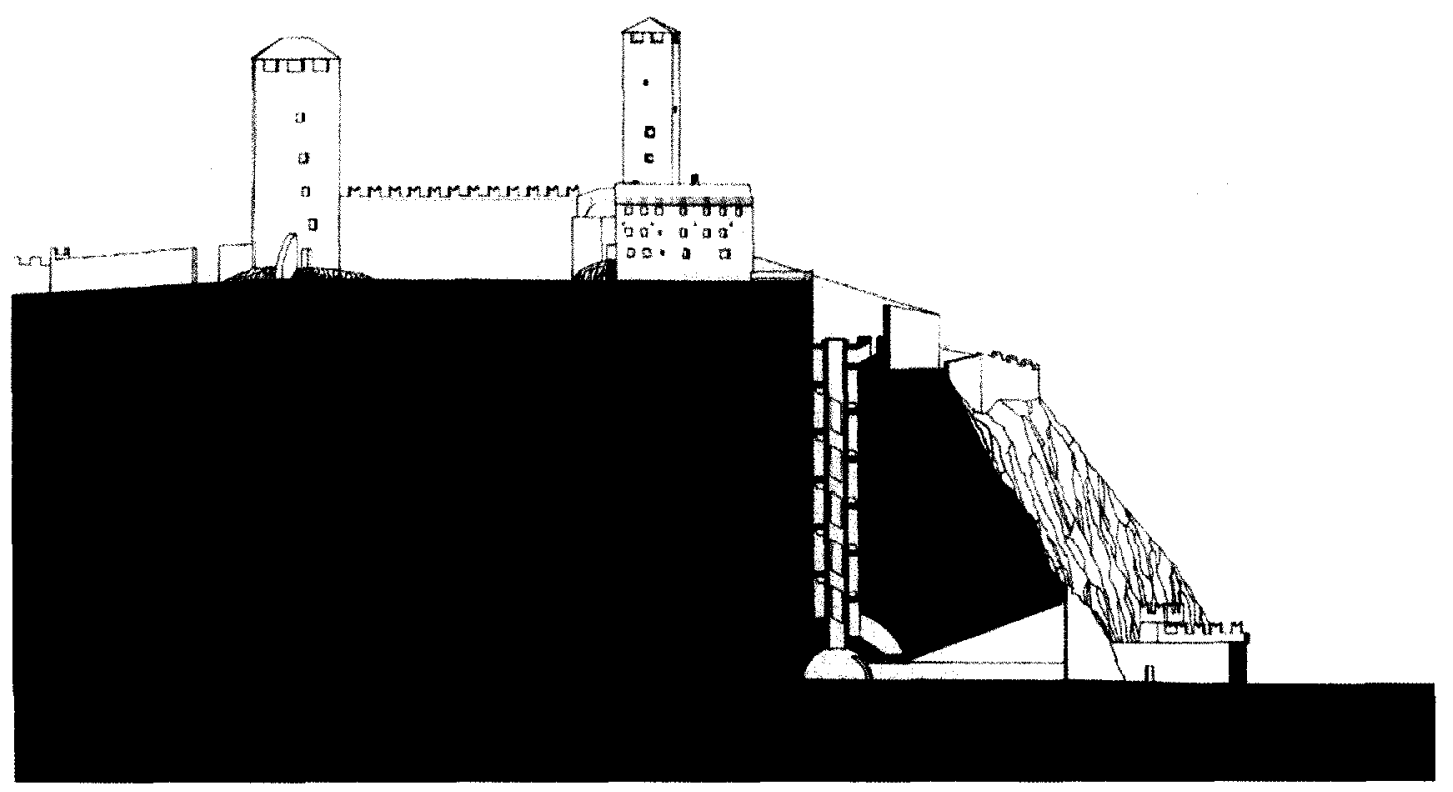

Fig. 6 Section through Castelgrande entrance sequence. 

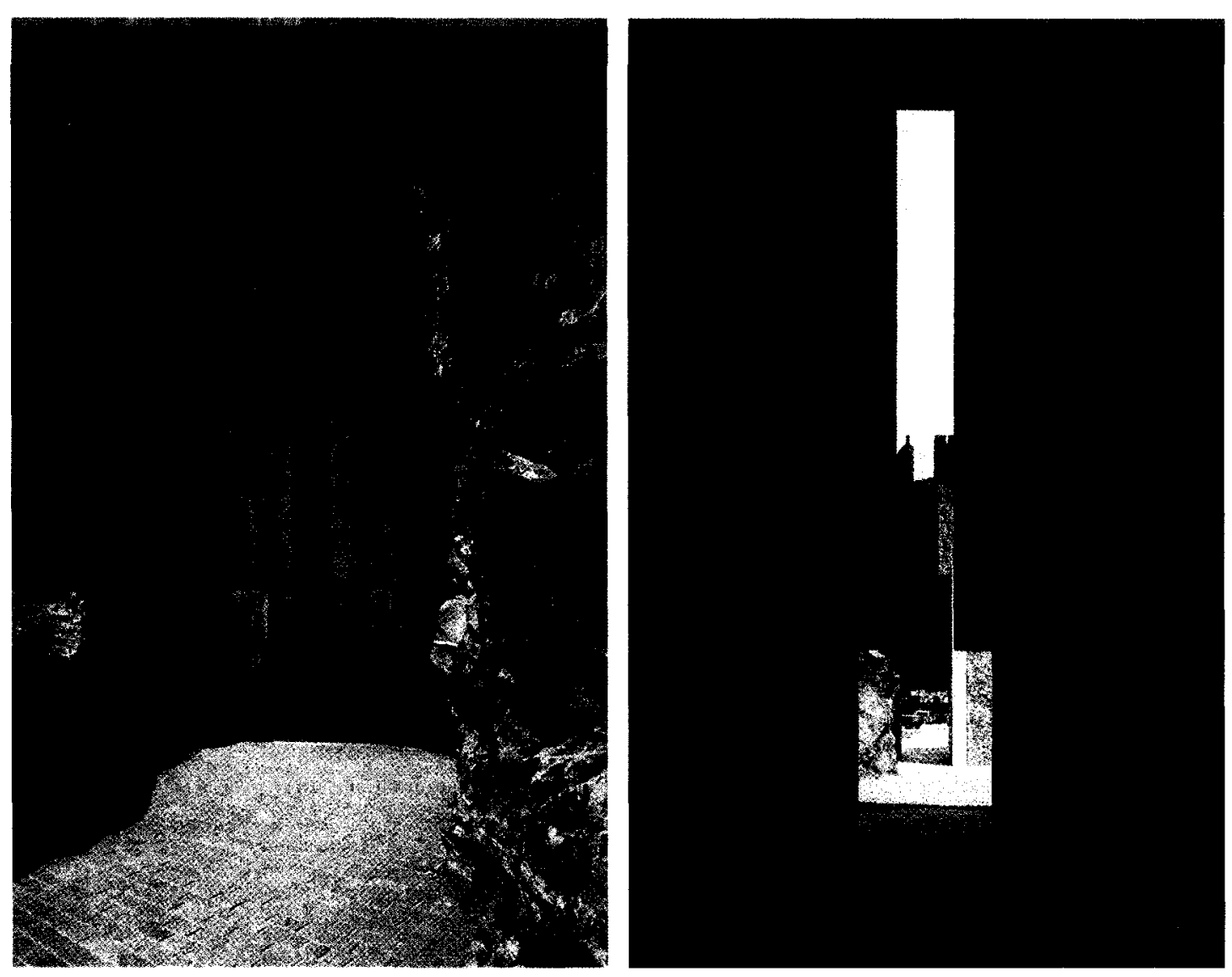

Fig. 7 The entrance to Castelgrande. 

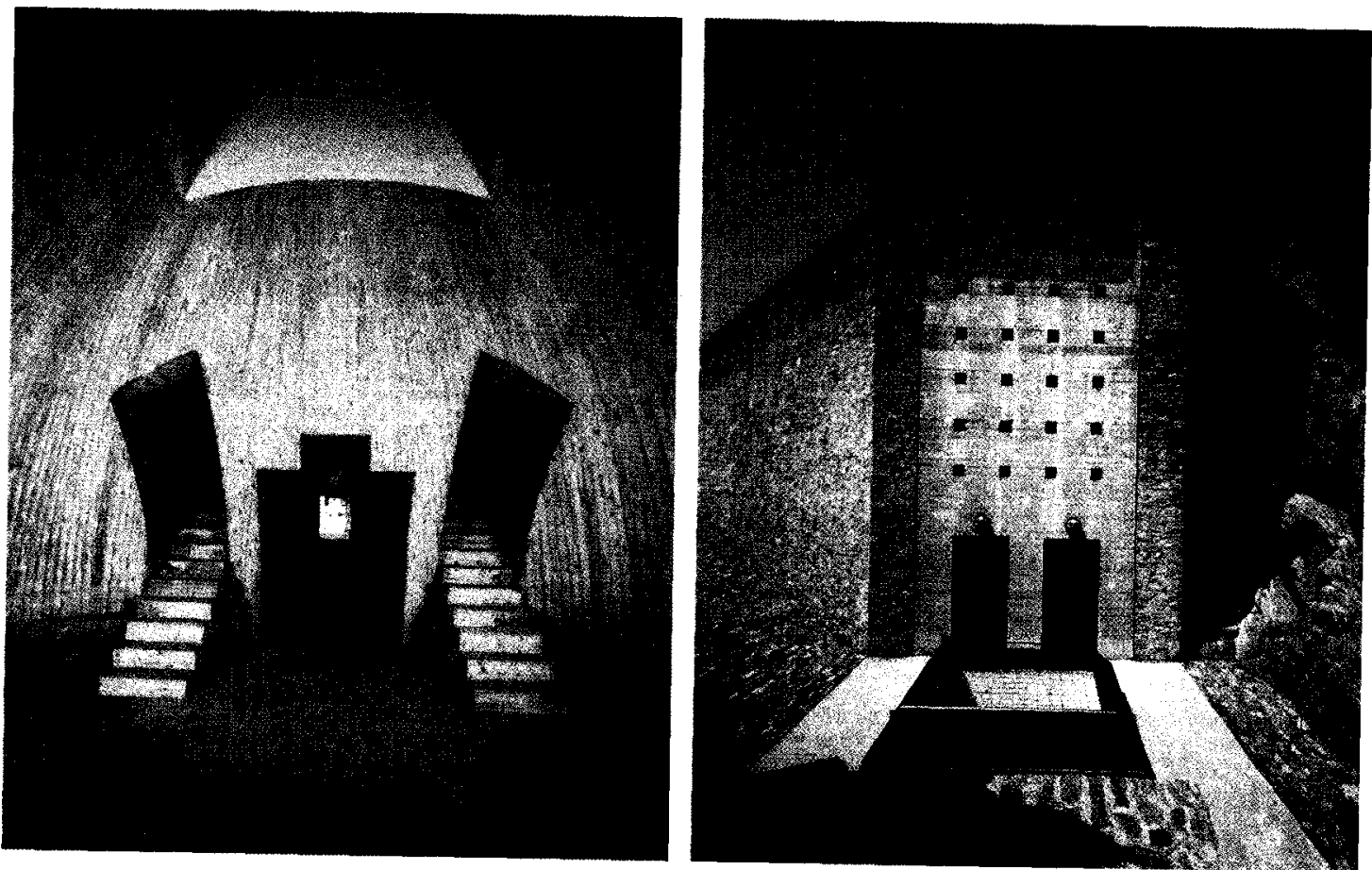

Fig. 8 The assent at Castelgrande. 


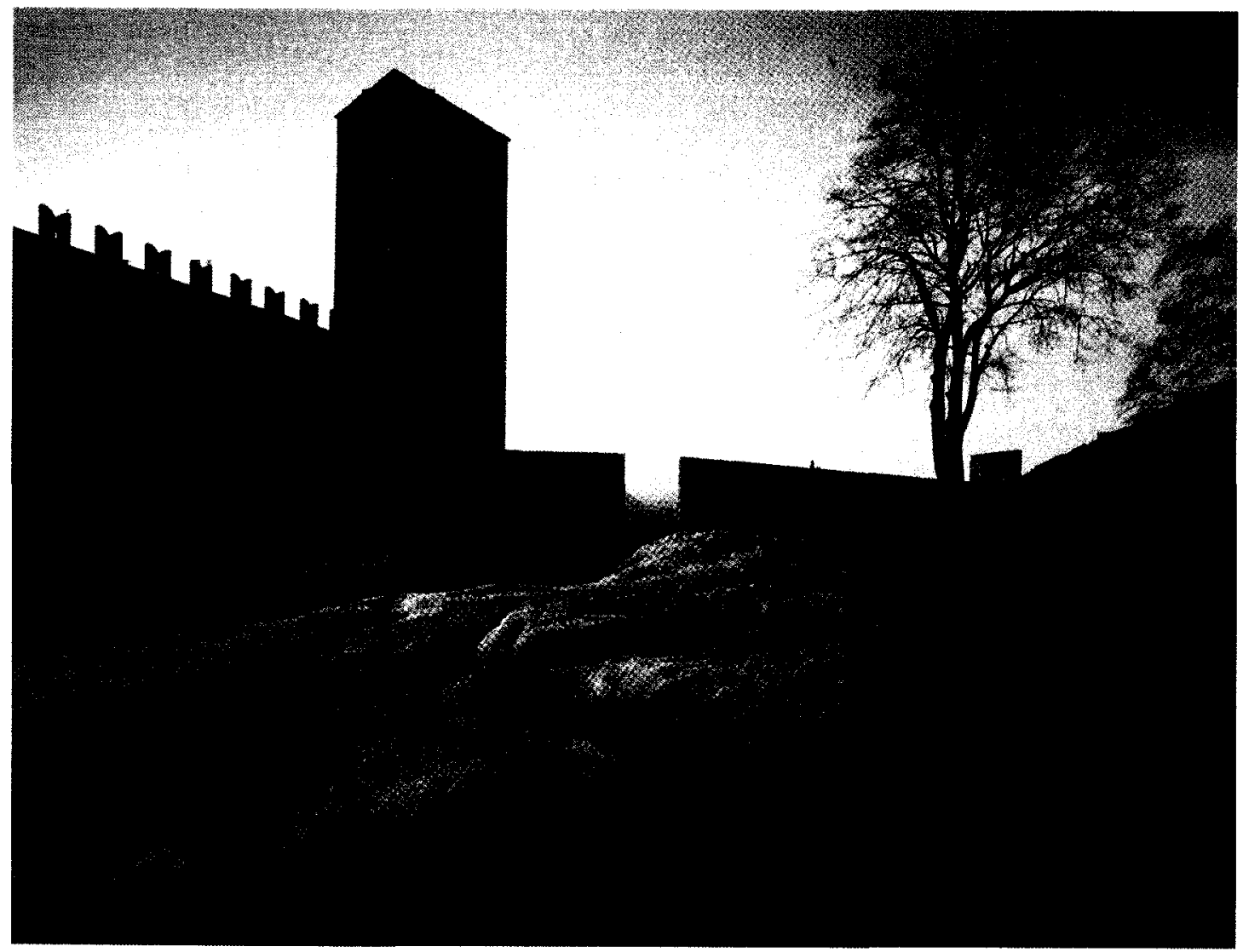

Fig. 9 The courtyard at Castelgrande. 


\section{Notes}

118 Galfetti quoted in Werner, Aurelio Galfetti, 17.

119 Frank Werner, Aurelio Galfetti: Castelgrande Bellinzona, (Berlin: Ernst \& Sohn, 1992), 7.

120 This need for general approval even saw the failure of a provocative vision for Castelgrande put forth in 1974 by Fabio Reinhart and Bruno Reichlin. See Werner, Aurelio Galfetti, 7.

121 Werner, Aurelio Galfetti, 9.

122 Werner, Aurelio Galfetti, 17.

123 Alberto Perez-Gomez, "Hermeneutics as Discourse in Design," Design Issues 15, no. 2 (1999), 78.

124 Galfetti quoted in Werner, Aurelio Galfetti, 17. This quote continues: "Thus restoration means establishing connections, making a link between existing form and its history on the one hand and the content required now - instead of the existing one - on the other hand."

125 This reference to the dialogue between new and old comes from a comparison between Galfetti's work and a 1974 renovation to Castello di Montebollo (the neighbouring castle), which was done very much in the Carlo Scarpa tradition. Werner, Aurelio Galfetti, 11.

126 Werner, Aurelio Galfetti, 13.

127 This description of the architecture and entrance sequence is based on Werner's writings of the project. For a more detailed description, see Werner, Aurelio Galfetti, 11.

128 Werner, Aurelio Galfetti, 17.

129 Werner, Aurelio Galfetti, 17. 


\section{A Proposal for the Future}

"Nationalism makes culture into an object and a thing of worship. Culture is made the servant of power."

$\sim$ Bruce Kapferer ${ }^{130}$

In the course of this thesis, a schism has been outlined that places in opposition our practices of conservation - reliant on the imposition of singular, static, and stable identities - with a desire to recognize the true contemporaneity of meanings and cultures. Nowhere does this schism seem more apparent and contentious than within the context of the Canadian 'cultural mosaic'131 - a singular identity arising from a plurality of cultures.

As the capital city of Canada, historical sites in Ottawa have been treated with particular conservatism in reference to their conservation. They fall victim to the universalizing and homogenizing vision of 'national heritage', because they are buildings that are vital to the construction of a 'national identity'. Thus, despite our notions of a multicultural Canada, practices of conservation continue their attempt at inscribing within the built environment singular stories of our country's history. This has been carried out by relying on the misappropriated and misunderstood terms and practices that have been discussed earlier in this thesis.

One site that has been the target of these aims is the remnants of the Ottawa Carbide Company mill, located on Victoria Island on the Ottawa River. It is a site that in itself elucidates the notion of storytelling described, that is, a site with multiple stories 


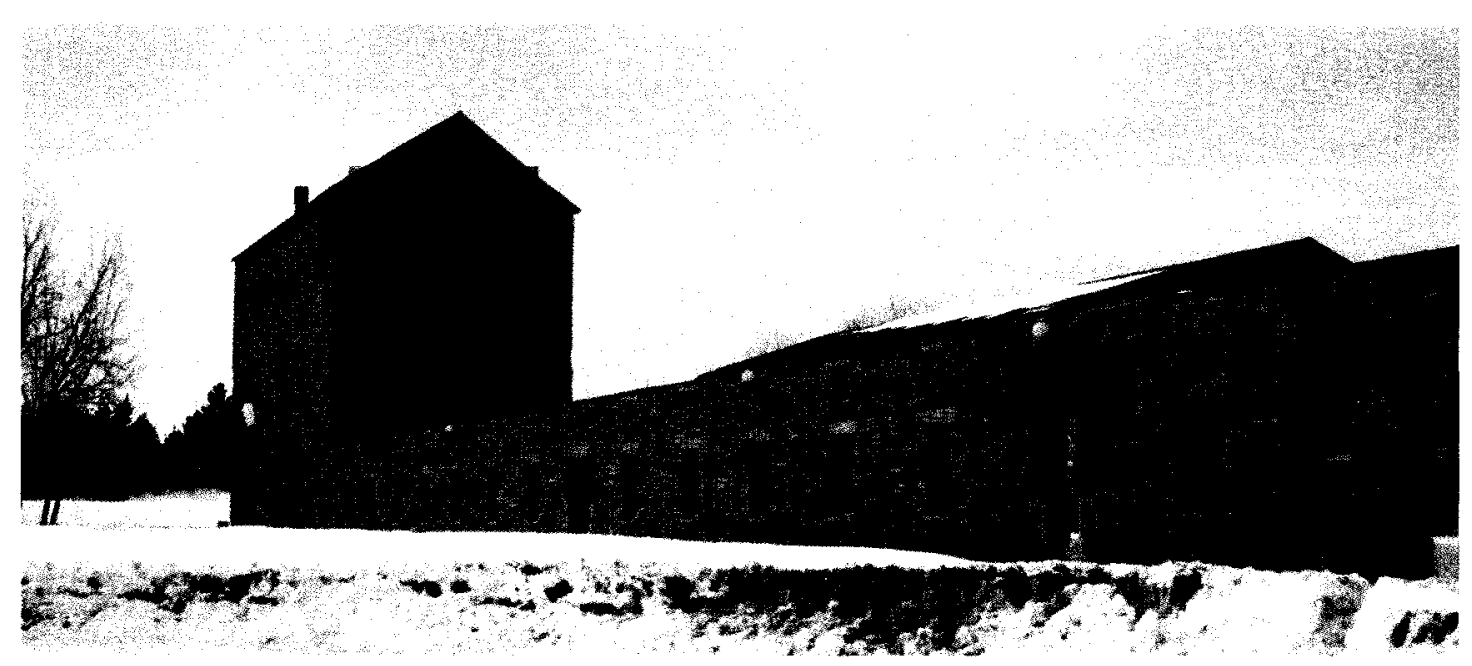

Fig. 10 The Carbide Mill.

embedded within it, but it has also been deemed as a site of "national significance" - one that played a key role in the development of the Capital of Canada. ${ }^{132}$

However, because the site contains a multiplicity of histories, stories that cross cultural, linguistic, and ethnic boundaries, conceiving of the site in any singular manner - in the image of national significance or identity - would be to confirm the practices of conservation critiqued. Indeed, to choose any one dominant story at this site (the plurality of which will be discussed in the coming chapter) would be reflective of the homogenizing and hegemonic practices of our time. Seidman reflects this thinking, stating that stories of 'national significance' always "disregard the enormous social complexities and heterogeneous struggles and strains within a specific society at a specific time." He continues by elucidating their point of weakness: "They utterly fail to grasp the multisided, heterogeneous, morally ambiguous social currents and strains that make up the life of any society." 133

It is for these reasons that the Carbide Mill has remained without use. Despite many 
proposals tendered for the site ${ }^{134}$, none have succeeded in reaching fruition. There are surely any number of causes for these failures, but like the innumerable proposals set forth for Castelgrande, it can be argued that none managed to gain common acceptance. This is not to suggest the acceptance of just one dominant cultural group, but rather the acceptance of the multiplicity of stakeholders in the site - the users that have authored (and will author) stories at the site.

Thus, the Carbide Mill site must be developed in a manner that recognizes the plurality of its stories and its users, while also proposing new possibilities for the site - new meanings, values, and a set of experiences. This is to be done by reauthoring its stories within the context of a new story - one that is a "proposal concerning the continuation of a story which is just unfolding." ${ }^{135}$ This new story, therefore, would provide an "openness of meaning" instead of an "authoritarian interpretation,"136 allowing for a multiplicity of meanings to co-exist while projecting towards the future. As Benjamin proclaims, "there is no story for which the question as to how it continued would not be legitimate." 137

\section{Notes}

130 Bruce Kapferer, Legends of People, Myths of State: Violence, Intolerance, and Political Culture in Sri Lanka and Australia, (Washington: Smithsonian Institution Press, 1988), 209.

131 A common understanding of the 'Canadian identity' is based on the conception of a multicultural Canada. This multicultural Canada is often referred to as a 'cultural mosaic', in which disparate ethnic groups are able to co-exist. This notion has been highly criticized though, as it is believed that this understanding of Canada is a fallacy, seen clearly in the disparity that exists between these groups. Even the fact that we still search for a single 'Canadian identity' is evidence enough to dispell such a suggestion.

132 Victoria Island: What Now?, (Ottawa: National Capital Commission, February 1979), 2.

133 Seidman, Steven, "The End of Sociological Theory: The Postmodern Hope," Sociological Theory 9 , no. 2 (1991), 131-46. 
134 The National Capital Commission has funded and published papers to research and outline potential uses for the site as early as 1979 and as recently as 2004. These have included proposals by Arthur Erickson and Douglas Cardinal.

135 Walter Benjamin, "The Storyteller: Reflections on the Works of Nikolai Leskov," in Illuminations, edited by Hannah Arendt, translated by Harry Zohn, (New York: Harcourt, Brace \& World, 1968).

136 Umberto Eco, and Stefan Collini, Interpretation and Overinterpretation, (Cambridge; New York: Cambridge University Press, 1992), 21.

137 Benjamin, "The Storyteller." 
$|9|$

\section{A Mythos in Practice}

"Buildings are cultural texts that are generated by assembling fragments, excerpts, citations, passages, and quotations."

$\sim$ Marco Frascari ${ }^{138}$

\section{The Site}

The history of Victoria Island - its multiplicity of stories - presents a complex constellation of relations on the site.

Long before the arrival of Europeans in the area, Victoria Island and the Ottawa River defined an Indian trading route. For the natives the Chaudière Falls (Fig. 11) - and the islands that sat adjacent to the falls - were revered as a site of religious importance. This significance etched Victoria Island into the culture of the aboriginals, but with the appearance of Europeans on Canadian shores, the site became the location of interaction with missionaries - explorers looking for land and fur sources to claim. ${ }^{139}$

Following early settlement in the region of Ottawa, lumber became a major reason for development in the area. The industry found a source of power in the falls, and after establishing trade routes east to Quebec City, quickly became the largest producer in the world. As a result, every available mill site was swiftly occupied, and the islands transformed into massive lumberyards. ${ }^{140}$ This led to the purchase of the site from the Crown ${ }^{141}$ (Fig. 12), and the natives inevitably lost any remaining rights the land.

After several decades of extensive lumber production, and on the eve of the new Century, the Carbide Mill (Fig. 13) was constructed. While it's opening would be delayed by the Great Fire of 1900 - which destroyed the stockpile of lumber on the island - the 
Carbide Mill escaped with only trivial damage. ${ }^{142}$ Once open, however, production would be marred by a constant water shortage problem, which inevitably led to the closure of the facility (with less than a decade in operation), and instigated a court battle between Quebecors and Ontarians. ${ }^{143}$

Following the failure of the Ottawa Carbide Company, the building was sold to the Federal Government. It was to be used as a machine shop for a variety of departments, including the Department of Public Works and the Royal Canadian Air Force (who occupied the building during the Second World War). ${ }^{144}$

After the completion of the war, however, the building was vacated and sat dormant until 1974. This dormancy was to be shattered though by the Native People's Caravan, who forcible occupied the building as an ad hoc commune (Fig. 14). The act was in protest of government policies - the policies that had marginalized them and expelled them from the land. At one point as many as 300 natives took up residence in the mill, until pressure from the public resulted in the eviction of the natives. A mere four weeks later the mill burned down (Fig. 15), resulting in a controversy over the origin of the fire, and leaving the ruins that exist on the site today. ${ }^{145}$

Each of these stories, and the experiences they represent, allude to the intersubjective reality of the site. They account for a particular constellation of social relations - one that stretches far beyond the borders of the island. Of course, not all of these stories have left material traces - some exist only in the tales of the storyteller - but through an appropriate practice of architectural conservation, the multiplicity of these stories can coexist on the site. 


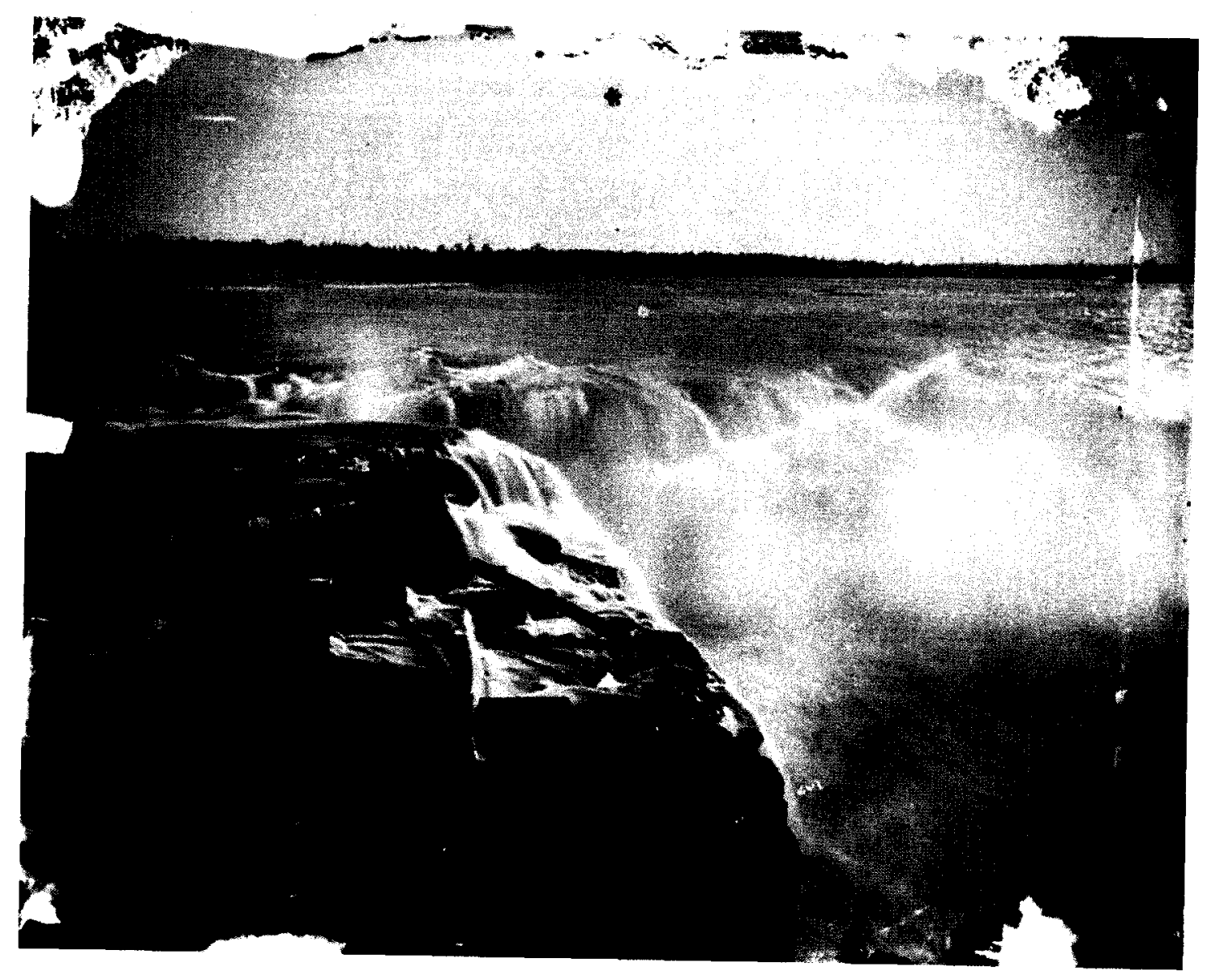

Fig. 11 The Chaudière Falls. 


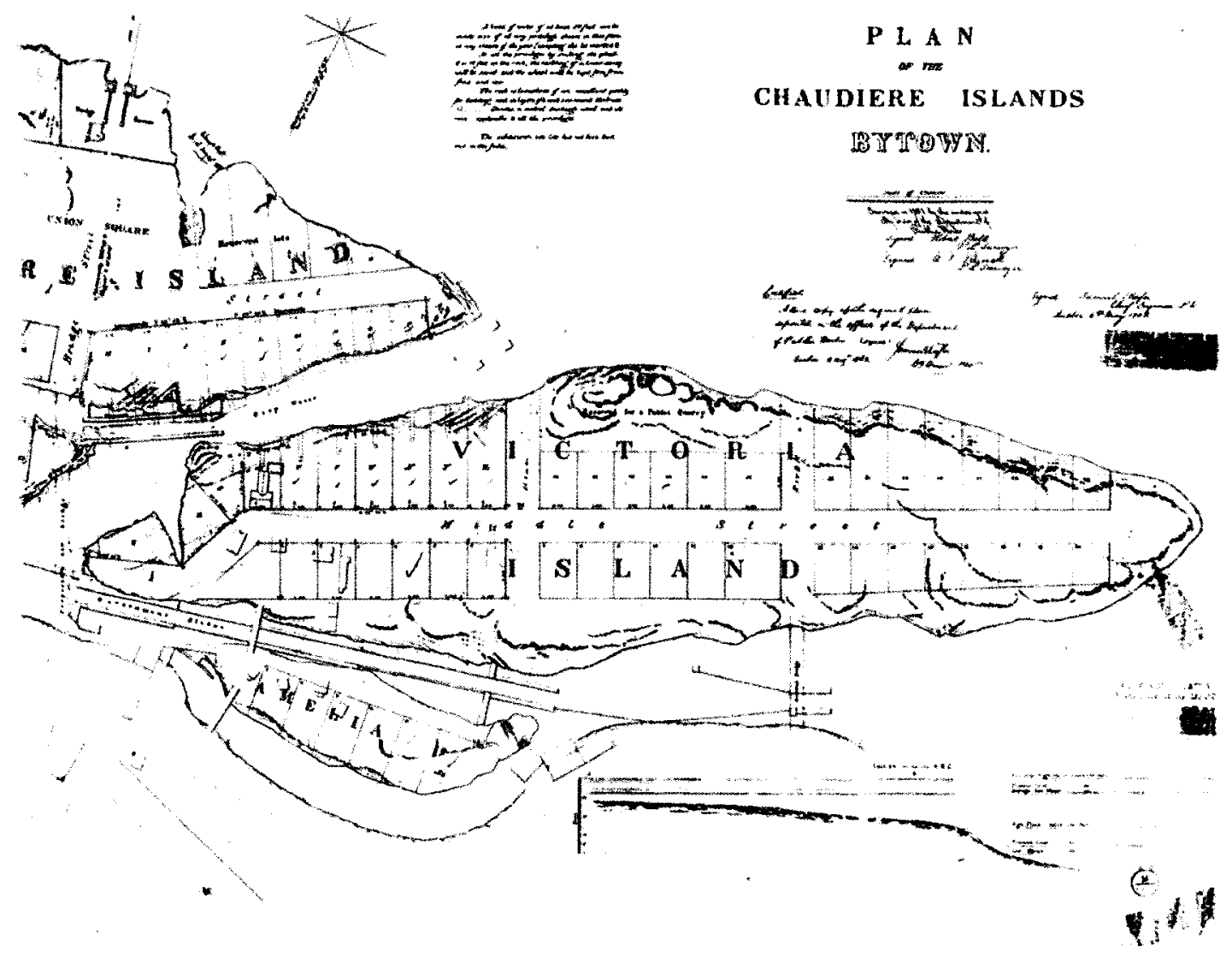

Fig. 12 The first survey of Victoria Island, 1852. 


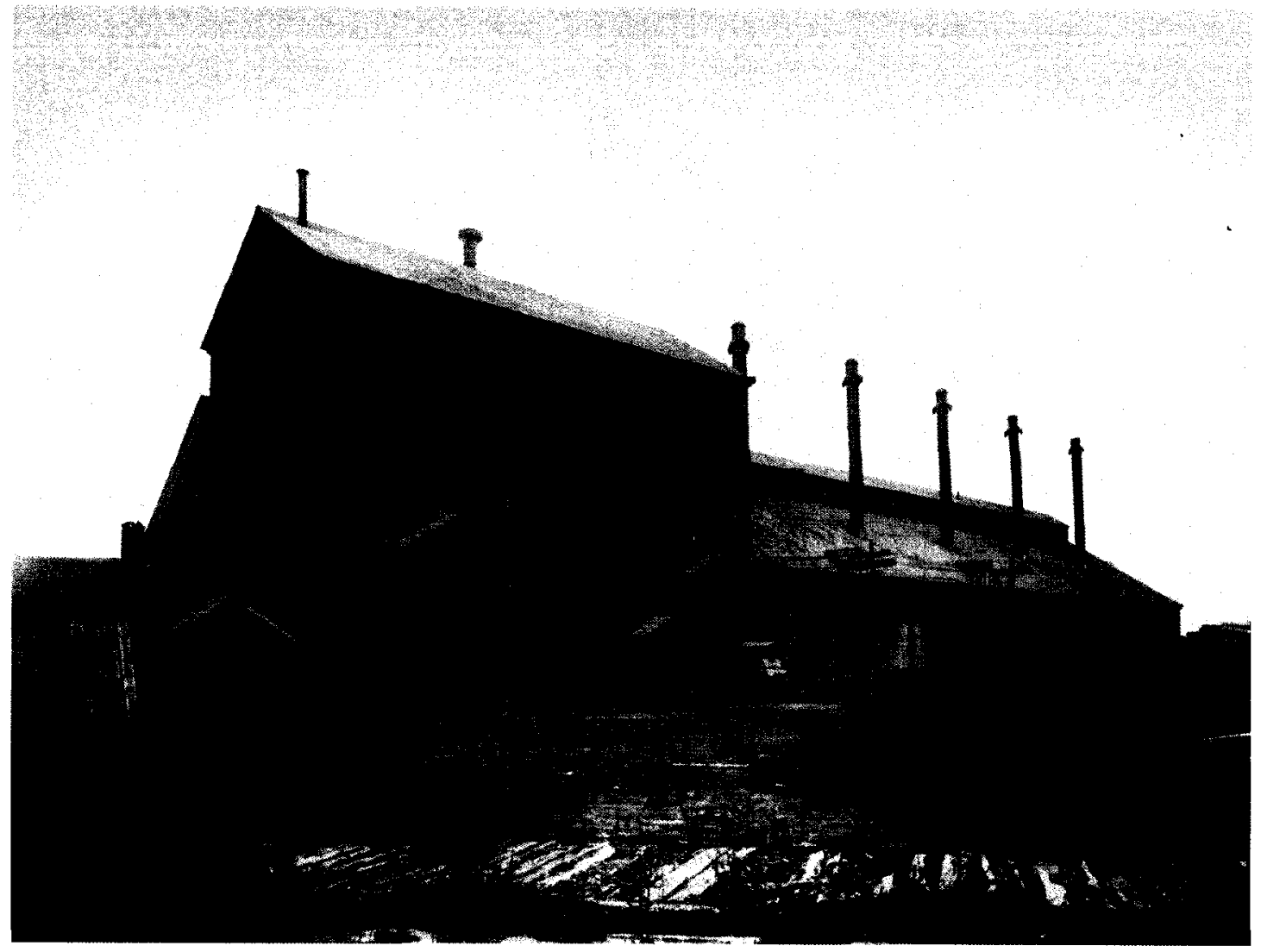

Fig. 13 The Carbide Mill, circa 1900. 


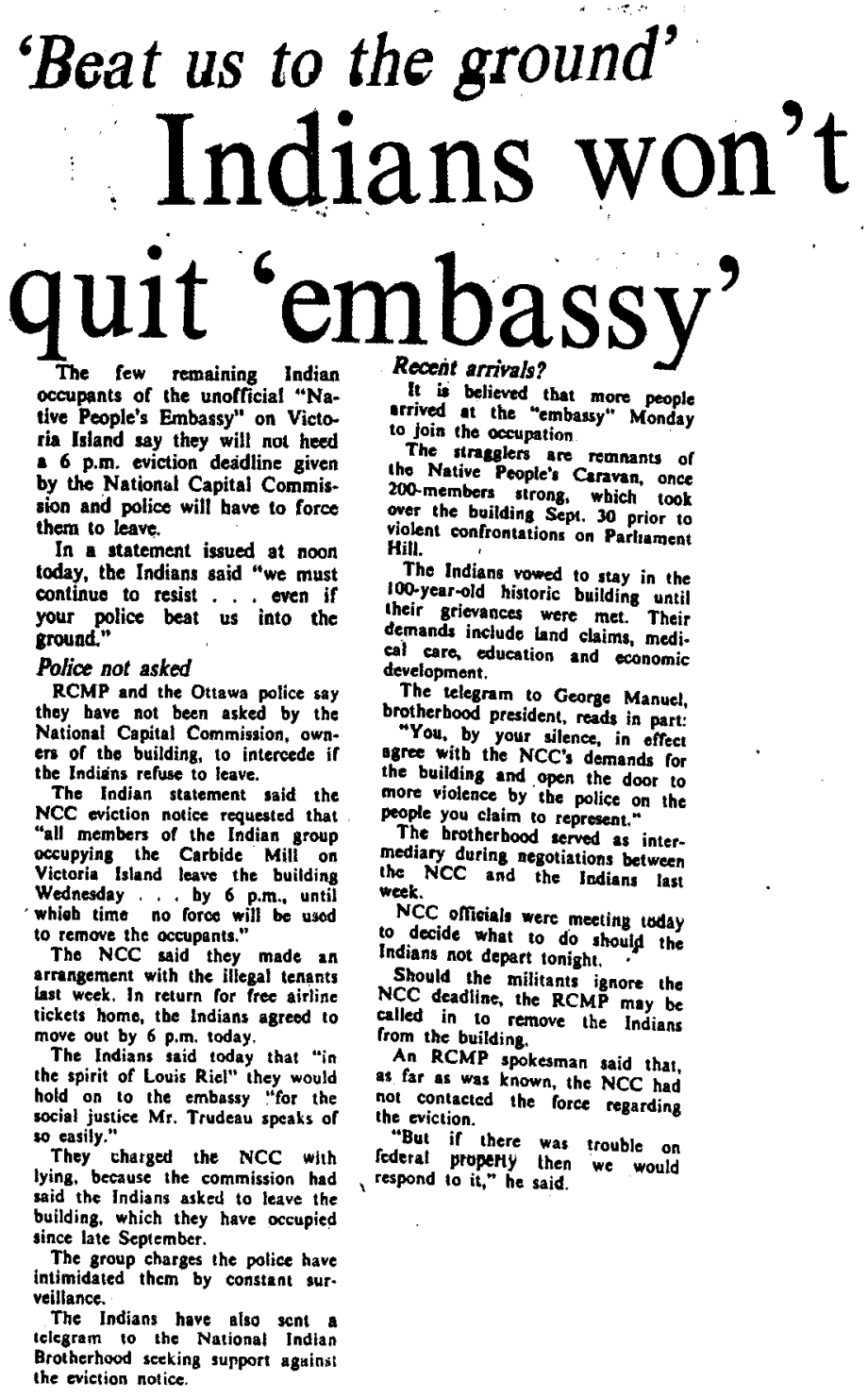

Fig. 14 Ottawa Citizen article, February 5, 1975. 


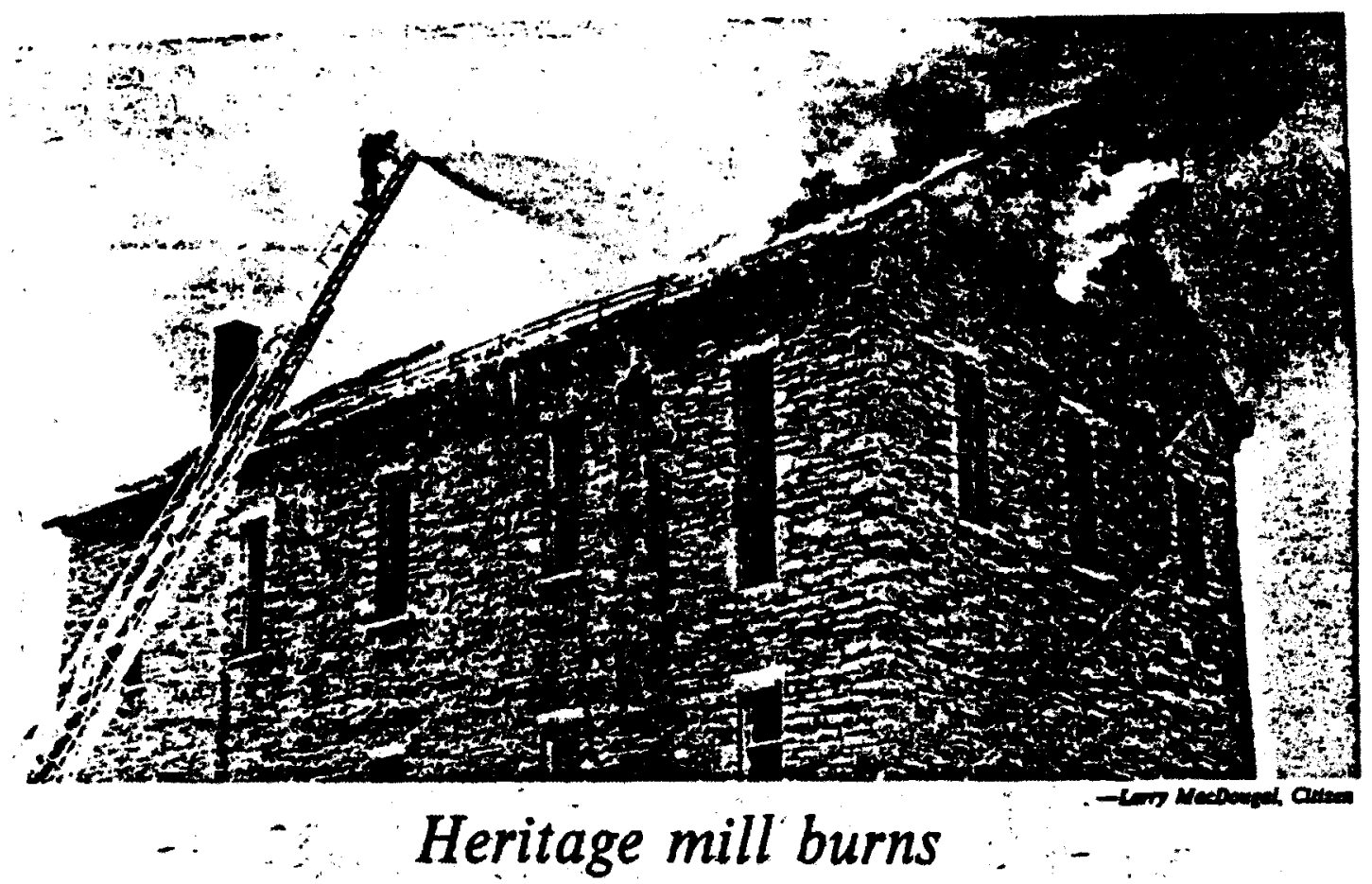

Arson is suspected in a spectacular roof blaze at the vacant century-old carbide mill on Victoria Island. The blaze at the vacant mill, owned by the National Capital Commission, sent smoke

billowing high overhead for about an hour before flames were were extinguished by firefighters about 8:40 p.m. Arson was also suspected in a house fire at. 9 O'Mearz St.

Fig. 15 Ottawa Citizen article, March 22, 1975. 


\section{The Program}

The complex relations, as recounted above, make the conservation of the Carbide Mill particularly engaging. They outline the contrasting stories of the site - stories that cross cultural, linguistic, and ethnic boundaries. As such they suggest a particular tension on the site, created through the antithetical experiences of the place. But as Jackson has noted regarding this friction, "The source of energy that both motivates and structures storytelling is the existential tension that informs every intersubjective encounter." ${ }^{146}$

Considering then the appropriateness of storytelling for this site, as well as the importance of the island in the histories of the area, this thesis aims to ground this demonstration as a material possibility - one that might reflect the conditions of an actual conservation project. For this reason it was decided that a program would not be personally selected, but rather assigned by a fictional 'owner' of the site - in this case assumed by Federica Goffi, who is also the advisor of this thesis investigation.

It would be the conflictual relations between the natives and the settlers that would inform Goffi's selection of a program for the building. Citing the importance of the industrial stories on the site, coupled with the significant histories of the natives on the island, Goffi sought a program that might address these disparate domains. For this reason, the program of a Native Cultural Centre was chosen - a sort of 'embassy' that would foster a dialogue between cultures on the site.

This thesis then will demonstrate the conservation of the Carbide Mill, by authoring a new story in the 'in-between' space - the 'joint' between the program of a Native Cultural Centre, and the industrial remains on the Carbide Mill site. The centre will be 
based on a prior proposal for the $\operatorname{site}^{147}$ (a choice that gives further actuality to this project), and will act as both a workspace and residence for the native community, as well as a public facility to be utilized by citizens. The program (as dictated by the previous proposal) will consist of the following programmatic elements: a gallery, restaurant, and a residence block, as well as workshops, offices, and a community centre.

\section{The Architecture}

The process of storytelling, as elucidated in Chapter Five of this thesis, is an agent that transgresses and traverses between boundaries. It mediates between disparate experiences of the world, and in doing so produces stories that are structurally 'in-between'.

This 'in-between' space that is constructed through storytelling, is reflected in the details of architectural constructions. The joints of a building, as argued by Frascari, are the "knots of the fabrication of architectural texts." ${ }^{48}$ Under this reading, it may be said that the architectural joint is analogous to the joints that are created between stories. This again is elucidated in the writings of Frascari, arguing that, "building elements are the joints of the construction of human culture; they are compelling demonstrations of how we inhabit the world."149

What this means then in reference to the materials of architecture, is that joints are the location of transformation berween fields. They are a means to affect change upon the experiences of a building, and in doing so, reauthor the stories of the place. It is only through the process of detailing these joints then, that a reauthoring of the stories of the site can occur. Frascari states, "the exercise of detailing is the primary procedure for both construction and construing" of architectural stories. ${ }^{150}$ 
Thus, in order to conserve the Carbide Mill site, this demonstration will focus on the joints between its stories.

The joints to be detailed in the conservation of the Carbide Mill, are not simply corners or material junctions (as might be understood in 'conventional' production). While the joints will most certainly consist of such things, they can also be seen as the connections between experiences - the functions, spaces, and events in the architecture. In this way, they are a physical expression of metabasis in the building - a passage or mediation between meanings in built form. ${ }^{151}$

It is useful then to elucidate a few examples of this notion, to make clear how the conservation of the building would proceed.

A first example finds roots in the native occupancy of the building. During the aboriginal appropriation of the mill, the numerous entrances to the building were blocked, leaving but a single point of access to the structure. This entry point was located at the second floor level, and was accessed by a narrow stairway on the external of the building. The purpose of this act was to maintain control over the building, disallowing any possible police sieges to occur. With a desire to reference this story in built form, the proposal will create an entrance sequence that communicates this story. It will locate the museum entrance (a public programmatic element) at the second floor level, accessed by a ramp that transforms from a compressive to expansive space. As a gesture, this provides a reference to the story in the building, but its experience - that of hostility and anger - is reauthored as a narrative of public invitation through the execution of purposeful architectural detailing (Fig. 30). 
Another example - one that is far more material than the previous - reflects the schism between native and settler habitation. The ruins of the Carbide Mill speak clearly of their past, and they stand as a testament to the industrial mill architecture. But while the architecture of the mill stands so prominently on the site, there is an absence of native architecture to be seen. Given then the selection for the program of the building, there existed an aspiration of creating dialogue between these architectures (and in doing so returning native constructions to the site). Looking, therefore, to the form and construction techniques of the longhouse, the proposal constructs a native building on the ruins of the mill. This is meant, of course, both literally and figuratively, as the metaphorical longhouse (in the form of a new roof structure for the building) rests plainly on the heavy walls that remain on the site. Furthermore, its construction techniques (as well as its materials) lie in oppositional dialogue with the stone construction of the mill (Fig. 31)(Fig. 32).

It is through these examples then (which are but two of many) that the mythos of storytelling becomes clear in this demonstration. Through the detailing of joints that mediate the stories of the site, the proposal will manifest a multiplicity of readings. In doing this (in the most purposeful of ways), it will open the site to a plurality of dialogues.

Thus, as Frascari has argued, detailing is never an abstract, passive, combining of joints, but rather a method of productive reasoning in material form ${ }^{152}$, resulting in an ethical practice in architecture. 


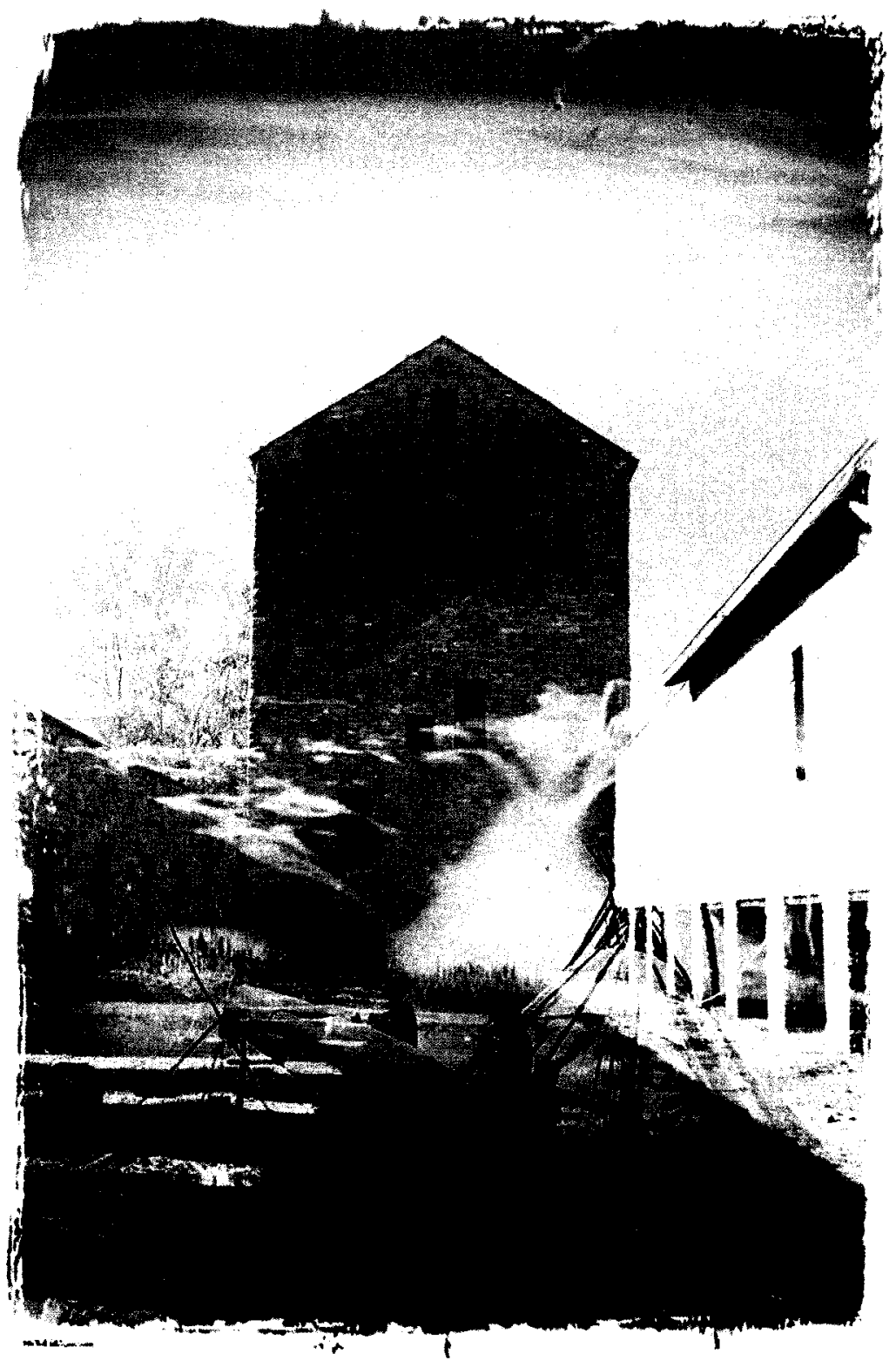

Fig. 16 Conceptual collage one. 


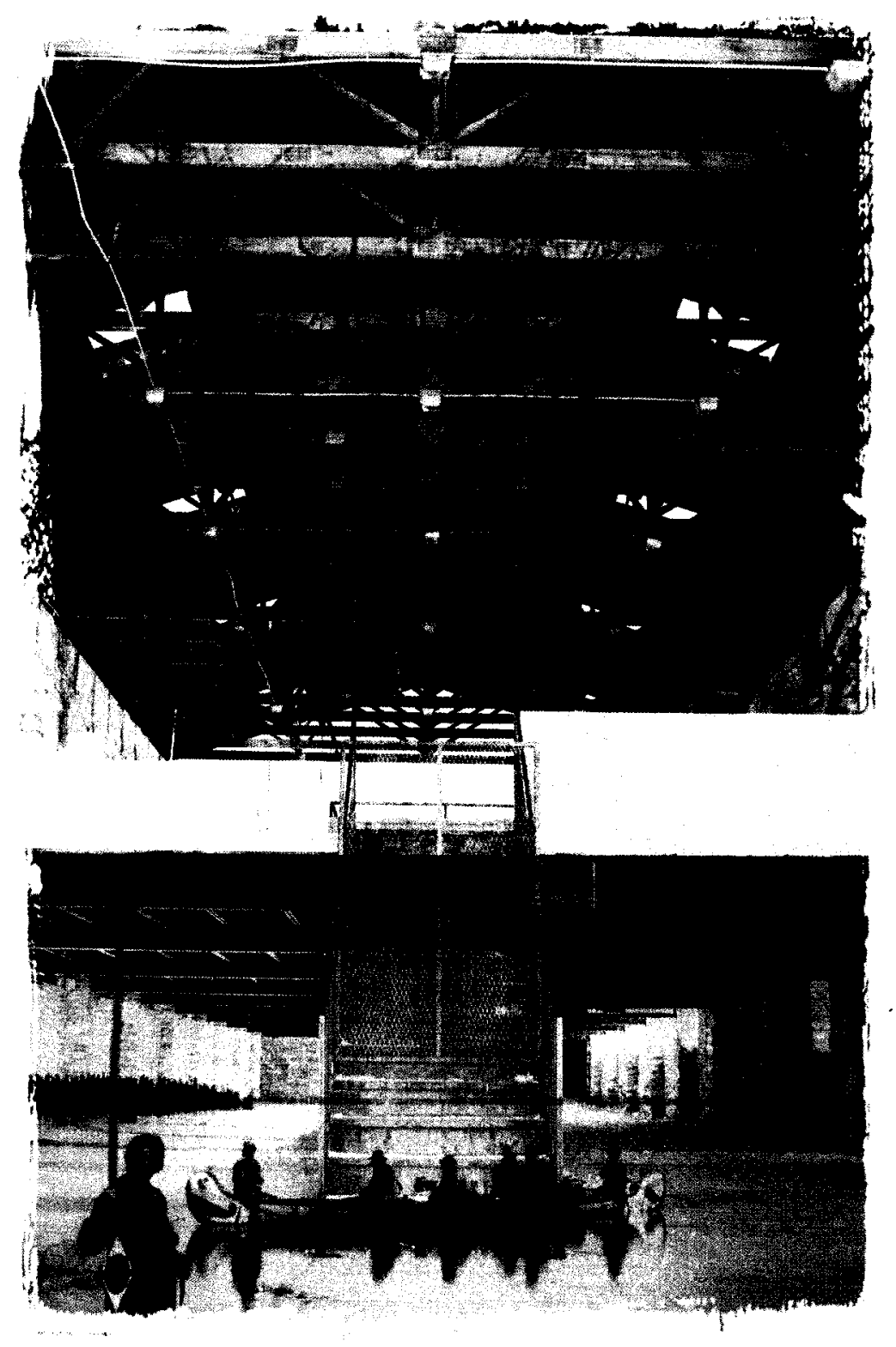

Fig. 17 Conceptual collage two. 


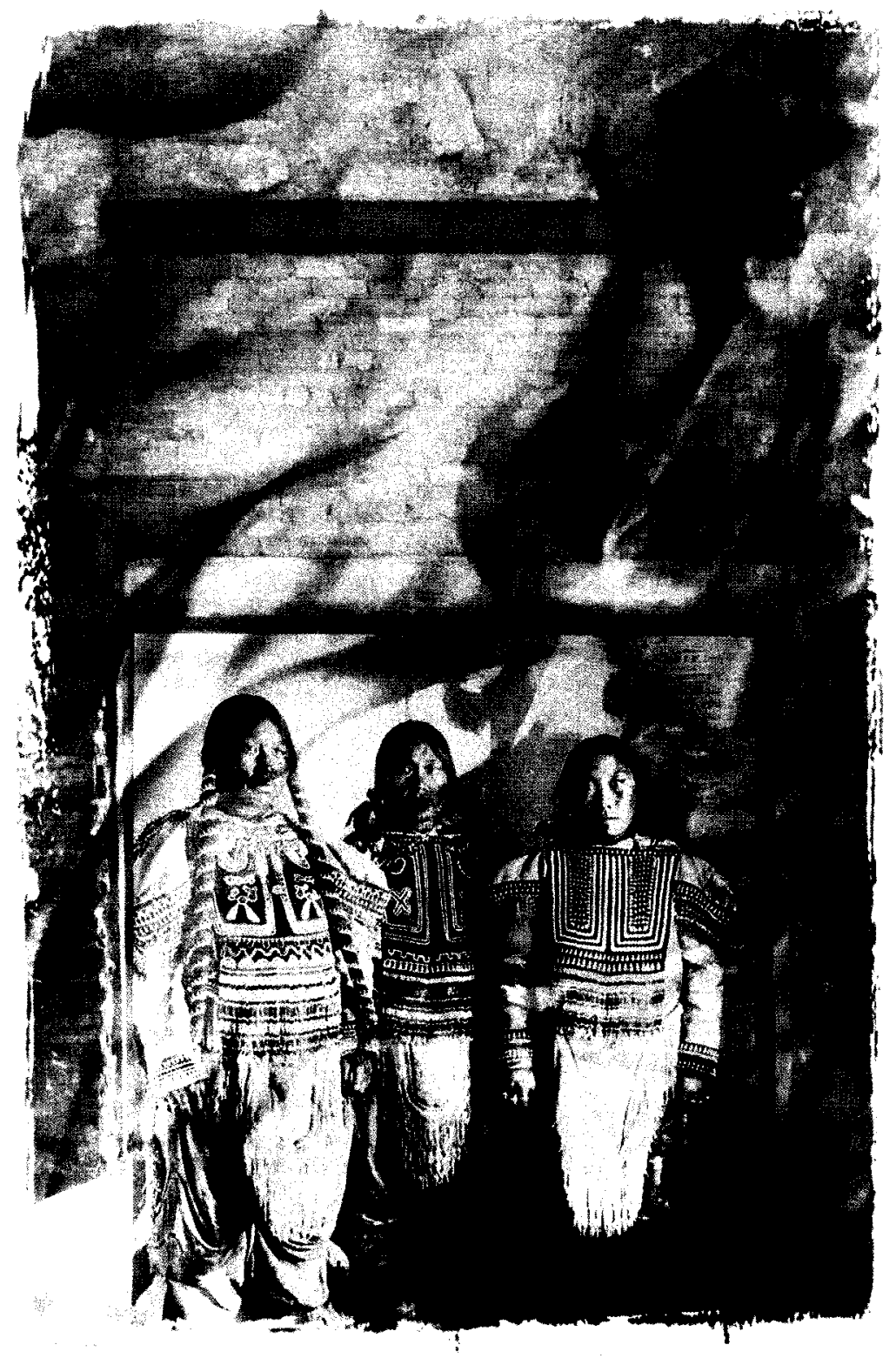

Fig. 18 Conceptual collage three. 


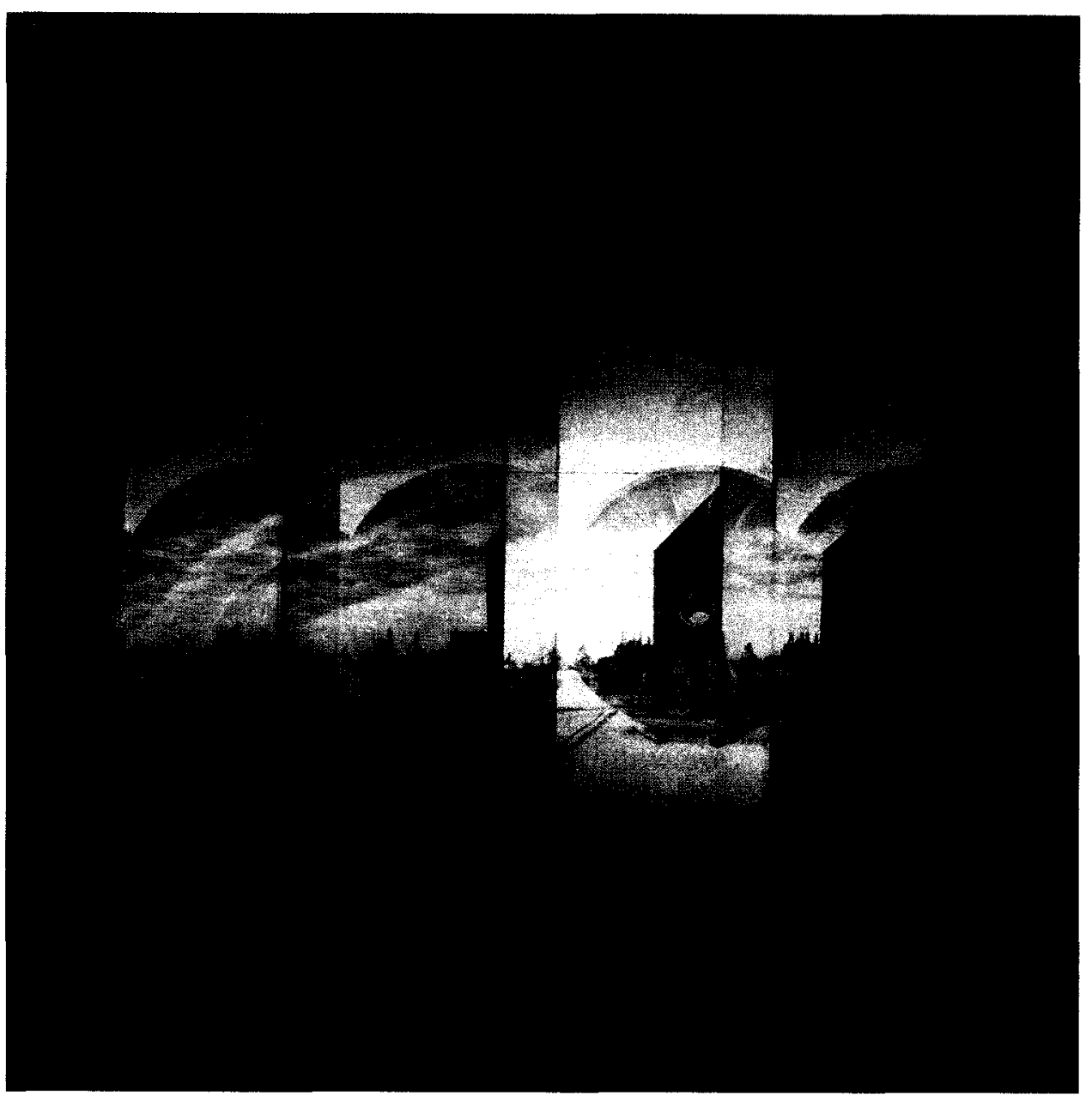

Fig. 19 Site investigation one. 


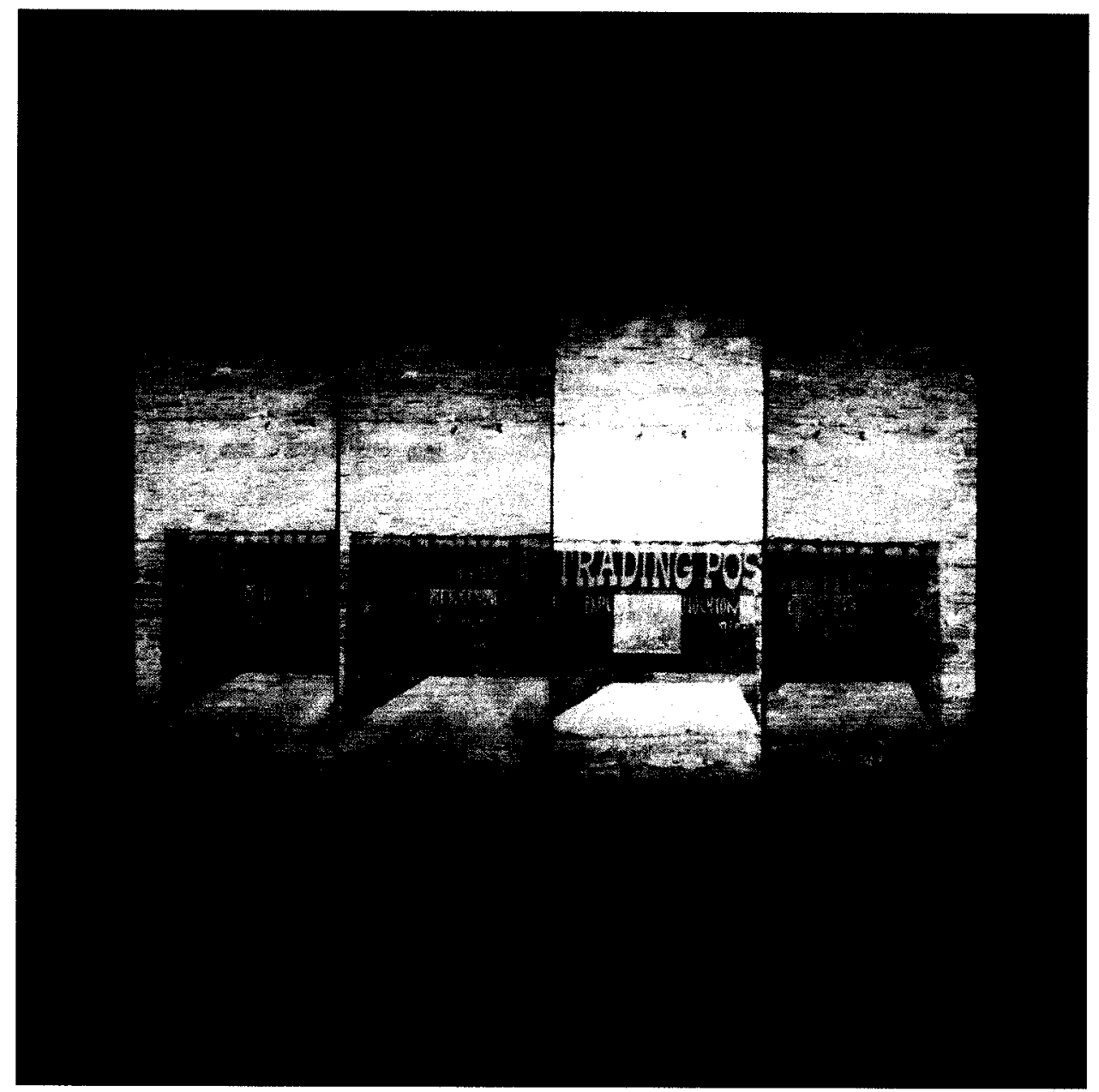

Fig. 20 Site investigation two. 


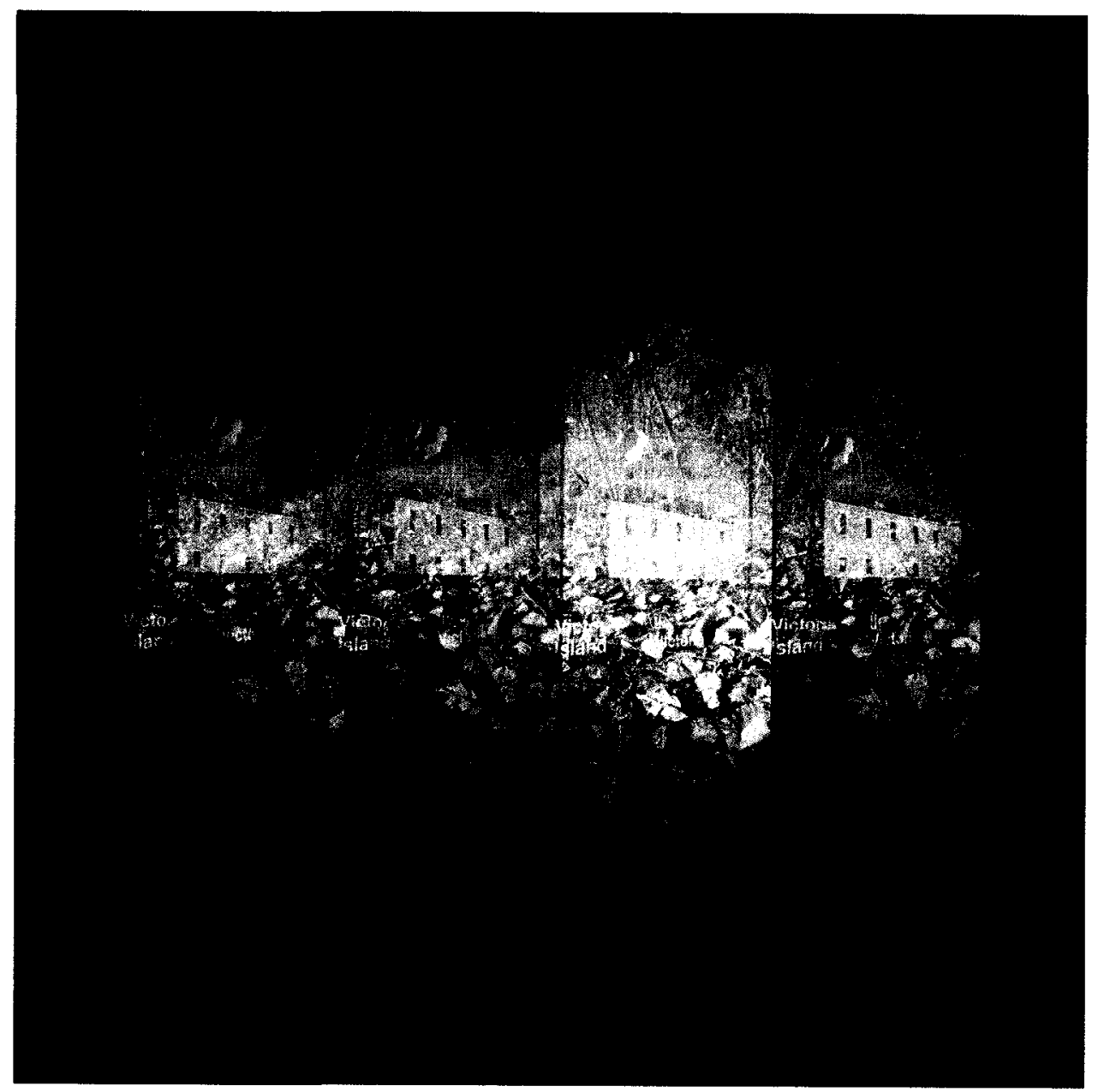

Fig. 21 Site investigation three. 


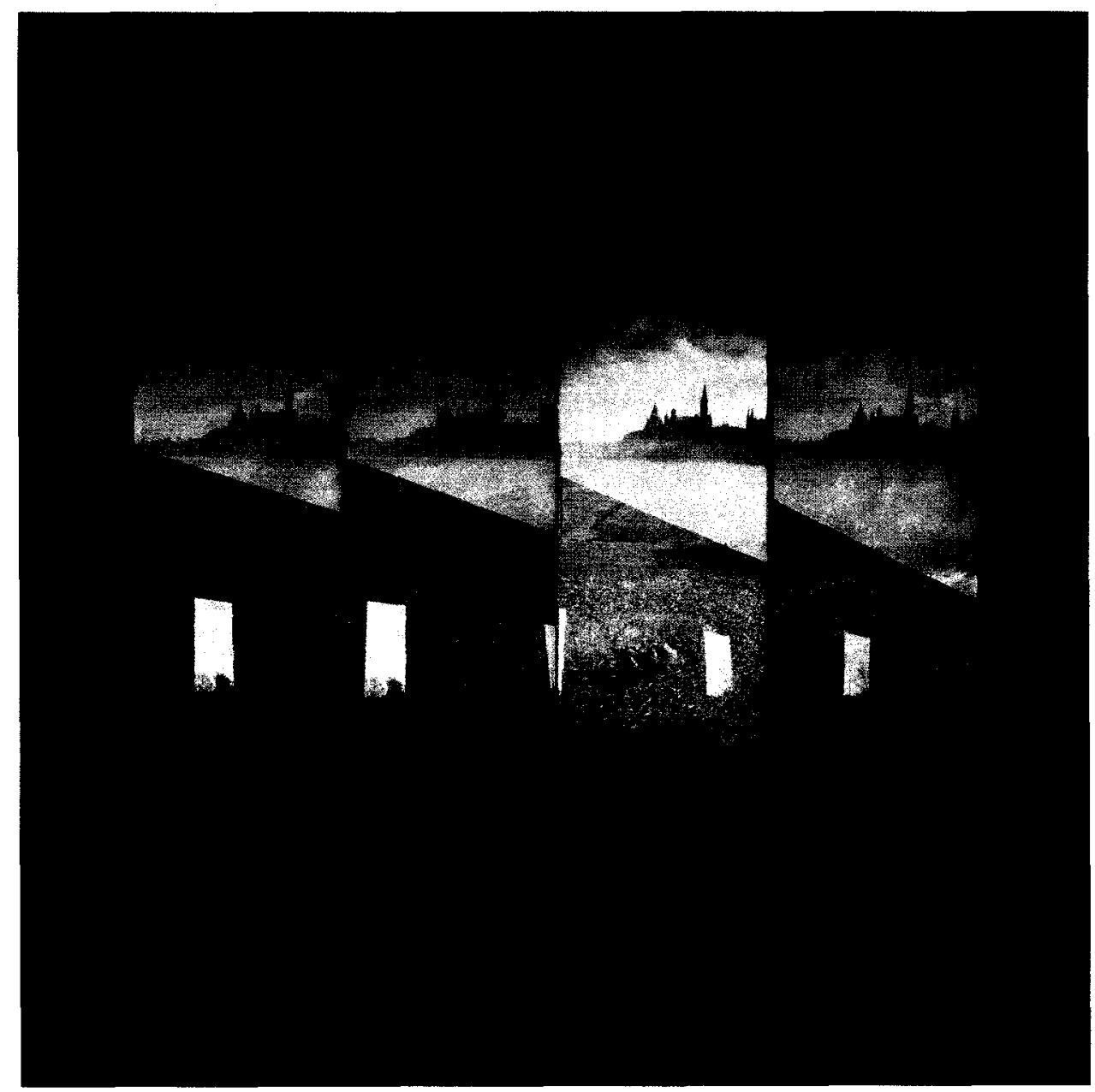

Fig. 22 Site investigation four. 


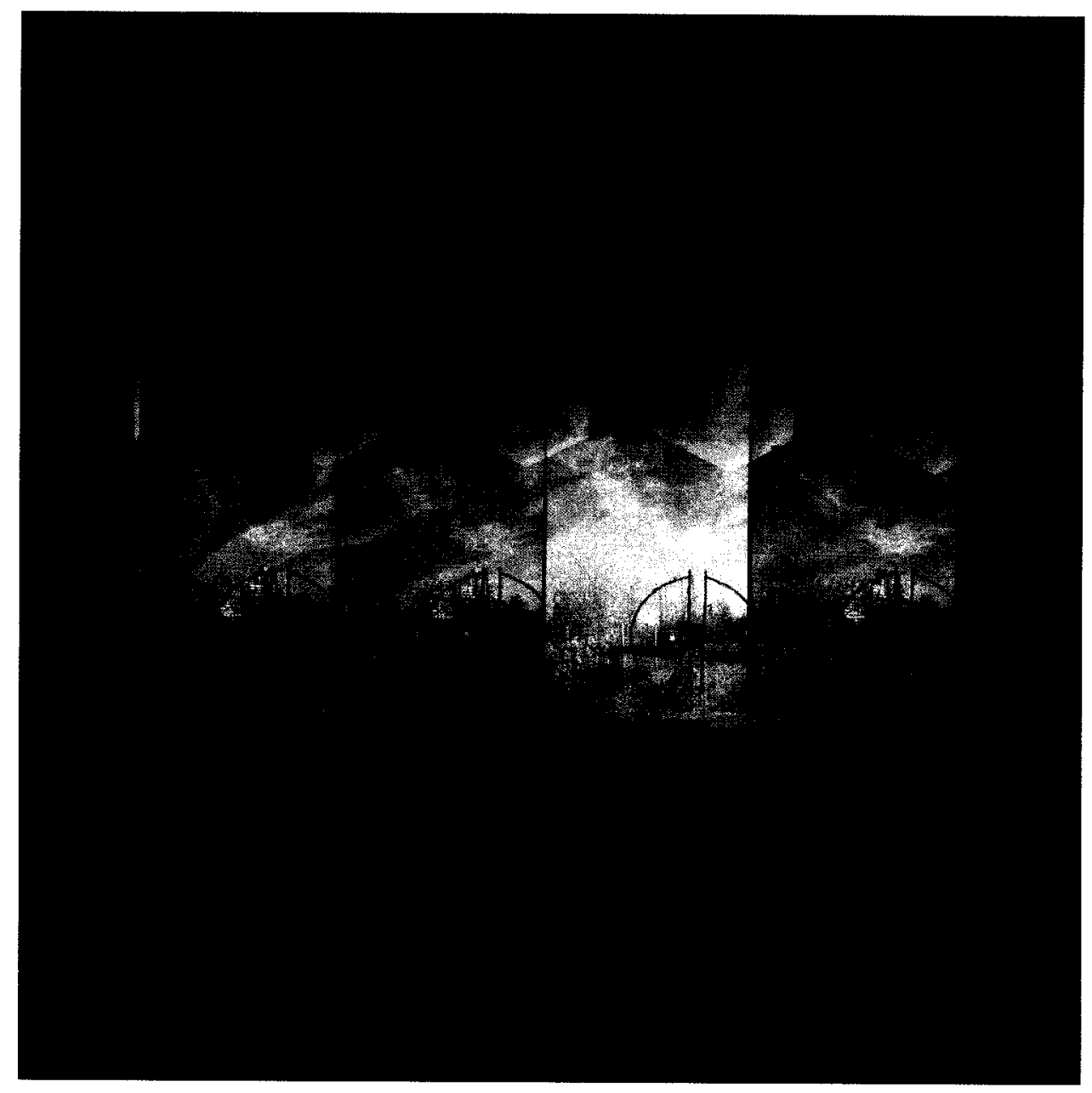

Fig. 23 Site investigation five. 


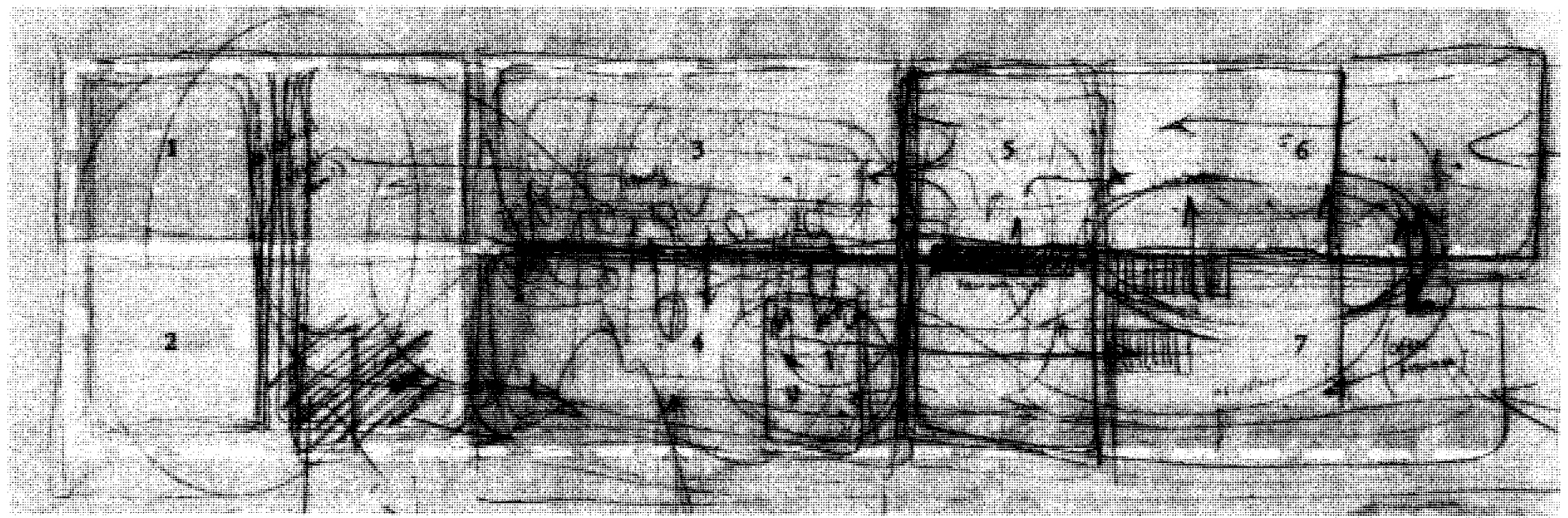

1 Artist-in-Residence Block

2 Community Centre

3 Workshop

2 Entry Courtyard

5 Museum Entrance

6 Museum and Gallery

7 Teaching Restaurant

Fig. 24 Programmatic sketch. 


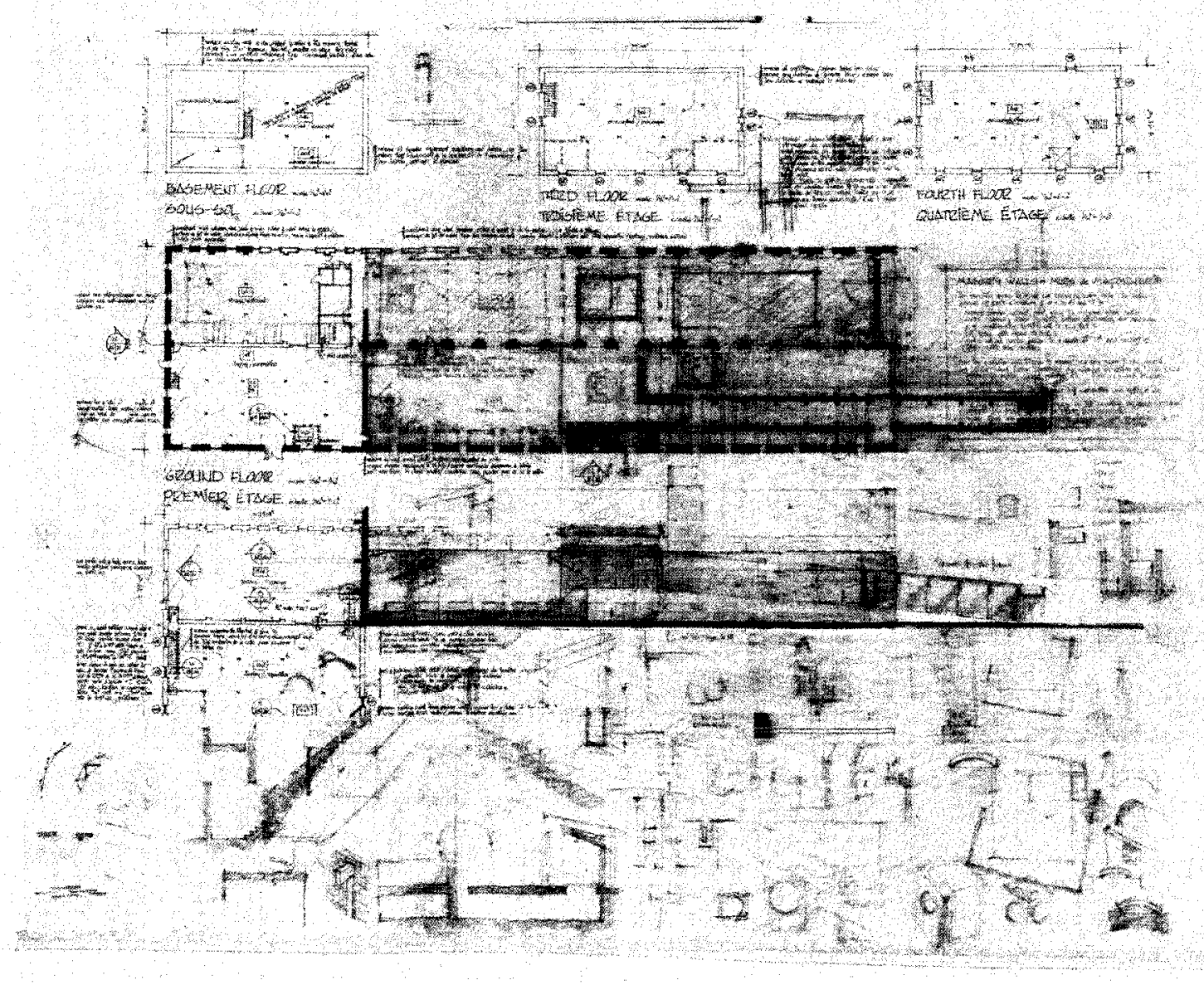

Fig. 25 Drawing one: preliminary plan and section. 


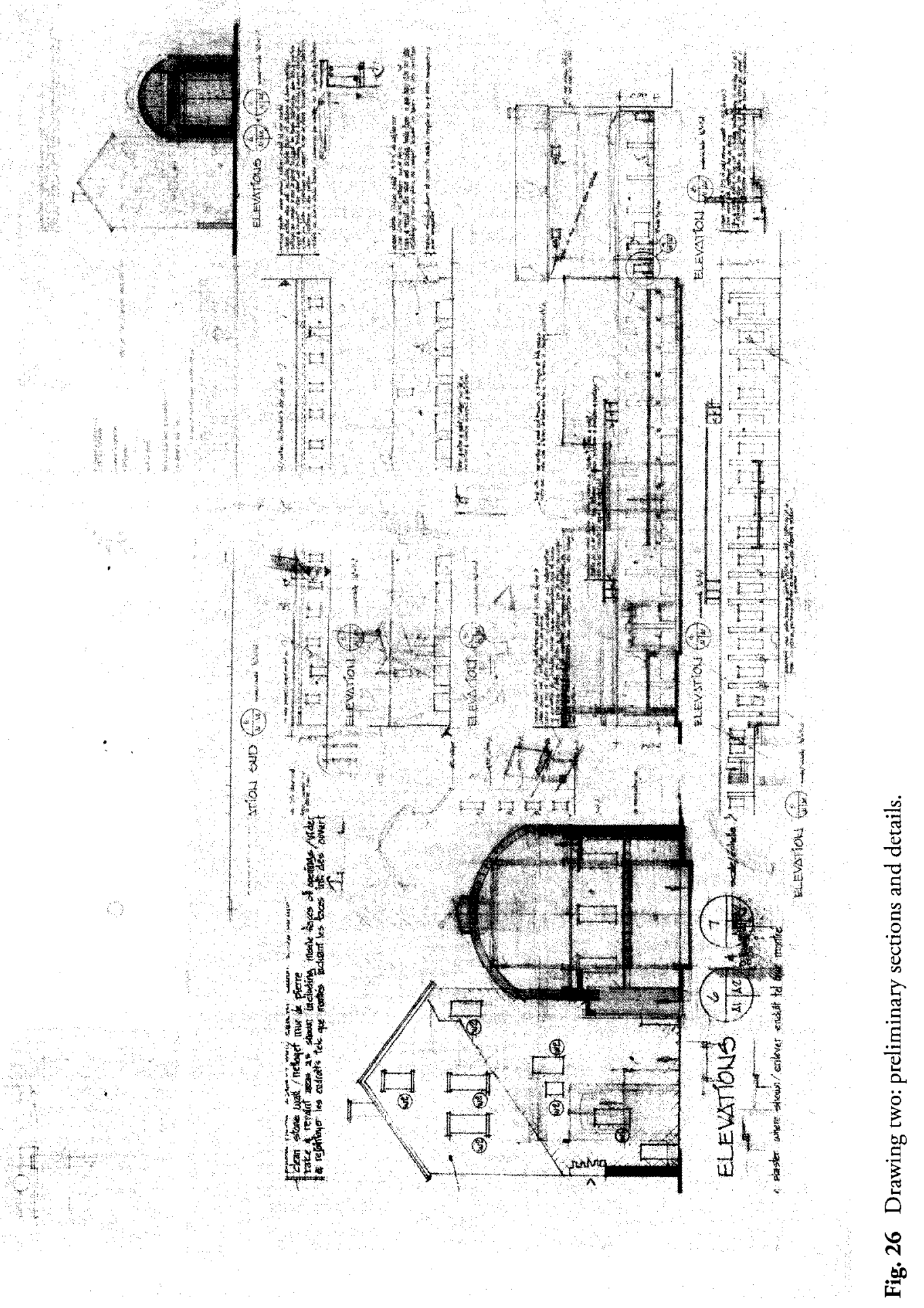




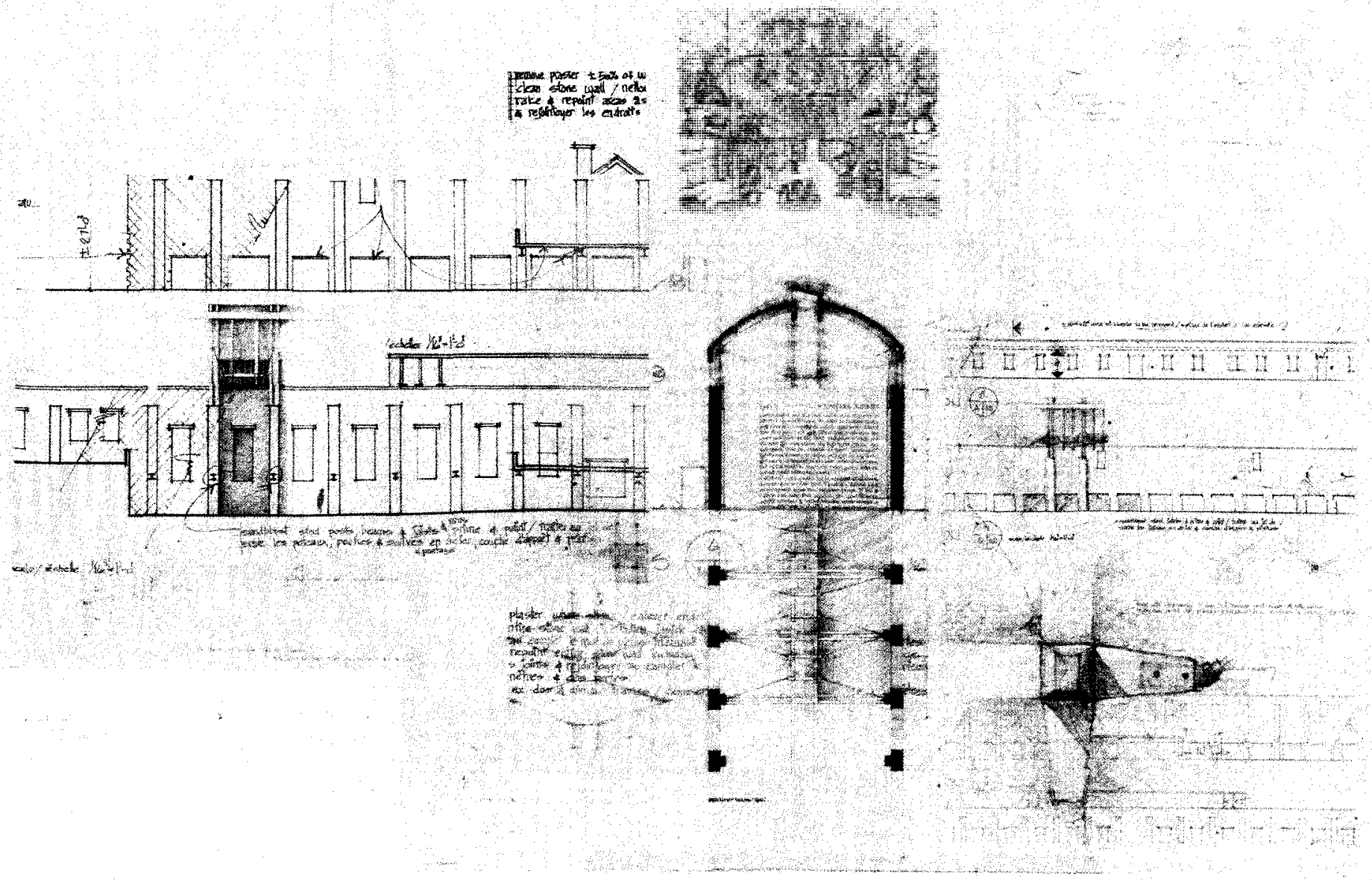

Fig. 27 Drawing three: detail of new roof. 


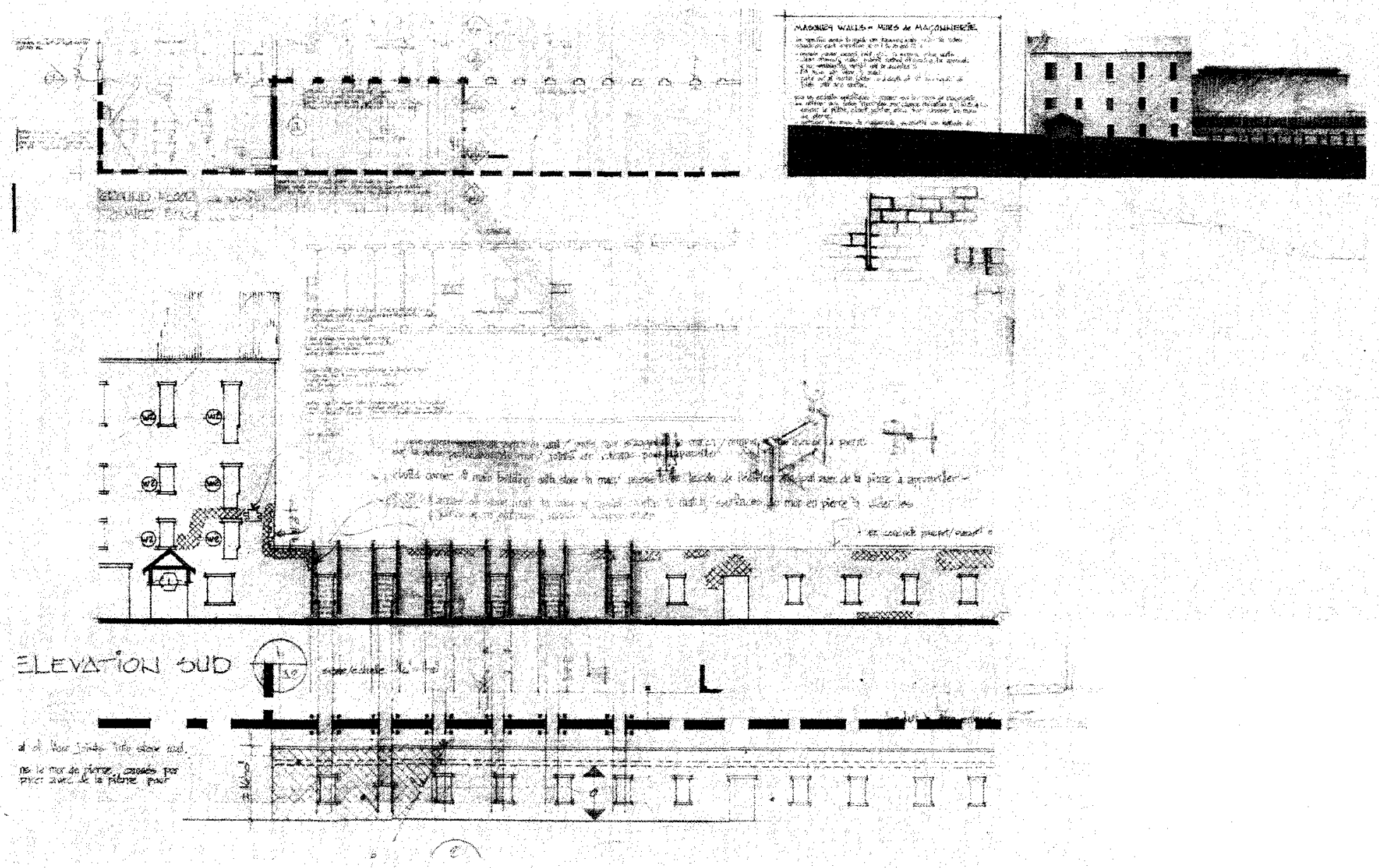

Fig. 28 Drawing four: detail of entry. 

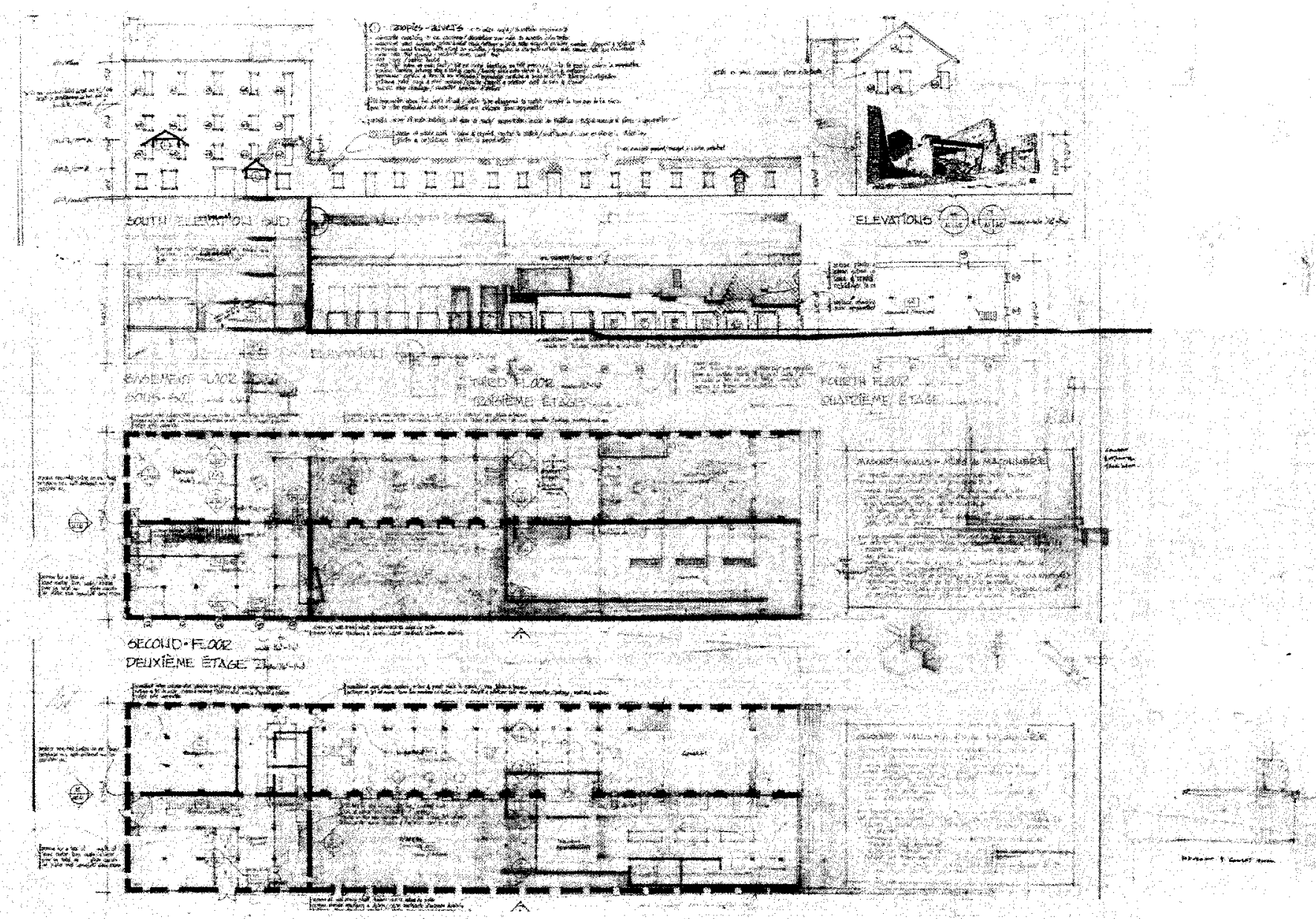

Fig. 29 Drawing five: plans and section. 


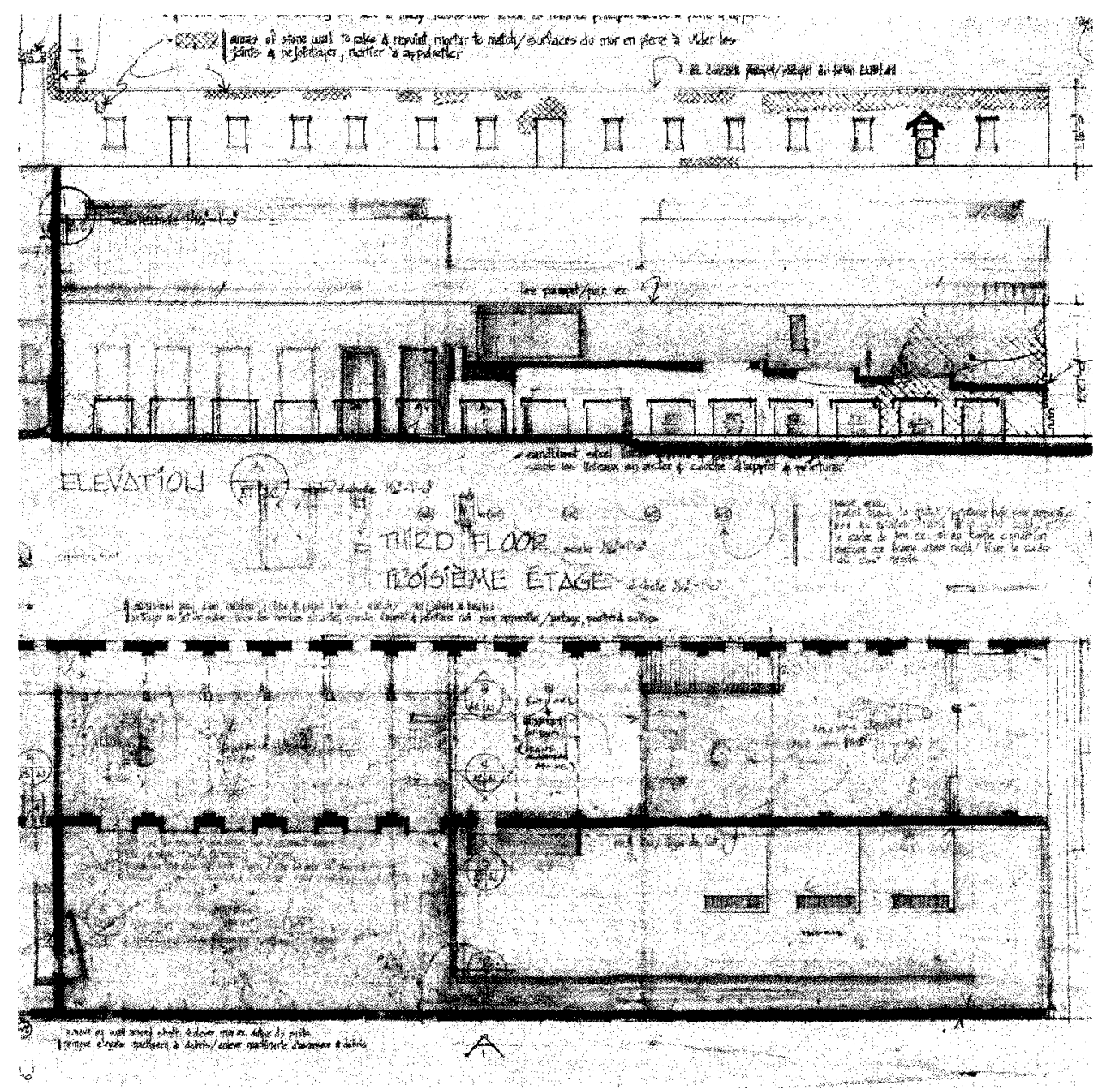

Fig. 30 Drawing detail: plan and section of gallery entry ramp. 


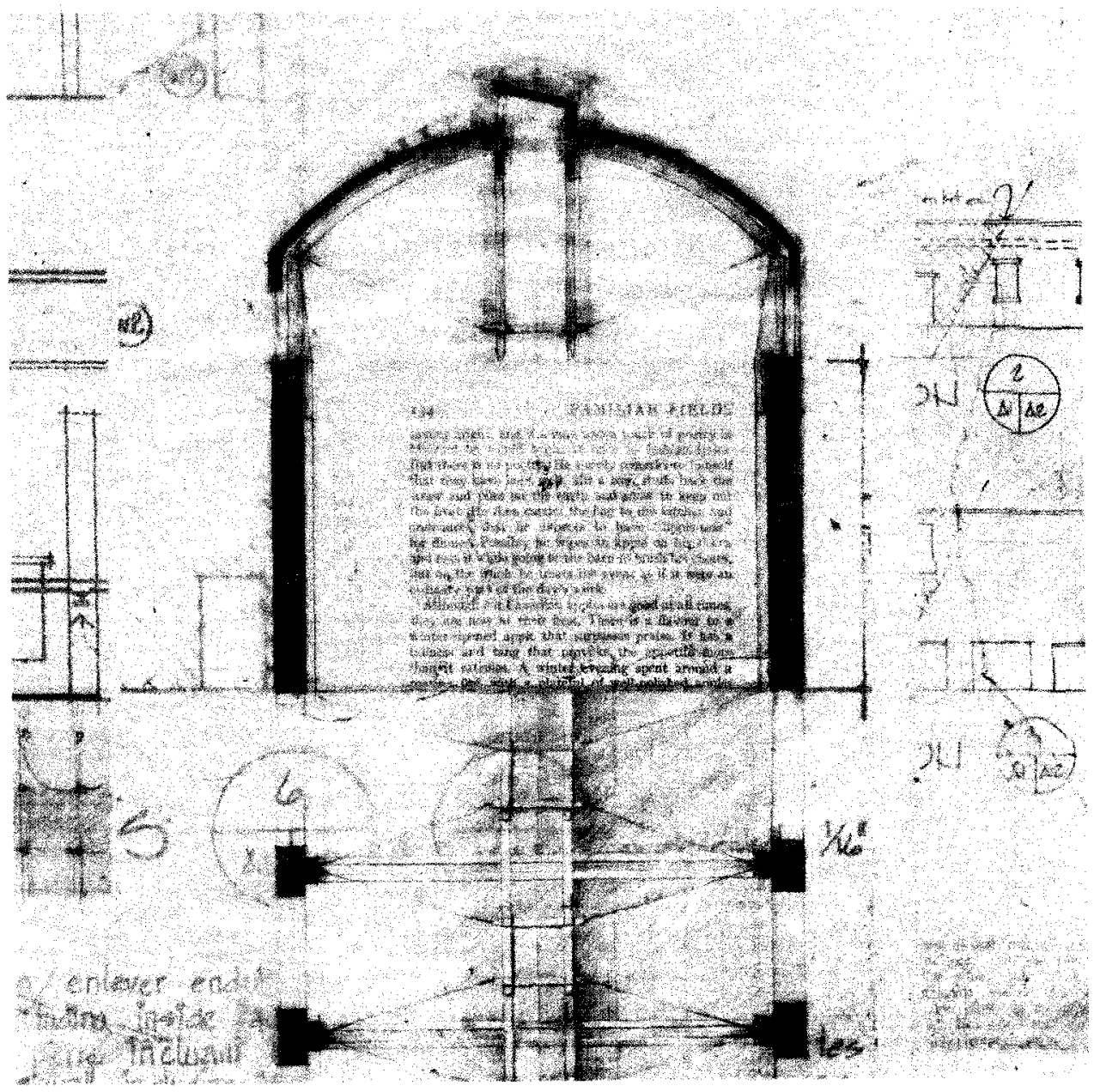

Fig. 31 Drawing detail: new roof structure. 


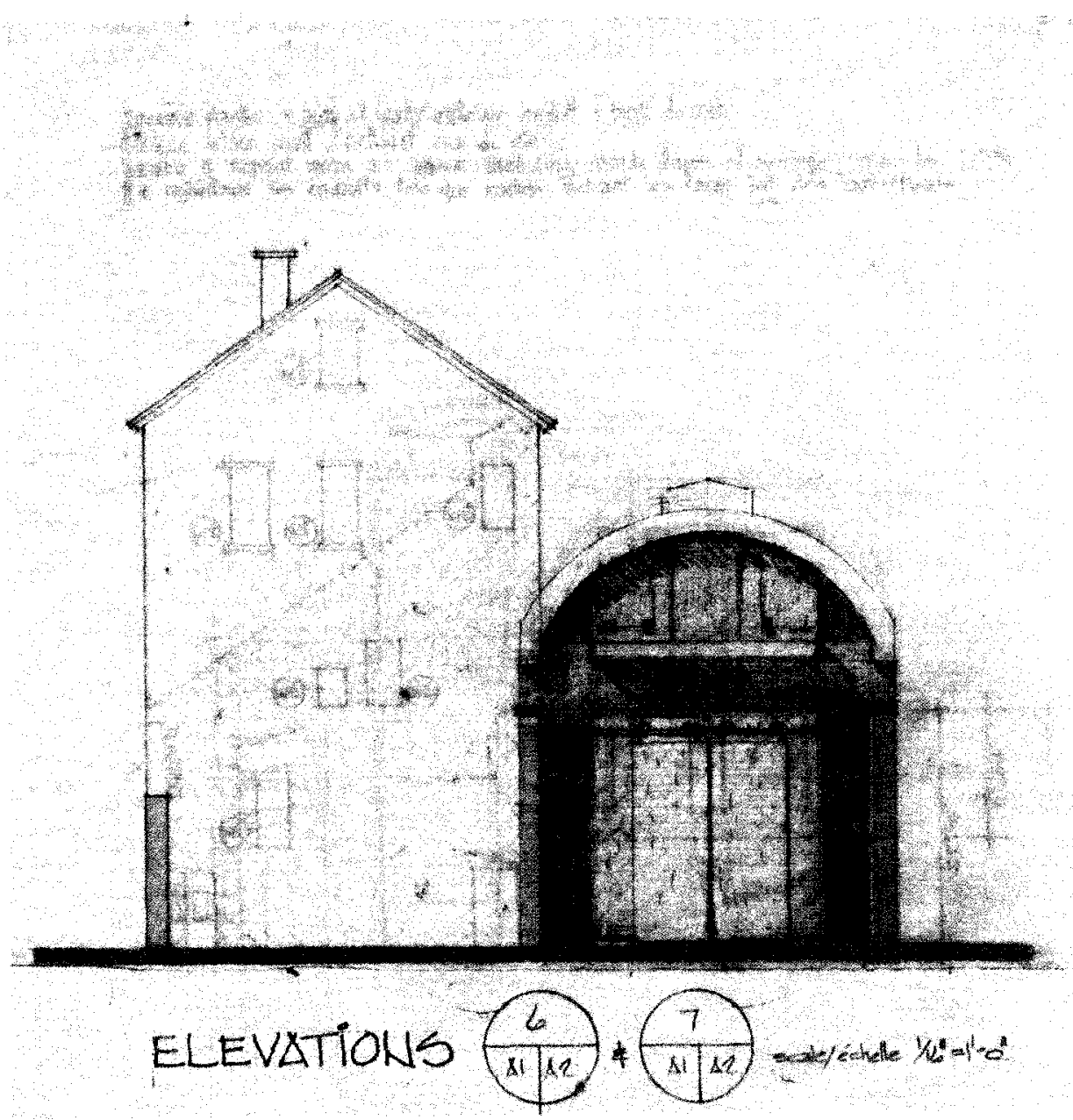

Fig. 32 Drawing detail: east elevation. 


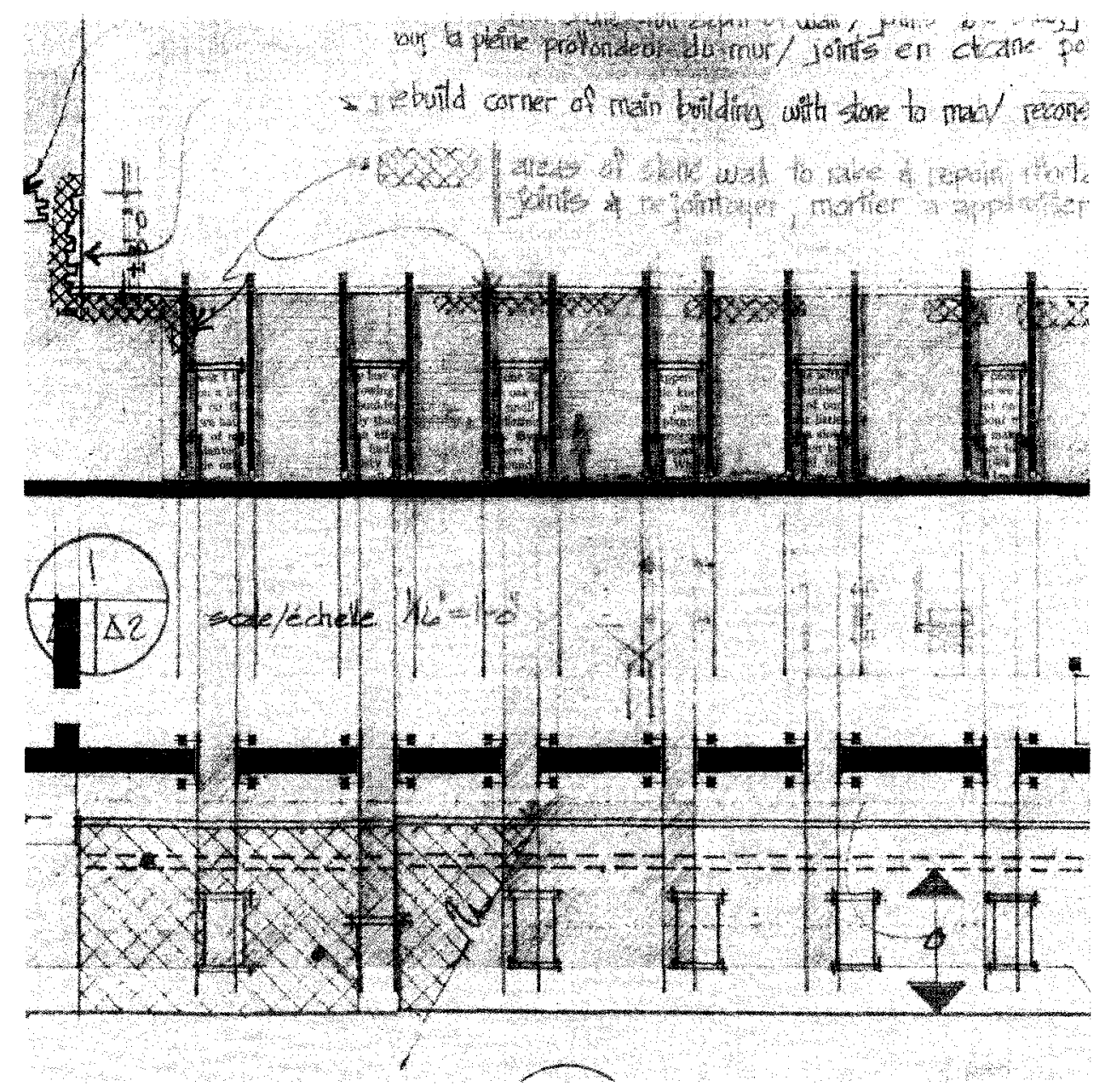

Fig. 33 Drawing detail: entry court threshold. 


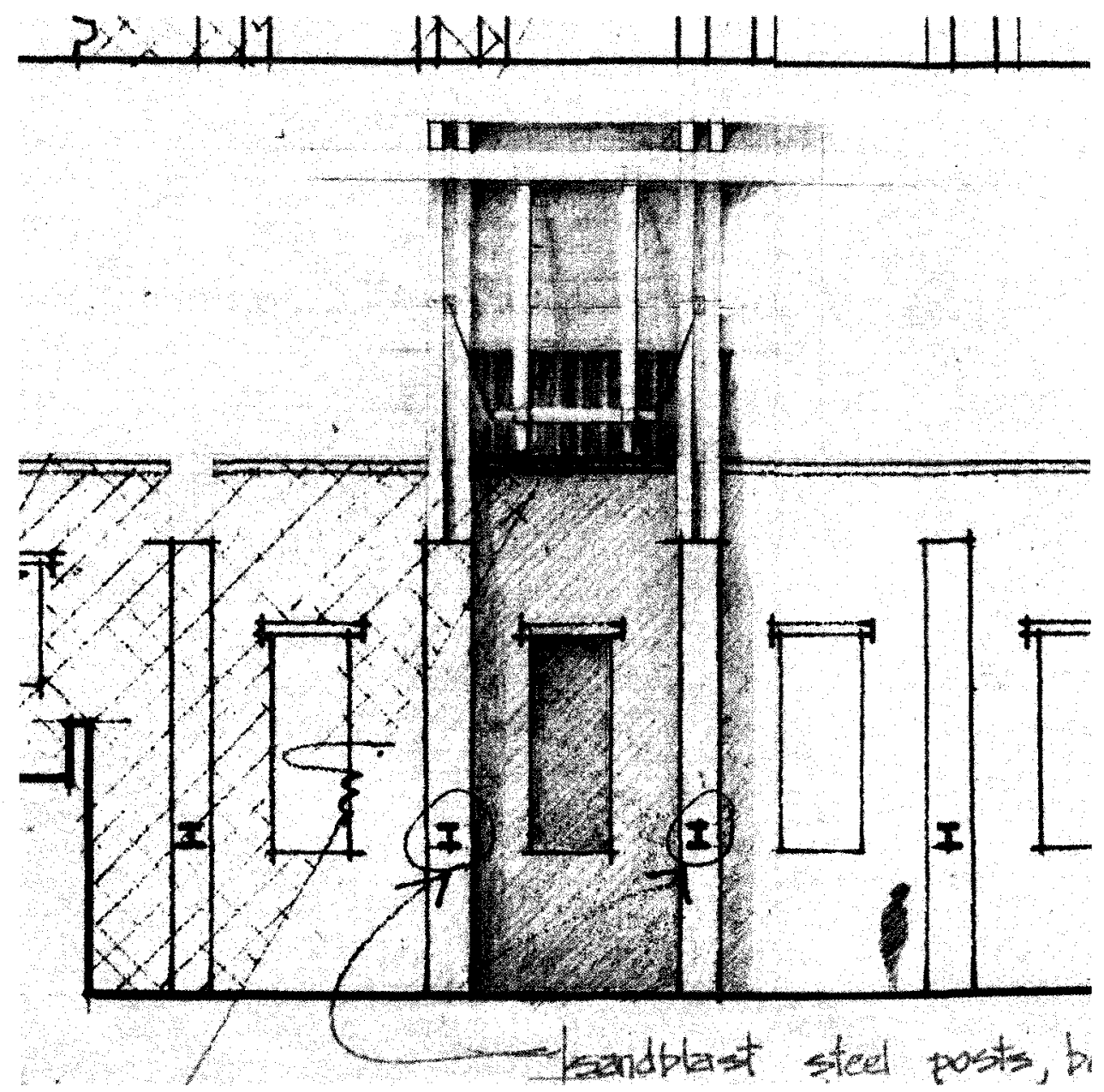

Fig. 34 Drawing detail: section through new roof structure. 

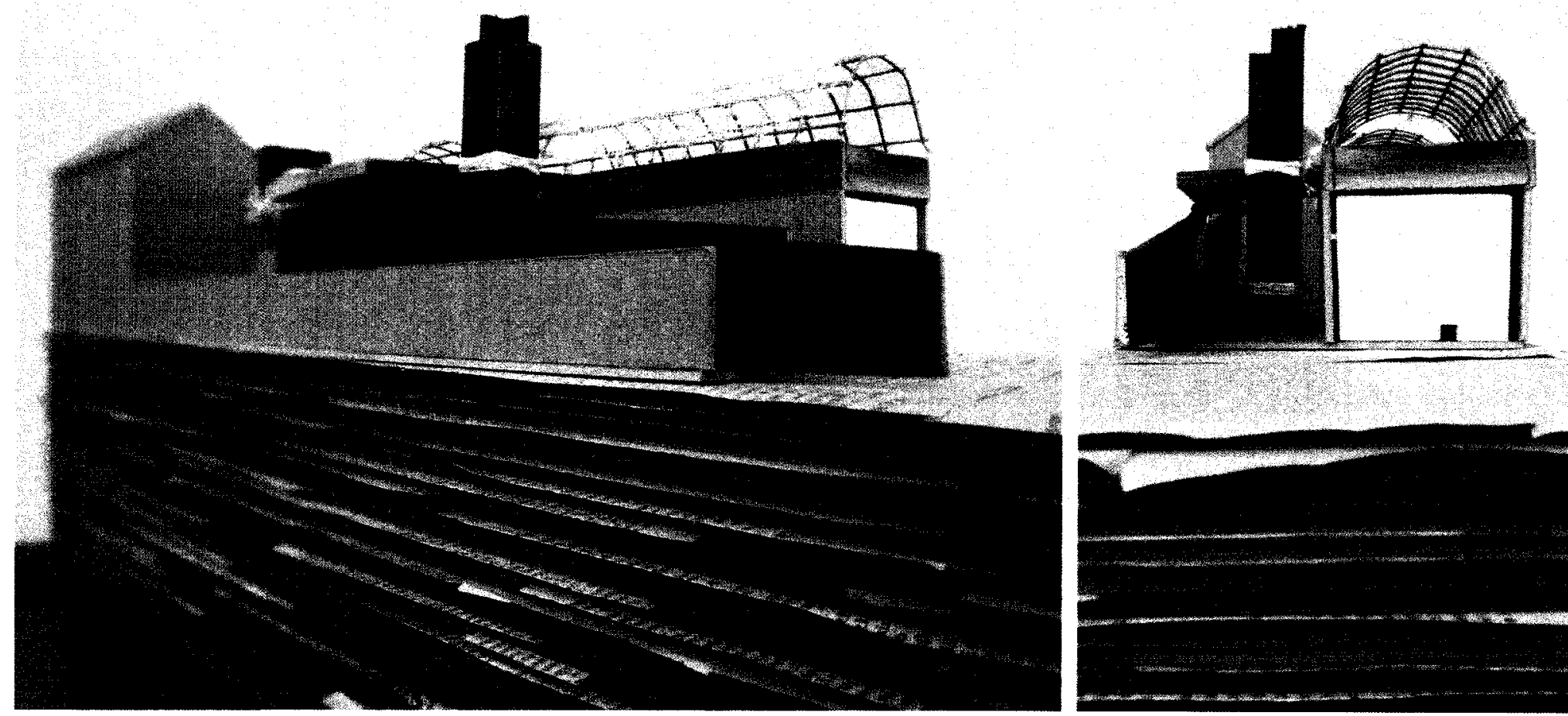

Fig. 35 Sketch model. 


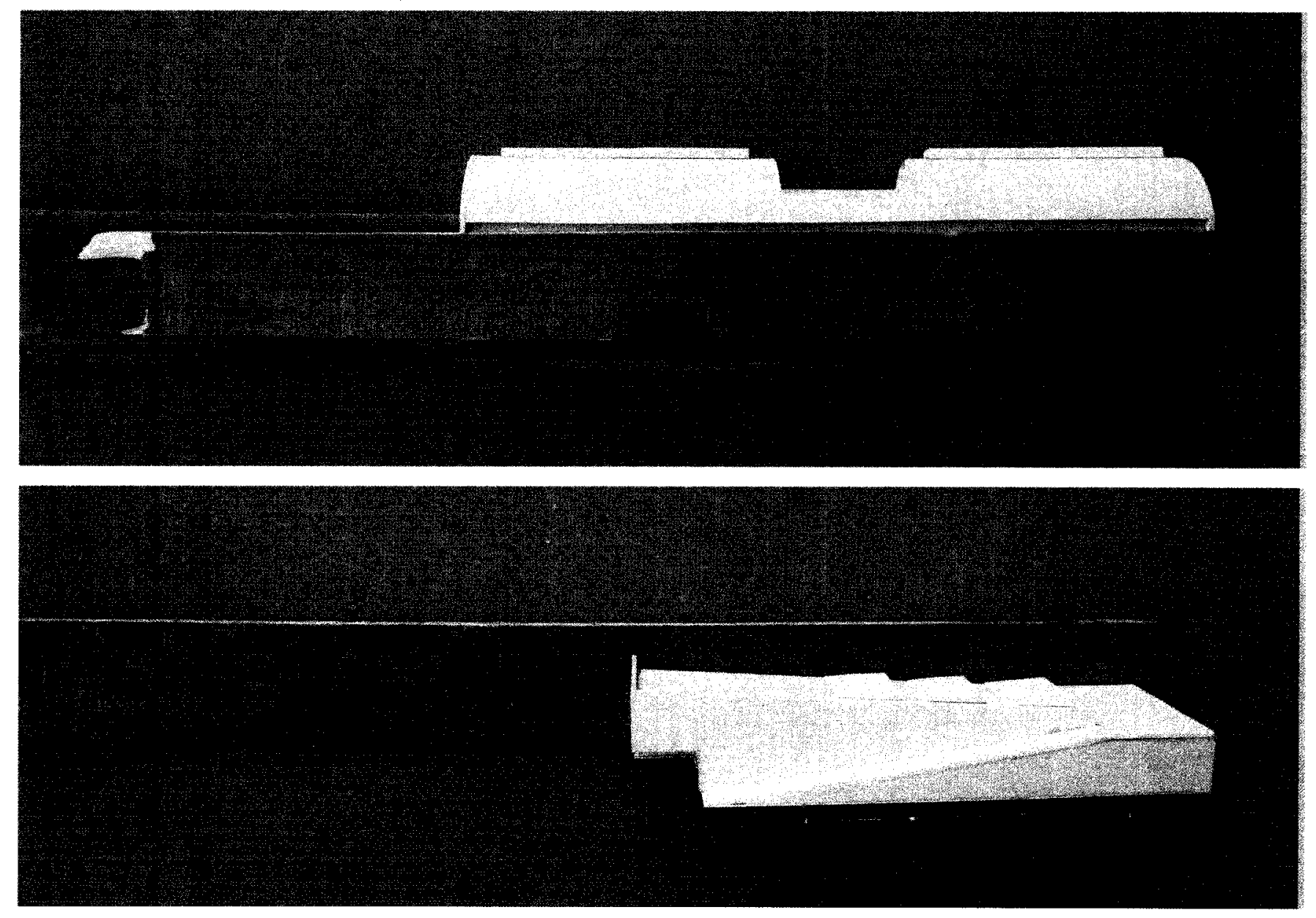

Fig. 36 Gallery and restaurant models. 


\section{Notes}

138 Frascari, Marco, Monsters of Architecture: Anthropomorphism in Architectural Theory, (Maryland: Rowman and Littlefield, 1991), 22.

139 Victoria Island: What Now?, (Ottawa: National Capital Commission, February 1979), 5.

140 Victoria Island and Surroundings, (Ottawa: National Capital Commission, August 1981), 10.

141 Chaudiere Historical Documentation: "First Round" Papers, (Ottawa: National Capital Commission, 1982), 8.

142 Salvage Archeology: Carbide Mill, Victoria Island, Ottawa, (Ottawa: National Capital Commision, August 1983), 2.

143 Chaudiere Historical Documentation, 13.

144 Salvage Archeology, 2.

145 Chaudiere Historical Documentation, 16.

146 Michael Jackson, The Politics of Storytelling: Violence, Transgression, and Intersubjectivity, (Copenhagen: Museum Tusculanum Press, 2002), 30.

147 The compenents that comprise the program, as well as the program itself, are informed by a proposal put forth by Douglas Cardinal in 2004.

148 Frascari, Monsters of Architecture, 11.

149 Frascari, Monsters of Architecture, 22.

150 Frascari, Marco, "The Particolareggiamento in the Narration of Architecture," Journal of Architectural Education 43, no. 1 (1989), 3-12.

151 Frascari, Monsters of Architecture, 22.

152 Frascari, "The Particolareggiamento in the Narration of Architecture," 8. 


\section{Conclusion}

"The issue is to ground design and its meanings through its relationship to language, to understand bistory (stories) as the one mode of speech capable of articulating buman truths relevant concepts that orient action 'here and now'..."

$\sim$ Alberto Perez-Gomez ${ }^{153}$

In reflecting upon practices of architectural conservation, one can see that the project of modernization - its dependency on unrepentant progression and its willingness to sacrifice any recognition of multiplicity - has led to the reduction of architecture (and its perceived values and meanings) to the most singular of forms. The resultant approaches to conservation seek coherence and consistency - between parts, between content, as well as between subject and meaning. They seek a homogenized and normalized perception of architecture. With this Gregotti states that,

"The solution is thus never the one that would suit the project and the place, one that would interpret them according to some necessity. It is more likely to be a solution already open to all hybridizations: not the solution that, in its clarity, is able to include and confront authentic differences, but rather a solution that tends to drown such differences in the process of homogenization set in motion by diversity turned into pure ideology." ${ }^{154}$

Indeed, practices of conservation have seemed to find difficulty in reconciling with the idea of plurality in architecture. They are unable to accept the inscription of multiple stories within the material of a single building - in fear that allowing such a practice would eliminate any conclusiveness of the value of a place. This can be attributed to a fundamental opposition to the values of the postmodern world - values that seem to discard the past and the future, and abolish history and its meaning in totality. ${ }^{155}$

This is, however, not the mythos I propose. The framework of storytelling does not 
disregard the past or the future, nor does it displace meaning to a cursory, or even nonexistent, position. Rather, through hermeneutical activity, it reorients meaning in the 'here and now', while reclaiming the past - in all its various forms and experiences - in order to project a future. Furthermore, the expectation is not that a single reader (or user) is required to construe more than a single meaning. Instead, storytelling allows a multiplicity of stories to contemporaneously exist in one building, just as many meanings exist in any one text, providing a multiplicity of meanings to be construed depending on the different cultural codes through which it is interpreted. The benefit of this is perseverance - the existence in a single building of "a plurality of significances is, empirically, a requirement and a distinguishing feature of the survivor." 156

But there is another particular advantage of the storytelling mythos. McLuhan has argued that against the destabilizing and unsettling effects of modernization - the effects that have led to a practice of conservation that relies on recourse to the past - a retribalization process of society is occurring. While we yearn for the nation-states that have characterized the past (as has been elucidated in the course of this thesis), we are entering a new era of a plurality of mini-states - ones that are based on tribal agglomerates, and promote the variegated culture of which the nation-state oppressed. ${ }^{157}$ If McLuhan is correct in making such arguments, then it is only through an alternate approach to conservation - one that recognizes the plurality of a retribalized world - that the historic buildings of our shared past will be able to maintain relevancy, as well as their ethical acceptance in society.

Thus, with these concerns in mind, we can no longer afford to conserve buildings through a rearview mirror lens - a lens that seeks a single identity, a single story, a single 
nationality - at the expense of the true cultural mosaic in which we live (through which these very histories have come into existence). We must practice conservation under the counsel of storytelling, so as to achieve an ethical practice that is oriented around a critical understanding of multiplicity, indeterminacy, and transformation in architecture.

\section{Notes}

153 Perez-Gomez, Alberto, "Hermeneutics as Discourse in Design," Design Issues 15, no. 2 (1999), 78.

154 Vittorio Gregotti, Inside Architecture, translated by Peter Wong and Francesca Zaccheo, (Chicago: Graham Foundation for Advanced Studies in the Fine Arts; Cambridge: MIT Press, 1996), 11.

155 Gregotti, Inside Architecture, xii.

156 Kermode quoted in Paul B. Armstrong, Conflicting Readings: Variety and Validity in Interpretation, (Chapel Hill: University of North Carolina Press, 1990), 129

157 Marshall McLuhan, "Playboy Interview: Marshall McLuhan,” Playboy, March 1969. 


\section{Bibliography}

Arendt, Hannah, The Human Condition, Chicago: University of Chicago Press, 1958.

Armstrong, Paul B., Conflicting Readings: Variety and Validity in Interpretation, Chapel Hill: University of North Carolina Press, 1990.

Bauman, Richard, Story, Performance, and Event: Contextual Studies of Oral Narrative, Cambridge; New York: Cambridge University Press, 1986.

Benjamin, Walter, "The Storyteller: Reflections on the Works of Nikolai Leskov," in Illuminations, edited by Hannah Arendt, translated by Harry Zohn, New York: Harcourt, Brace \& World, 1968, 83-107.

Bickford, Susan, "Reconfiguring Pluralism: Identity and Institutions in the Inegalitarian Polity," American Journal of Political Science 43, no. 1 (1999), 86-108.

Bickford, Susan, "Constructing Inequality: City Spaces and the Architecture of Citizenship," Political Theory 28, no. 3 (2000), 355-376.

Chaudiere Historical Documentation: "First Round" Papers, Ottawa: National Capital Commission, 1982.

Eco, Umberto, and Stefan Collini, Interpretation and Overinterpretation, Cambridge; New York: Cambridge University Press, 1992.

Frascari, Marco, "The Particolareggiamento in the Narration of Architecture," Journal of Architectural Education 43, no. 1 (1989), 3-12.

Frascari, Marco, Monsters of Architecture: Anthropomorphism in Architectural Theory, Maryland: Rowman and Littlefield, 1991.

Fraser, Nancy, "Rethinking the Public Sphere: A Contribution to the Critique of Actually Existing Democracy," Social Text 25, no. 26 (1990), 56-80.

Gregotti, Vittorio, Inside Architecture, translated by Peter Wong and Francesca Zaccheo, Chicago: Graham Foundation for Advanced Studies in the Fine Arts; Cambridge: MIT Press, 1996.

Habermas, Jurgen, The Structural Transformation of the Public Sphere: An Inquiry into a Category of Bourgeois Society, Cambridge, Mass.: The MIT Press, 1989. 
Hall, Stuart, "Encoding/Decoding," in Media Studies: A Reader, edited by Paul Morris and Sue Thornton. Edinburgh: Edinburgh University Press, 1996, 166-176.

Jackson, Michael, The Politics of Storytelling: Violence, Transgression, and Intersubjectivity, Copenhagen: Museum Tusculanum Press, 2002.

Kapferer, Bruce, Legends of People, Myths of State: Violence, Intolerance, and Political Culture in Sri Lanka and Australia, Washington: Smithsonian Institution Press, 1988.

Kunze, Donald, "Giambattista Vico as a Philosopher of Place: Comments on the Recent Article By Mills," Transactions of the Institute of British Geographers New Series 8, no. 2 (1983), 237-48.

Kunze, Donald, Thought and Place: The Architecture of Eternal Place in the Philosophy of Giambattista Vico, New York: P. Lang, 1987.

Lipietz, Alain, "The Spaciality of Social Life: Towards a Transformative Retheorization," in Social Relations and Spacial Structures, edited by Derek Gregory and John Urry, Basingstroke, Hampshire: Macmillan Education, 1985.

Lyotard, J.F., The Postmodern Condition: A Report on Knowledge, Manchester: Manchester University Press, 1986.

Massey, Doreen B., Space, Place, and Gender, Minneapolis: University of Minnesota Press, 1994.

Massey, Doreen B., "Space-Time, 'Science' and the Relationship Between Physical Geography and Human Geography," Transactions of the Institute of British Geographers New Series 24, no. 3 (1999), 261-76.

Massey, Doreen B., For Space, London; Thousand Oaks, Calif.: SAGE, 2005.

McLuhan, Marshall, "Playboy Interview: Marshall McLuhan," Playboy, March 1969. 26-27, $45,55-56,61,63$.

Otero-Pailos, Jorge, "The Contemporary Stamp Of Incompleteness," Future Anterior 1, no. 2 (2004), ii-viii.

Page, Max, and Randall Mason, Giving Preservation a History: Histories of Historic Preservation in the United States, New York; London: Routledge, 2004.

Perez-Gomez, Alberto, Architecture and the Crisis of Modern Science, Cambridge, Mass.: MIT Press, 1983. 
Perez-Gomez, Alberto, "Architecture as Embodied Knowledge," Journal of Architectural Education 40, no. 2 (1987), 57-58.

Perez-Gomez, Alberto, "Hermeneutics as Discourse in Design," Design Issues 15, no. 2 (1999), 71-79.

Pickles, J., David W. Black, and Donald Kunze, Commonplaces: Essays on the Nature of Place, Lanham: University Press of America, 1989.

Salvage Archeology: Carbide Mill, Victoria Island, Ottawa, Ottawa: National Capital Commision, August 1983.

Seidman, Steven, "The End of Sociological Theory: The Postmodern Hope," Sociological Theory 9, no. 2 (1991), 131-46.

Stovel, Herb, "Appendix 1: Nara Document on Authenticity" in Nara Conference on Authenticity, edited by Knut Einar Larsen, Japan: Agency for Cultural Affairs UNESCO World Heritage Centre, 1995.

The Declaration of Amsterdam, Amsterdam: Congress on the European Architectural Heritage, 1975, http://www.icomos.org/docs/amsterdam.html (accessed 25 October 2007).

The Venice Charter: International Charter for the Conservation and Restoration of Monuments and Sites, Paris: International ICOMOS, 1964, http://www.icomos.org/venice_charter.html (accessed 25 October 2007).

Werner, Frank, Aurelio Galfetti: Castelgrande Bellinzona, Berlin: Ernst \& Sohn, 1992.

Victoria Island: What Now?, Ottawa: National Capital Commission, February 1979.

Victoria Island and Surroundings, Ottawa: National Capital Commission, August 1981. 